\title{
IntechOpen
}

\section{Surfactants and Detergents}

Edited by Ashim Kumar Dutta

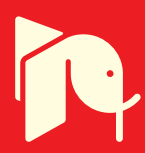





\section{Surfactants and Detergents}

Edited by Ashim Kumar Dutta 

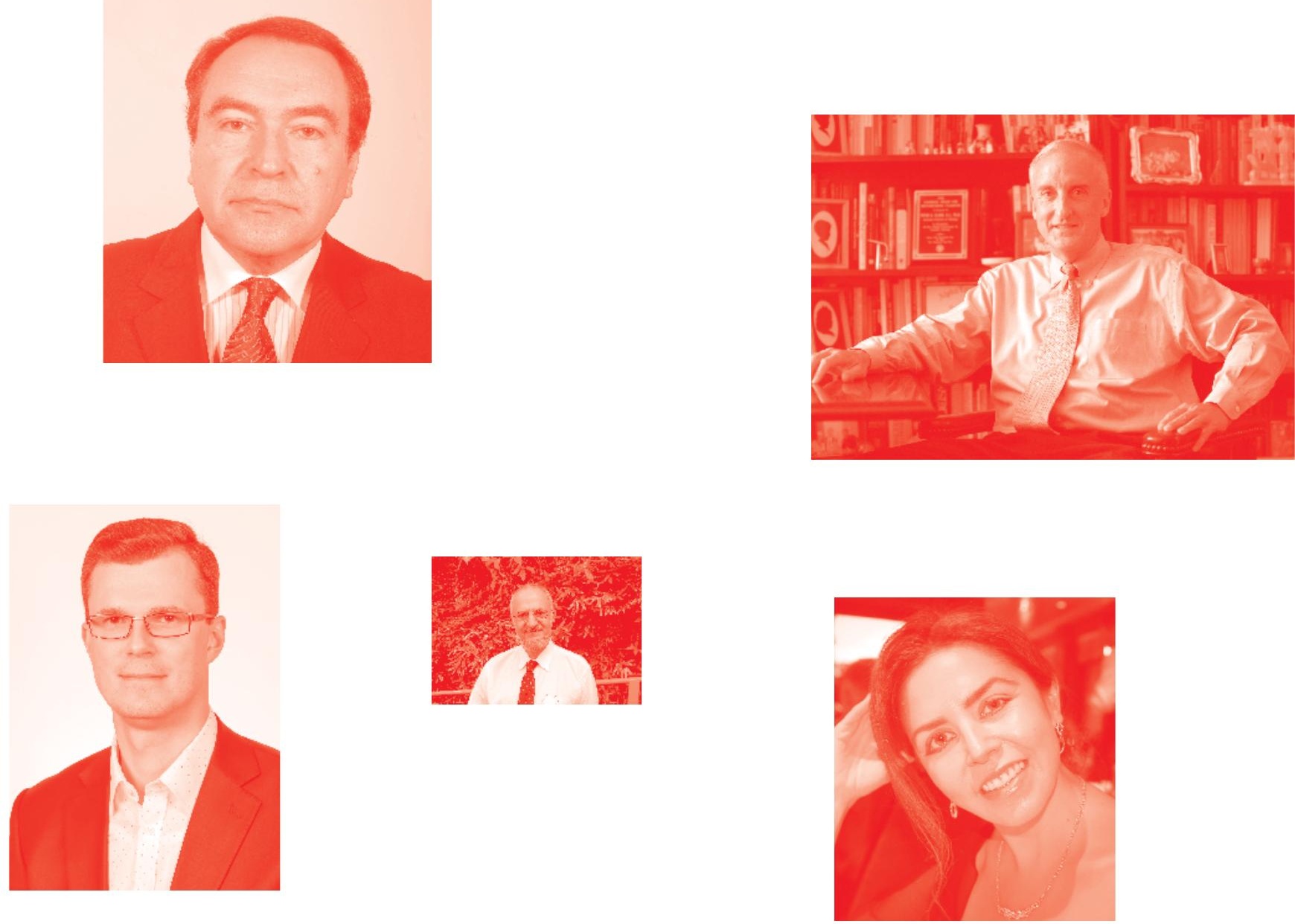

Supporting open minds since 2005
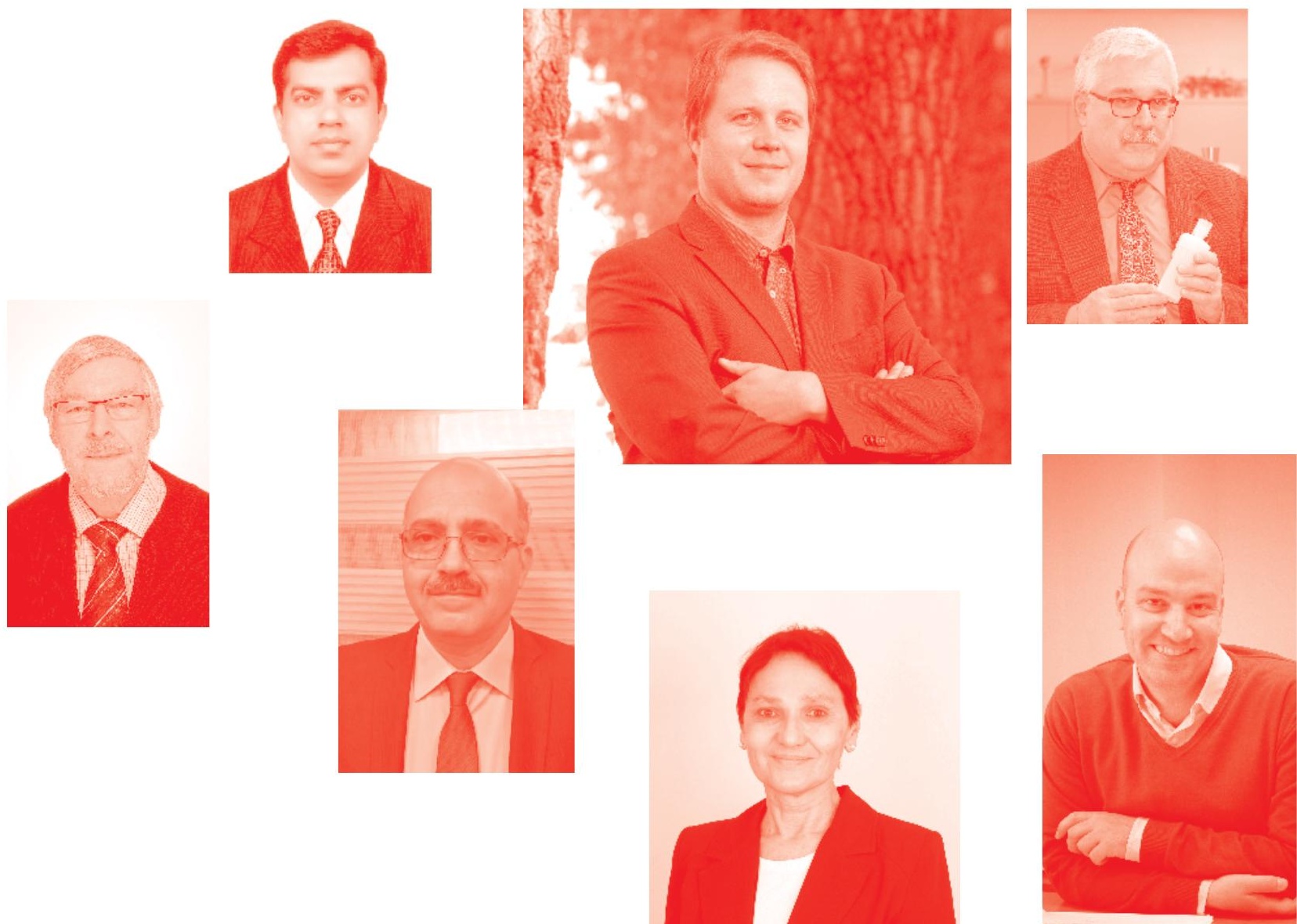
Surfactants and Detergents

http: //dx. doi. org/10.5772/intechopen. 77548

Edited by Ashim Kumar Dutta

\section{Contributors}

Abhyarthana Pattanaik, Venugopal Rayasam, Ashim Kumar Dutta, Ana Maria Carmona-Ribeiro, Pavlína Basařová, Mária Zedníková, Camillo La Mesa, Gianfranco Risuleo, Anne-Marie Delort, Pascal Renard, Isabelle Canet, Martine Sancelme, Maria Matulova, Iveta Uhliarikova, Boris Eyheraguibel, Lionel Nauton, Julien Devemy, Mounir Traikia, Patrice Malfreyt

() The Editor(s) and the Author(s) 2019

The rights of the editor(s) and the author(s) have been asserted in accordance with the Copyright, Designs and Patents Act 1988. All rights to the book as a whole are reserved by INTECHOPEN LIMITED . The book as a whole (compilation) cannot be reproduced, distributed or used for commercial or non-commercial purposes without INTECHOPEN LIMITED's written permission. Enquiries concerning the use of the book should be directed to INTECHOPEN LIMITED rights and permissions department (permissions@intechopen.com).

Violations are liable to prosecution under the governing Copyright Law

\section{(cc) BY}

Individual chapters of this publication are distributed under the terms of the Creative Commons Attribution 3.0 Unported License which permits commercial use, distribution and reproduction of the individual chapters, provided the original author(s) and source publication are appropriately acknowledged. If so indicated, certain images may not be included under the Creative Commons license. In such cases users will need to obtain permission from the license holder to reproduce the material. More details and guidelines concerning content reuse and adaptation can be found at http : //www . intechopen . com/copyright-policy . html.

\section{Notice}

Statements and opinions expressed in the chapters are these of the individual contributors and not necessarily those of the editors or publisher. No responsibility is accepted for the accuracy of information contained in the published chapters. The publisher assumes no responsibility for any damage or injury to persons or property arising out of the use of any materials, instructions, methods or ideas contained in the book.

First published in London, United Kingdom, 2019 by IntechOpen IntechOpen is the global imprint of INTECHOPEN LIMITED, registered in England and Wales, registration number: 11086078 , 7th floor, 10 Lower Thames Street, London,

EC3R 6AF, United Kingdom

Printed in Croatia

British Library Cataloguing-in-Publication Data

A catalogue record for this book is available from the British Library

Additional hard and PDF copies can be obtained from orders@intechopen.com

Surfactants and Detergents

Edited by Ashim Kumar Dutta

p. cm.

Print ISBN 978-1-78984-660-7

Online ISBN 978-1-78984-661-4

eBook (PDF) ISBN 978-1-83962-838-2 


\section{We are IntechOpen, \\ the world's leading publisher of Open Access books}

\section{Built by scientists, for scientists}

\section{$4,400+$}

Open access books available

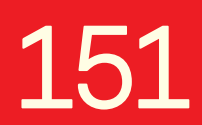

Countries delivered to

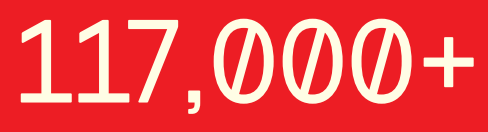

International authors and editors
$130 \mathrm{M}+$

Downloads

Our authors are among the

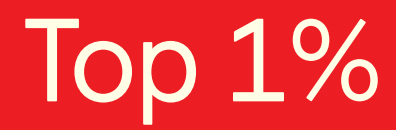

most cited scientists

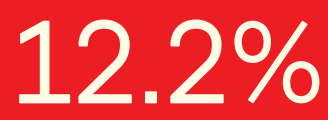

Contributors from top 500 universities

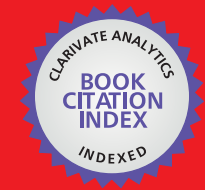

WEB OF SCIENCE ${ }^{\text {IM }}$

Selection of our books indexed in the Book Citation Index in Web of Science ${ }^{\mathrm{TM}}$ Core Collection (BKCI)

\section{Interested in publishing with us? \\ Contact book.department@intechopen.com}

Numbers displayed above are based on latest data collected.

For more information visit www.intechopen.com 



\section{Meet the editor}

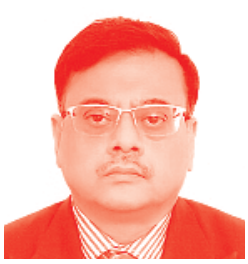

Dr. Ashim Kumar Dutta holds a PhD in Physical Chemistry from Jadavpur University, India. He has worked extensively on the characterization and spectroscopy of surfactant monolayers and supramolecular assemblies. His publication list includes 36 articles in international journals and 19 patents. Dr. Dutta has been the recipient of several international postdoctoral fellowships in Japan, Canada and the United States. Having started his career in product development and innovations with Unilever he later moved into agrochemicals and worked as the Head of Global Formulations with United Phosphorus Limited and Indofil Industries. Presently, he works as a vice president (R\&D) with the surfactant major, India Glycols Limited. His research interests continue to be in the areas of colloidal chemistry, novel surfactants, self-assembled nanostructures, and bio-inspired and bio-mimetic supramolecular systems. 



\section{Contents}

Preface

Chapter 1

Introductory Chapter: Surfactants in Household and Personal Care

Formulations - An Overview

by Ashim Kumar Dutta

Chapter 2

Role of Surfactants in Mineral Processing: An Overview

by Abhyarthana Pattanaik and Rayasam Venugopal

Chapter 3

Effect of Surfactants on Bubble-Particle Interactions

by Pavlína Basařová and Mária Zedníková

Chapter 4

Surfactant Mixtures: Performances vs. Aggregation States

by Camillo La Mesa and Gianfranco Risuleo

Chapter 5

Biomimetic Nanomaterials from the Assembly of Polymers, Lipids, and Surfactants

by Ana Maria Carmona-Ribeiro

Chapter 6

Cloud Microorganisms, an Interesting Source of Biosurfactants by Pascal Renard, Isabelle Canet, Martine Sancelme, Maria Matulova, Iveta Uhliarikova, Boris Eyheraguibel, Lionel Nauton, Julien Devemy, Mounir Traïkia, Patrice Malfreyt and Anne-Marie Delort 



\section{Preface}

Surfactants or detergents, as they are often referred to, are vital ingredients in most formulated products that we use on a daily basis. These include food, medicines, cosmetics and laundry detergent. The use of surfactants is equally important in other industrial applications such as oil recovery from oil wells, lubricants, processing chemicals for textiles, adjuvants in agrochemicals, and so on.

This book is a compilation of chapters from leading experts highlighting the use of specific surfactants and their functional properties in new and emerging areas of science and technology. Experts and novices alike will find the information contained herein to be of great value.

Chapter 1 discusses the fundamental aspects of surfactants and their surface active properties arising from their molecular structure and subsequent self-assembly at interfaces and in bulk. It also briefly covers emulsification of oils and their stability; the various mechanisms of cleaning, especially removal of tough oily soil from soft substrates like fabrics, skin and hair; and the importance and need of mild surfactants in baby and skin care products.

Chapter 2 provides an overview on the role of surfactants in the selective separation of specific minerals from their ores by the froth floatation process. The biggest challenge is choosing appropriate surfactants or their mixture that will selectively attach the particles of a specific mineral to the surface of air bubbles that forms the froth while allowing the other mineral ingredients of the ore to sink and get separated as sludge. The process of attachment of a particle to the bubble surface is complex in that it is a dynamic process involving several parameters like wettability of the surfaces, contact angle, hydrophilicity or hydrophobicity of the mineral particle and, more importantly, the rate of draining of the liquid in the film that forms the bubble wall. These features are discussed in some detail in Chapter 3.

Mixed surfactants and surfactant-polymer systems provide the flexibility of designing systems with tailored properties that have been extensively used in home and personal care, pharmaceuticals and food products. Systems with oppositely charged surfactants and polymers are complicated and continue to be an area of intense research. Chapter 4 investigates catanionic systems consisting of sodium dodecylsulphate (SDS) and cetyltrimethylammonium bromide (CTAB) and lysozymeperfluorononanoate and provides insight into the concentration-dependent interactions between the various ingredients in these systems.

In recent years there has been much interest in nanoparticles because of their interesting physico-chemical properties, which are different from the bulk properties of the same material. Tailor-made nanoparticles have been extensively used for numerous applications in semiconductor devices, sensors and light-emitting optical devices. Chapter 5 reviews various polymer-based nanoparticle systems in context to their microbial activities that may be utilized in the design of medical devices and biomedical screening systems. 
Bio-surfactants or surfactants extracted from renewable biological substrates like fruits, roots, vegetables and micro-organisms are well known and encouragingly used in various applications because they are mild, natural and have low toxicity in contrast to their synthetic counterparts. However, their extraction from microorganisms present in the atmosphere has never been reported. Chapter 6 reports the extraction of bio-surfactants from atmospheric clouds for the very first time. This report is not the only one of its kind, but it opens up a totally new area of research in terms of an unexplored source of bio-surfactants. It also paves the way for understanding the role of these ingredients in the behavior of clouds and controlling such properties as precipitation from the clouds that the directly influences weather and environment.

I would like to thank all the authors for their efforts in writing the various chapters in this book. I would also like to thank IntechOpen's editorial and publishing staff for their cooperation and help at every juncture to make publication of this book possible.

Last but not least, I dedicate this book to the loving memory of my parents, and I thank my wife, Malabika, and my two children, Sourav and Siddharth, for their help and cooperation and for bearing with me in this endeavor.

\author{
Dr. Ashim Kumar Dutta \\ Vice President (R\&D), \\ India Glycols Limited, \\ Uttarakhand, India
}




\title{
Introductory Chapter: Surfactants in Household and Personal Care Formulations - An Overview
}

\author{
Ashim Kumar Dutta
}

\section{Introduction}

Surfactants are ubiquitous and form a part of almost every essential household product we use on a daily basis and have become synonymous with detergents and cleaning agents. The global surfactant consumption is 18,000 kilotons per annum that had a market value of USD 43,655 million in 2017 and is projected to reach USD 66,408 million in 2025 with a compound annual growth rate (CAGR) of 5.4\% [1]. Interestingly, the first detergent known to man was soap, the origin of which may be traced back to the Egyptian civilization in 2800 BC. Cylinders containing soap made from animal fats and ashes recovered from excavations in Babylon confirm that indeed soap was known to the Babylonians. The Ebers Papyrus (1550 BC) also mentions the use of soap for bathing and cleaning, and in the Bible, soap has been referred to as "Borith" meaning a cleaning agent made from wood and vegetable ashes. Paintings on the walls in the pyramids confirm that the Egyptians maintained a very high level of hygiene and both men and women used to be well-groomed. While the men folk especially the nobles sported a clean shaven head with a short braid, women kept their hair short [2]. The use of various oils (sesame, olive, and almonds) and herbs like lavender, myrrh, rosemary, rose, and cedar to make perfumes becomes evident from their extensive use in the embalming of Egyptian pharaohs. They also used various metallic oxides like ochre, malachite green, and antimony grounded to a very fine powder and mixed with an oil to color their lips and cheeks. Antimony ground to a fine powder and mixed with burnt almonds was used as kohl [2].

Before the nineteenth century, there was extreme poverty in Europe, and people lived in squalor and under very unhygienic conditions that is supposed to be one of the main reasons for the plague epidemics that recurred time and again. The deadly bacterial strain (Yersinia pestis) that was transmitted from rodents to man by fleas wiped out 25 million lives in Europe between 1347 and 1665. Mass realization that plague was related to the lack of cleanliness eventually led to a renaissance in hygiene. By 1525 at least two companies in Marseilles (France) had started producing and selling soap. In 1789, Andrew Pears made the first ever transparent soap, and almost a century later in 1886, the two brothers William and James Hesketh Lever made the first commercial soap manufacturing unit in Warrington which over the years evolved to become Unilever as we know it today.

In fact soap was the only detergent commercially available till the late 1950s when linear alcohol benzene sulfonic acids (LABSA) were synthesized from crude oil. Today almost all detergents contain LABSA [3] that form the heart of a multibillion detergent industry thriving worldwide.

In this chapter, we review the basic properties of surfactants with specific focus on their use as cleansers in household and personal care applications. As these 
individual subjects are large enough to cover several book volumes, we intend to cover cleaning of fabrics (laundry), skin, and hair cleansing The intent to review the basics arises from the need to make this book equally useful to a newcomer to this area of research and at the same time be a ready reference to an expert in the subject.

\section{Basic concepts}

\subsection{Surface tension and surface activity}

Liquid surfaces are known to behave like stretched membranes that make it possible for small insects like water strider to walk across its surface as if it were a solid substrate. While molecules within the bulk of the liquid experiences no net force being pulled equally from all possible directions, at an interface it experiences unbalanced forces arising from the pull from molecules in the liquid layer just below it that makes the interface behave like a stretched membrane. These forces called the surface tension act parallel to the plane of the interface and are defined as force per unit length or surface energy per unit area of the interface and are a characteristic of the interface [4]. Typical surface tension at the water-air interface is $72 \mathrm{mN} / \mathrm{m}$, while for the mercury-air interface, it is $456 \mathrm{mN} / \mathrm{m}$.

Surface active molecules or surfactants or amphiphiles as they are often called consist of a hydrophilic (water loving, polar) group at one end and a hydrophobic (water hating, nonpolar) group at the other. These molecules are unique in that when added to water, its surface tension reduces significantly $[4,5]$. The coexistence of the hydrophilic and hydrophobic end group in the same molecule allows them to self-organize at interfaces that make them surface active. While the hydrophilic end remains in contact with water, the hydrophobic end stands out in air, and the axis of the molecule makes an angle with the plane of the air-water interface which is a characteristic of the molecule and depends on its molecular structure and packing at the interface. It is this self-organization of the amphiphile at the air-water interface that reduces the surface tension of water. It has been observed that the extent of surface tension lowering depends on several factors, namely, (a) the structure of the molecule, (b) temperature, (c) electrolyte concentration of the aqueous phase, and most importantly $(d)$ concentration and (e) purity of the amphiphile.

Figure 1 shows that as the bulk concentration of the amphiphile is increased, surface tension decreases (Figure 1) and reaches a minimum beyond which it remains almost constant. This bulk concentration beyond which surface tension does not change is referred to as the critical micellar concentration $(\mathrm{cmc})[4,5]$ and corresponds to a configuration of the system where the air-water interface is fully saturated with specifically oriented surfactant monomers. Other bulk properties like conductivity and turbidity show sharp changes at $\mathrm{cmc}[4,5]$ suggesting a phase transition.

As more and more molecules are added to the bulk, they rapidly migrate to the surface and get organized at the interface till the monolayer at the air-water interface is saturated; further addition causes the amphiphiles to get organized in a spherical ball-like configuration in the bulk where the hydrophilic groups are located on the surface of the sphere and the hydrophobic groups of all the molecules are clustered at the center of the sphere as shown in the inset of Figure 1. These spherical ball-like structures with a hydrophilic surface and a hydrophobic core are called micelles. Polarity-sensitive fluorescent dyes introduced in micelles have confirmed that the polarity within the micellar core is less polar than the aqueous environment outside the micelles [6]. Because of their nonpolar core, micelles are excellent vehicles for solubilizing highly hydrophobic and poorly water-soluble 


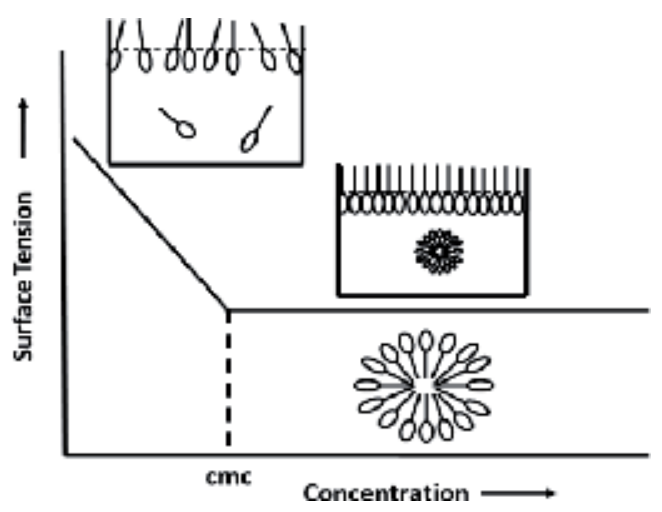

Figure 1.

Schematic of surface tension versus surfactant bulk concentration. Inset shows the organization of monomers at the interface and bulk.

molecules that has been used successfully in various drug and cosmeceutical delivery systems.

Micelles are often characterized by their aggregation number $(\mathrm{N})$ which is a measure of the number of monomers that form the micelle. Concentrationdependent studies have demonstrated the existence of other organized structures, namely, bilayers, lamellar, hexagonal phases, vesicles, and wormlike micelles that may be accounted for by the core packing parameter (CPP) model [4]. In fact the most important structural parameter predicting the structure of an organized ensemble formed is given by $\mathrm{V}_{\mathrm{H}} / \mathrm{L}_{\mathrm{c}} \mathrm{A}_{0}$ where $\mathrm{V}_{\mathrm{H}}$ is the volume of the hydrophobic micellar core, $L_{c}$ is the length of the hydrophobic chain, and $A_{0}$ is the cross-section area of the hydrophilic head group at the micellar water interface. It is confirmed that different values of this ratio given within parenthesis yield different micellar structures in the aqueous medium, for example, spheroidal (0-0.33), cylindrical (0.33-0.5), lamellar (0.5-1.0), and inverse (reverse) micelles $(>1)$ in nonpolar media $[4,5]$. In concentrated systems where the amphiphile loading is high, multiple micelles are available that fuse together to give rise to lamellar, hexagonal, bicontinuous, and liquid crystalline phases that can be readily identified by polarized optical microscopy and X-ray diffraction or both $[4,5]$.

Other parameters that help compare surface activity of different surface active molecules are their $\mathrm{C}_{20}$ and the $\mathrm{cmc} / \mathrm{C}_{20}$ values. As defined by Rosen [4], $\mathrm{C}_{20}$ is the bulk concentration of the surface active material required to depress the surface tension of pure water by $20 \mathrm{mN} / \mathrm{m}$. To compare the effect of environmental or external factors like temperature or an additive influencing, the adsorption and aggregation process and the $\mathrm{cmc} / \mathrm{C}_{20}$ ratio provide rich insights into these two competitive processes as a function of that external parameter. While a lower $\mathrm{C}_{20}$ value indicates a higher tendency of the molecule to get adsorbed at the air-water interface, a lower $\mathrm{cmc}$ value is indicative of a higher tendency of the molecule to form micelles. While a higher $\mathrm{cmc} / \mathrm{C}_{20}$ implies inhibition of micellization and an enhancement of adsorption at the air-water interface, a lower $\mathrm{cmc} / \mathrm{C}_{20}$ implies inhibition of adsorption and enhancement of micellization under the given set of conditions [4].

\subsection{Emulsions and emulsion stability}

Oil and water when mixed are known to separate out into two distinct layers. However, when a surfactant is added to the mixture and the surfactant is water-soluble, an oil in water $(\mathrm{O} / \mathrm{W})$ emulsion is formed and vice versa. The larger the amount of surfactant used, the finer is the emulsion [7]. Because emulsions consist of two 
phases, oil and water, and their refractive indexes are different, these droplets scatter light that make emulsions appear translucent or milky. The droplet size depends on the ratio of oil and water and the surfactant used. Microemulsions are special in that they appear isotropic and transparent and are known to be thermodynamically stable, and interfacial tension at the oil-water interface is zero $[4,5,7]$. Over time, emulsions tend to separate out either as a creamy layer at the top or a heavy liquid at the bottom which is caused as a result of coalescence of droplets colliding due to Brownian motion. Prevention of coalescence is key to emulsion stability which is achieved by introducing (a) electrostatic repulsion between the droplets and (b) steric hindrance. While the electrostatic repulsion may be brought about by charged surfactants anionic or cationic, steric hindrance may be brought about by using polymeric surfactants which because of its residence at the oil-water interface of the droplet prevents close approach of the droplets and their coalescence. Emulsions stabilized by adsorbing submicron silica or polymer beads at the oil-water interface of the emulsion droplets providing a physical barrier to coalescence of the droplets in the absence of charged surfactants are known as "Pickering emulsions" $[4,5,7]$.

\section{Mechanism of substrate cleaning and detergency}

Detergents help clean a substrate on which some unwanted material or debris has deposited. Clearly, the ease with which the material may be removed depends on how firmly the material is adhering to the substrate and whether the binding is chemical or physical. In this chapter, we will not consider chemical binding of the debris to the substrate but will only consider removal of debris that is physically bonded to the substrate like food stains, sweat, sebum, oils, grease, mud, and airborne particles like silica, carbon, iron oxide, clay, etc. Often the debris is a complex composite material consisting of oily and fatty matter (sebum) and particulates. Sebum secreted from the skin differs from person to person depending on food habits and ethnicity. Typically, sebum contains triglycerides, wax esters, fatty acids and their esters, squalene, and a small amount of cholesterol and is a soft semisolid at $25^{\circ} \mathrm{C}$ that melts at about $35^{\circ} \mathrm{C}$. A key mechanism by which sebum is removed from a substrate (e.g., fabric) is solubilization. When the concentration of surfactant is sufficiently high and exceeds cmc, a large number of micelles available readily solubilize the semisolid sebum that is retained in the micellar core.

Another important cleanup mechanism is through emulsification. Surfactant molecules get adsorbed at the sebum-water interface lowering the sebum-water interfacial tension that emulsifies the sebum which is transported away from the substrate into the bulk of the solution resulting in a cleanup of the substrate as shown in the schematic (Figure 2).

Roll-up mechanism is yet another important mechanism at work. This is applicable for liquid oil sticking to the substrate. The work of adhesion $\left(\mathrm{W}_{\mathrm{SO}}\right)$ is given by

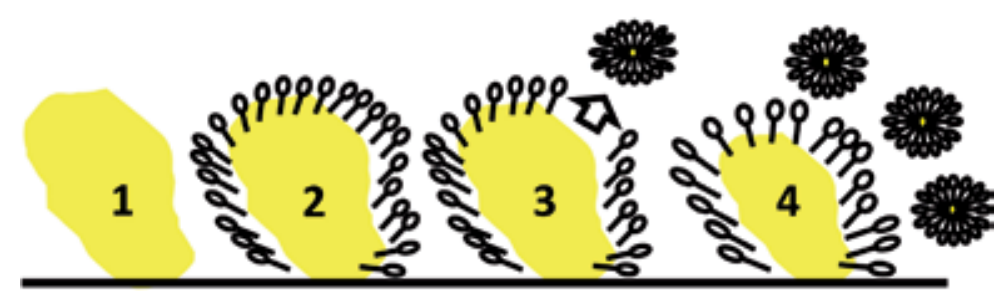

Figure 2.

(1) Oily material, (2) adsorption of surfactant on oily material, (3) solubilization of oily material and emulsification, and (4) oily mass removal. 
$\mathrm{W}_{\mathrm{SO}}=\gamma_{\mathrm{SO}}(1+\cos \theta)$ where $\theta$ is the contact angle of the oil with the substrate and $\gamma_{\mathrm{SO}}$ is the surface tension at the substrate-oil interface. For $W_{\mathrm{SO}}$ to be zero, $\cos \theta$ has to be -1 which means that this condition $\gamma_{\mathrm{so}}=\gamma_{\mathrm{ws}}+\gamma_{\mathrm{ow}}$ has to be fulfilled for the removal of oil from the substrate. Now $\gamma_{\text {so }}$ and $\gamma_{\text {ow }}$ (oil-water interfacial tension) are constants and therefore $\gamma_{\mathrm{ws}}=\gamma_{\mathrm{so}}-\gamma_{\mathrm{ow}}$ which is readily achieved as surfactant adsorbing at the substrate-water interface $\left(\gamma_{\mathrm{ws}}\right)$ lowers the surface-water interfacial tension. Once the above condition is achieved, the oil detaches itself from the substrate that is subsequently removed by hydraulic current generated through agitation which removes the oil from the substrate. Because sebum has a melting point of about $35^{\circ} \mathrm{C}$, the roll-up mechanism does not come into picture when wash temperature is below $35^{\circ}$ as sebum at that temperature is in a semisolid state.

\section{Classification of surfactants}

Surfactants typically have a hydrophobic chain (R) with an end group. Anionics have a negatively charged polar group, while the charge on a cationic is positive, and zwitterionics have a positive charge at one end and a negative charge at the other end. Nonionics have neutral end groups.

1. Anionics-Carboxylates $\left(\mathrm{R}-\mathrm{COO}^{-}\right)$, alkyl sulfonates $\left(\mathrm{R}-\mathrm{SO}_{3}{ }^{-}\right)$,

2. Cationics-Alkyl ammonium chloride $\left(\mathrm{RNH}_{3}{ }^{+} \mathrm{Cl}^{-}\right)$

3. Zwitterionics-Sulfobetaines $\left(\mathrm{RN}^{+}\left(\mathrm{CH}_{3}\right)_{2} \mathrm{CH}_{2} \mathrm{CH}_{2} \mathrm{SO}_{3} \mathrm{O}^{-}\right)$

4. Nonionics-Polyoxyethylenated alcohols $\mathrm{R}\left(\mathrm{OC}_{2} \mathrm{H}_{4}\right)_{\mathrm{n}} \mathrm{OH}$

\subsection{Surfactants in household cleaning}

Household cleaning may be divided into two main groups: (a) hard surface cleaning (floors, table and kitchen tops, toilets, etc.) and (b) soft surface cleaning (fabrics, linens, etc.). In this section we will focus on some aspects of fabric cleaning only. The most common surfactants used in laundry are anionics and nonionics. The anionics used are the sodium salts of (1) linear alkyl benzene sulfonate, (2) paraffin sulfonate, (3) alkyl ether sulfate, (4) fatty acid soaps, and (5) methyl ester sulfonate, while in nonionics (6) fatty alcohol ethoxylates, (7) amine oxides, and

(8) N-methylglucamide are extensively used.

The most extensively used surfactant in fabric wash is LABSA which consists of a mixture of $\mathrm{C}_{10}$ and $\mathrm{C}_{13}-\mathrm{C}_{14}$ chains with a phenyl group substituted either at 2 or 5 position of the carbon chain. The chain distribution and substitution depend upon the raw materials and the substitution process used. It has excellent wetting and foaming properties in addition to being highly stable over a wide range of temperatures and $\mathrm{pH}$. Moreover, LABSA have no proven adverse effects on human health or the ecosystem, but its lower biodegradability is a concern as it tends to accumulate in the environment.

Calcium $\left(\mathrm{Ca}^{2+}\right)$ and magnesium $\left(\mathrm{Mg}^{2+}\right)$ ions naturally present in water replaces the sodium in LABSA to form surface inactive calcium and magnesium salts of LABSA. Hence, detergency or cleaning efficiency decreases in hard water. The insoluble calcium salt of LABSA gets entrapped in the interfiber spaces in fabrics making it appear dull, gray, and rough over time. To prevent deactivation of LABSA, sequestering agents called builders are added to soften the water. Some of the common sequestering agents are sodium tripolyphosphate (STTP), sodium 
silicate, and sodium carbonate which added to hard water removes the $\mathrm{Ca}^{2+}$ and $\mathrm{Mg}^{2+}$ by converting them into insoluble phosphates, silicates, and carbonates. Zeolites and soaps are also used as builders. Although used extensively in the 1980s and 1990s, the use of phosphates is strongly discouraged as they tend to cause eutrophication of water masses that adversely affects the environment.

A typical fabric wash formulation today contains about 10-20\% LABSA, $15-30 \%$ sodium carbonate, and $4-6 \%$ sodium silicate as the main ingredients. Because LABSA perform the best at high $\mathrm{pH}>10$, detergent formulations usually have $\mathrm{pH}$ between 10 and 12 [8-10]. A mixed active consisting of LABSA and nonionic (a fatty alcohol ethoxylate) is often used to boost cleaning that is achieved through lowering of $\mathrm{cmc}$ of the mixture and improved wetting as nonionics are unaffected by $\mathrm{Ca}^{2+}$ and $\mathrm{Mg}^{2+}$. Not more than 2-3\% of nonionics may be added in spray-dried powders as blue fumes that catch fire are produced during spray drying. However, in liquid formulations no such restrictions exist. Because soil removed from fabrics remains dispersed in the wash liquor, it tends to get reabsorbed back into the fabric to prevent which anti-redeposition agents like carboxymethylcellulose or sodium polyacrylate $(0.1-0.2 \%)$ are added. Other ingredients used to complete the formulated products are fillers (zeolites, sodium sulfate bentonite, etc.), enzyme mixtures (proteases, lipase, and cellulases), and perfume. It must be pointed out that cleaning efficiency depends on several factors (a) the recipe, (b) the soil composition (food, oil, stains, etc.), (c) water hardness, (d) the wash protocol, (e) temperature of wash, (f) the agitation provided, and (g) the fabric under consideration.

In developing countries like India, Pakistan, Sri Lanka, Bangladesh, and the Philippines, a substantial fraction of the population still washes clothes by hand and often using a brush to scrub the fabrics clean. In India about $60 \%$ of the population still washes clothes by hand using a detergent powder for soaking and a detergent bar and brush to scrub their clothes clean. The divide between hand and machinewash users is about 60:40, although the number of machine users is rising rapidly due to the availability of affordable machines and a higher disposable income. Powder detergents dominate the Indian market, while liquid detergents are the only product in the European and American markets.

The challenges for the detergent industry in India, Pakistan, and Bangladesh include harsh conditions like water hardness which varies from 80 to $200 \mathrm{ppm}$ and acute water shortage in many areas. Again average temperatures exceed $40^{\circ} \mathrm{C}$ that cause profuse sweating, and because of high atmospheric pollution, clothes rapidly become dirty. The high levels of sebum and fine suspended matter from the atmosphere make the soil tough and difficult to remove. In contrast, water hardness and atmospheric pollution in the USA and Europe is very low, and hence, the soil generated is very low and easy to remove as washing with hot water is the usual practice. Despite the large differences between the Indian and European and American washing practices, there however exists a similarity—need for a lower cost per wash. While in Europe and the USA a large fraction of the cost per wash may be attributed to electrical heating costs, in India a large component of the cost per wash arises from the need to use larger quantities of surfactants and builders. One solution to the above problem is to find an alternative to LABSA.

Fatty alcohol methyl ester sulfonates (FAMES) that are obtained from sulfation of fatty alcohols derived from renewable sources like palm, rapeseed, soya, or corn oils have been used as alternatives to LABSA. Although 100\% biodegradable, it is yet to find a substantial place in the detergent industry as it is often not very costcompetitive, and availability of the same in very large quantities is often a matter of concern. Moreover, increasing demands of palm and soya oils have given rise to massive deforestation in Malaysia, Indonesia, and Brazil that is a huge concern for the 
environment. Other challenges include a slightly lower performance of FAMES than LABSA at lower temperatures and its tendency to decompose in humid and high temperatures. Decomposition of FAMES is associated with a foul odor that interferes with the fragrance of detergents which is unacceptable to most consumers that continues to make FAMES unfavorable for commercial use in household products [11].

\subsection{Surfactants in personal care}

\subsubsection{Surfactants in skin care}

A glowing skin and shiny well-groomed hair not only adds to self-confidence but also is a reflection of health and personality of that person. It is something that every person looks forward to that forms the base on which the multibillion global cosmetic industry thrives. The global skin care market in 2016 was estimated to be USD 136,304 million and estimated to reach USD 194, 961 million in 2024 with a CAGR of 4.5\%, while the global hair care market is about USD 18072 million in 2017 and is expected to reach USD 23601 million in 2024 with a CAGR of $4.1 \%$.

The skin happens to be the largest organ of the human body that provides a tough barrier to almost all types of bacteria and allergens in addition maintaining a constant body temperature through expulsion of moisture in the form of sweat and exchange of heat with the surroundings. Sweat contains mineral salts and sebum (a waxy organic material organic matter secreted by the sebaceous glands) that keep the skin surface lubricated and forms a moisture barrier preventing excess moisture loss. Because of its waxy nature, dirt mainly particles from the atmosphere (carbon, silica iron oxide, etc.) and dead skin cells readily accumulate and forms the breeding ground for bacteria which readily finds nutrients for its survival and growth giving rise to foul odor and irritation [12]. Hence, skin cleansing is essential.

The structure of the skin is complex and may be broadly divided into three main layers, (1) epidermis, the outermost layer; (2) dermis, the middle layer; and (3) hypodermis, the bottom layer. The epidermis may be further subdivided into five sublayers: (a) stratum corneum (SC), (b) stratum lucidum (SL), (c) stratum granulosum (SG), (d) stratum spinosum (SS), and (e) stratum basale (SB). The outermost layer SC consists of dead cells called corneocytes, the main constituent of which is keratin. The SG layer contains active cells that produce lipids, which are released into the SC. Keratin-producing cells called keratinocytes are located in the SS and the SB and consists of a single layer of cells that undergoes cell division continuously. The dermis consists of collagen and provides structural strength and flexibility, while the lowermost layer called the hypodermis or subcutis consists of fat cells that act as a shock absorber and insulator that helps preserve heat.

Because secretion of sebum and sweat facilitates deposition of airborne dust and allows bacteria to thrive, the essential cleaning step must be such that the soil residing on the skin surface is removed without interfering with the subepidermal structures of the skin. The SC is often modeled as a brick and mortar ensemble where the dead cells correspond to the bricks and the lipid layers represent the mor$\operatorname{tar}[13,14]$. These tightly packed lipid layers help retain moisture and also prevent its loss. Measurements of transepidermal water loss (TEWL) have been identified as a parameter that is directly related to irritation of the skin [15]. Surfactants and strong chemicals disrupt the organization in the protein and lipid layers that enhance TEWL causing dryness, irritation, itch, and feeling of tightness of the skin [14-16].

The $\mathrm{pH}$ of the human skin surface varies between 4 and 6, but within the skin structure, the $\mathrm{pH}$ varies between 7 and 9, i.e., there exists a clear $\mathrm{pH}$ difference of two to three units between the SC and layers deep inside the skin [15, 16]. pH influences homeostasis, SC integrity, cohesion, and antimicrobial immunity, and 
although low $\mathrm{pH}$ is a potent defense against microorganisms, it helps the synthesis of key enzymes that act as a skin barrier [13-16]. High $\mathrm{pH}$ in the absence of surfactants was seen to cause SC swelling and lipid rigidity resulting in skin irritation and feeling of discomfort that explains the feeling of tightness and dryness of the skin on using soap. Synthetic detergents (syndets), namely, sodium cocylisethionate (SCI) and sodium isethionate, on the other hand did not induce such feelings. Detailed studies $[13,15]$ revealed that syndets had $\mathrm{pH}$ in the range 5-7 soaps had $\mathrm{pH}>10$.

Other mild nonirritating cleansers frequently used are sodium salts of lauryl ether sulfates (SLES) containing 1-3 moles of ethylene oxide (EO). It is an excellent degreasing and foaming agent without the harshness of its parent sodium lauryl sulfate (SLS). Detailed studies have demonstrated that addition of EO groups in the main chain reduced detergency and skin irritation. Although SLES (1EO) is extensively used in body washes and shampoos, SLES (3EO) being milder is used in baby products as baby skin is thinner and prone to irritation. Cocoamidopropylbetaine (CAPB), sulfosuccinates, and alkylpolyglucosides (APG) are even milder than SLES. In fact in a scale of 1 to 100 where 1 is the mildest and 100 is the harshest, the sequence is as follows:

Water $<$ APG $<$ SLES+CAPB $(2: 1)<$ syndet $<$ SCI $<$ soap $<$ SLS [13].

CAPB has therefore been used successfully in tearless shampoos, and often mixtures of SLES:CAPB (2:1) are used in baby shampoos. Very high-end mild products are formulated with CAPB and APG's mixtures containing glycerin as humectant.

\subsubsection{Surfactants in hair care}

The human hair consists of the outermost layer called the cuticle which consists of dead and overlapping hard scalelike structures. The inner layer is the cortex that imparts strength and color to hair, and the innermost layer is the medulla which is present in thick hair but often absent in thin and fine hair. Detailed studies [12] have revealed distinct differences between Caucasian, African, and Asian hair. Not only the cross sections are distinctly different, but the very structures and strengths are different. While the African hair is fine and tends to be kinky, Asian hair is straight, thick, and strong. Sebum secreted from the scalp acts as an emollient that coats the hair shaft making it soft, shiny, and manageable. Atmospheric dust and aerosols present in the environment is readily captured by hair owing to its large surface area making it appear greasy, and because colonies of bacteria flourish due to sebum, it gives rise to an unpleasant odor which may be highly embarrassing. Although the mechanisms of cleaning remain the same as discussed in an earlier section, for skin, extra caution is necessary while designing a cleanser for hair as harsh chemicals and unfavorable $\mathrm{pH}$ may make hair dry and brittle [9]. Very clean hair is unattractive and may appear to be dry, lifeless, without shine or gloss, difficult to comb, and unmanageable as it tends to tangle. It is the presence of moisture and oil, natural or otherwise, that imparts a smooth, silky appearance that makes hair manageable and looks beautiful. Therefore, ingredients in shampoos need to be carefully selected such that balance of oil and moisture is maintained for hair to appear attractive and lively. Because hair washing practices vary from country to country and the quality of hair is very different, shampoo formulations used in different countries are different although the same ingredients may be used. For oily hair, sodium lauryl sulfate (SLS) or triethanolamine dodecylbenzene sulfonate (TEA-DBS) is used solo being an excellent degreaser and foaming agent or often as a mixture with its milder counterpart SLES (1EO). A conditioner is usually not added in the formulations for oily hair. However, for normal and dry hair, a milder surfactant like ammonium lauryl sulfate (ALS) with a conditioner like fatty alcohols or fatty esters, vegetable and mineral oils, and humectants (glycerin) is 
preferred. As in the skin, $\mathrm{pH}$ control is of utmost importance as it tends to cause the hair shaft to swell that causes the protective layer, i.e., the cuticle, to loosen allowing the hair shaft to be damaged. Neutral $\mathrm{pH}$ is the best. Conditioner imparts volume and adds sheen and gloss in addition to making hair soft and manageable. Cationics like distearyltrimethylammonium chloride or ceto-stearyl trimethyl ammonium chloride, polyquaternium-6 (poly-diallyldimethylammonium chloride), or polyquartenium-10 (cationic hydroxycellulose) are used as voluminizer $[9,16]$. Silicone oils are often used as anti-tangling agent for lubrication and minimal resistance while combing. In skin and hair formulations, the addition of fruit oils, herbal and floral extracts that are rich in antioxidants, and vitamins that contain antimicrobial and antifungal ingredients besides their characteristic perfume is a common trend.

\section{Conclusions}

In this chapter, we have briefly reviewed various surfactants commonly used in household and personal care industry. The mechanisms at the heart of the cleaning processes whether it be for skin, fabrics, or hair has been discussed. Because local conditions like water hardness, temperature, food habits, nature of food stains, extent of atmospheric pollution, nature of soil, and most importantly cleaning habits differ from country to country, surfactants need to be chosen judiciously so as to optimize performance under those local conditions. Mild surfactants suitable for skin and hair care for people with sensitive skin and babies have been discussed in some detail.

\section{Author details}

Ashim Kumar Dutta

India Glycols Limited, Kashipur, Uttarakhand, India

*Address all correspondence to: askdu1@gmail.com

IntechOpen

(C) 2019 The Author(s). Licensee IntechOpen. This chapter is distributed under the terms of the Creative Commons Attribution License (http://creativecommons.org/licenses/ by/3.0), which permits unrestricted use, distribution, and reproduction in any medium, provided the original work is properly cited. (cc) BY 


\section{References}

[1] Allied Market Research Report. 2018. Available from: http://www.alliedmarket research.com/surfactant-market

[2] Lucas A. Cosmetics, perfumes and incense in ancient Egypt. The Journal of Egyptian Archaeology. 1930;16(1/2):41-53

[3] Sweeney WA, Olson AC. Performance of straight chain alkylbenzene sulfonates (LAS) in heavy duty detergents. Journal of the American Oil Chemists' Society. 1964;41(12):815-822. DOI: $10.1007 /$ BF02663964

[4] Rosen MJ. Surfactants and Interfacial Phenomena. 3rd ed. New York: WileyInterscience; 2004. ISBN 0-471-47818-0

[5] Holmberg K, Jonsson B, Kronberg B, Lindman B. Surfactants and Polymers in Aqueous Solution. 2nd ed. New York: Wiley; 2002. ISBN 978-0-4714-9883-4

[6] Matzinger S, Hussey DM, Fayer MD. Fluorescent probe solubilization in the head group and core region of micelle: Fluorescent lifetime and orientational relaxation measurements. The Journal of Physical Chemistry. B. 1998;102:7216-7224

[7] Tadros TF. Emulsion Formation and Stability. 1st ed. New York: Wiley; 2013. ISBN 978-3-527-31991-6

[8] Miller CA, Raney KH. Solubilizationemulsification mechanisms of detergency. Colloids and Surfaces A: Physicochemical and Engineering Aspects. 1993;74:169-215. DOI: 10.1016/0927-7757(93)80263-E

[9] Ho LTT. Formulating Detergents and Personal Care Products: A Complete Guide to Product Development. 1st ed. New York: AOCS Press; 2000. ISBN 1-8939-9710-3
[10] Watson RA. Laundry detergent formulations. In: Showell M, editor. Handbook of Detergents Part D. New York: CRC Press Taylor \& Francis Group; 2006. ISBN 978-0-8247-0350-9

[11] Cox MF, Weerasooriya U. Methyl Ester Ethoxylates. In: Friedli F, editor. Detergency of Specialty Surfactants. New York: Marcell Dekker Inc; 2001 ISBN 0-8247-0491-6

[12] Freinkel RK, Woodley DT. The Biology of the Skin. 1st ed. New York: The Parthenon Publishing Group; 2001. ISBN 1-85070-006-0

[13] Ananthapadmanabhan KP, Subramanyan K, Rattinger GB. Moisturizing cleansers. In: Leyden JJ, Rawlings AV, editors. Skin Moisturization. 1st ed. New York: Marcel Dekker Inc.; 2002. ISBN 978-0-8247-4413-7

[14] Loden M, Maibach HI. Dry Skin \& Moisturizers: Chemistry and Function. 1st ed. New York: CRC Press; 2000. ISBN 0-8493-7520-7

[15] Chew AL, Maibach HI. Irritant Dermatitis. 1st ed. New York: Springer; 2006. ISBN 978-3-540-00903-0

[16] Wolfram LJ. Hair cosmetics. In: Barel AO, Paye M, Maibach HI, editors. Handbook of Cosmetic Science and Technology. 1st ed. New York: Marcel Dekker Inc; 2001. ISBN 0-8247-0292-1 


\title{
Role of Surfactants in Mineral Processing: An Overview
}

\author{
Abhyarthana Pattanaik and Rayasam Venugopal
}

\begin{abstract}
Depletion of high-grade resources has necessitated the use of low-grade fines, which contain good amount of mineral values and also liberate in finer sizes. Froth flotation, a physico-chemical surface-based process, is the most established solution, both technologically and economically, compared to other alternatives for fines beneficiation. For a successful and effective flotation performance, an understanding of the mineral surface and proper selection of the surfactant/reagent regimes along with their molecular chemistry and their specific adsorption mechanism are mandated. This chapter focuses on the complexity of the flotation process along with adsorption and interaction mechanism of different surfactants in accordance to mineral surface characteristics and their dependency on many microevents. To further strengthen mineral flotation chemistry and advancement of mineral engineering, research gears at investigating new surfactants, specific for particular mineral surface. The selection of reagents/surfactants with appropriate chemical composition and their administration are of critical importance in view of varied mineralogy, chemical complexity and size consist of feed material. Costeffective and lower cost flotation reagents can be synthesized through insertion of new functional groups, molecular modelling of reagents for more environmentfriendly nature, modifying the structure of other chelating agents and novel green chemicals from renewable resources, adding aliphatic alcohol and carboxylic acid to bio-based collectors and adding chaotropic anions to alkyl and aryl surfactants and organic and inorganic salts having strong orientation with more proton donor and acceptor; addition of another cationic group to known cationic surfactants can be tried for enhanced flotation performance. The study also provides an idea on the effect of other parameters like $\mathrm{pH}$, composition of pulp, zeta potential, electrostatic potential, etc. For envisagement of a successful flotation performance, proper selection of the reagent system according to the specific surface and understanding of the mineral surface-specific adsorption mechanism are mandated.
\end{abstract}

Keywords: flotation, ore fines, reagents, reagent system for specific objective

\section{Introduction}

The most innovative and ingenious process development of the century is the emergence of the froth flotation process for the treatment of low-grade ores. Froth flotation process, which uses the difference in hydrophobicity of minerals, is employed in several industries (mineral processing and others) for fines processing. It is a process of upgradation of minerals by taking advantage of differences in 
physico-chemical surface properties between valuable and gangue minerals of two different minerals.

Froth flotation process can be effectively applied to the system where more amount of fine liberated valuable and gangue mineral grains are present rather than of interlocked forms [1]. Froth flotation, being an established method, has been known in a century's practice across the globe for its efficiency to eliminate impurities from different ores to produce good grade concentrate.

\subsection{Froth flotation}

The grade of mined ore is depleting day by day where as demand for metal and steel is increasing steeply. Improving the resource base and exploitation of iron ore resources through the processing and upgradation is the most important challenging task. A nation's socio-economic development completely depends on effective and judicious utilization of its mineral resources.

Proper utilization of wastes is achieved through balance between natural resource management and sustainable growth process to minimize the burden on ecological pyramid due to enormous growth of industrialization. With regard to the tailings management, reduction of tailing volume is feasible, if the maximum metallic content is extracted or recovered by a suitable technology [2]. The conventional ore processing and mining operations generate fines and slimes of huge quantities to the tune of $10-15 \%$ of run of mine which are generally of poorer grade and being discarded. These discarded tailing stockpiles occupy a huge space, which contain good metallic values, cause pollution to ground and surface water, and are having a negative impact to the environment. They need to be processed to recover metallic values for resource augmentation and to meet environmental stipulation.

These fines and slimes cannot be utilized directly as feed to metallurgical plants due to size specification; besides these occupy a huge space and cause environmental and ecological problems, which need to be clearly assessed. The scarcity of highgrade ore is compelling the mineral processing industries to look for low-grade ore fines. Hence it is essential to beneficiate and to recover the additional mineral values from these fines, not only to earn additional revenue to the mineral industries but also from the point of view of conservation of mineral wealth. These low-grade slimes can be considered as national resource rather than a waste of nuisance.

In the present days, the minerals liberated at extremely fine sizes, and in addition the ore typically consists of valuable mineral intergrowth with unwanted/ gangue minerals making the mineral surface quite complex. This nature of particle characteristic compels to be separated by the technique that relies on surface properties. So the flotation technique is being developed to treat these low-grade ore and waste slimes.

Low-grade ores imply finer liberation size and cannot be upgraded by conventional gravity concentration techniques. Wet and dry low-intensity magnetic separation (LIMS) techniques are used to process ores that contain minerals with strong magnetic properties, such as magnetite and titanomagnetite. Wet high-gradient magnetic separators (WHGMS) and wet high-intensity magnetic separators (WHIMS) are used to separate the minerals having weak magnetic properties such as hematite, goethite and limonite from gangue minerals $[3,4]$. Synchronically Xiong et al. [5] explained major problems about the WHIMS and WHGMS that when metallic ores are treated in these separators, matrix dogging and mechanical entrainment of nonmagnetic particles occur, because hematite ore contains a large amount of weakly magnetic particles along with it. The change from gravity-based separation to magnetic-based separation improved the iron grade by approximately $13 \%$. 
Concurrently, Pradip [6] examined that multigravity separation is the most effective technique for processing low-grade Indian iron ore slimes to decrease alumina content. However according to Roy and Das [7], this beneficiation method is not commercially successful due to its low capacity. Later on people combined two methods, i.e. magnetic separation and selective flocculation, and found good results. The gravity and magnetic methods, i.e. physical separation techniques, are restricted to coarse-grained sizes.

So, when the size is extremely fine, in case of slimes, the physico-chemical properties start dominating over physical properties; hence these methods are unable to give satisfactory results.

Hence, froth flotation is the single most important unit operation, which is the root solution to all these problems and used for the recovery and upgradation of valuable mineral, especially below 150 . Froth flotation which uses the difference in physico-chemical surface properties of minerals is employed in several industries for fines processing. This chapter addresses how flotation has been and can be helpful in recovering the metallic values from the tailings, through a review of basics and fundamentals, efforts made earlier and future directions for research.

\section{Fundamentals of froth flotation}

The most important factor in froth flotation process is the selectivity, which means the choice of a suitable reagent to selectively modify the surface of desired mineral to enhance its hydrophobicity. This implies a thorough knowledge of the particle surface property, the mechanism of particle surface-reagent interaction and the correct type and quantity of the reagent to create the best selectivity conditions. Surfactants play the most important role for a successful operation of flotation process. To make the mineral float, the surface of such minerals has to be modified by adsorption of suitable surfactants in order to reduce the Gibbs' energy. Ensuring maximum floatability of desired minerals through maximum selectivity with the aid of reagents is the key element of flotation research and the driving force of flotation research efforts $[8,9]$. From an early modest beginning to treat base metal sulphides, it has been established itself as the most versatile process for the treatment of oxide ores, carbonate ores, industrial minerals and fine coal. It is not an exaggeration to state that there is not a single mineral or ore system which cannot be treated by froth flotation (Figure 1).

In flotation of minerals, contact angle plays a major role in hydrophobicity as it is directly proportional to hydrophobicity. The more the contact angle, the greater is the hydrophobicity and the more is the floatability.

Despite numerous years of research and development work since 1900, flotation is still not fully interpretable and remains a challenge, as there is involvement of the major phases (macroprocesses) and the number of inter-related events (microprocesses) (Figure 2).

Ensuring maximum floatability of desired minerals (with good grade and high recovery) through maximum selectivity with the aid of reagents/surfactants is the key element and driving force of a successful flotation research.

Flotation of different minerals is broadly divided into three main types:

a. Salt-type flotation

b.Sulphide flotation

c. Oxide flotation 
- Salt-type minerals include carbonate, phosphate, sulphate, tungstate and some halide compounds. They are known for their ionic bonding and moderate solubility in water. Salt-type minerals are difficult to float because they contain common cations; hence modifying agents, e.g. ammonium phosphate, calcium sulphate, sodium sulphate, nickel chloride, zinc chloride, sodium chromate, barite, celestite, gypsum, etc., are used to obtain the selectivity.

- Sulphide minerals are less electronegative than oxide minerals; hence it forms fewer ionic bonds than oxygen. Sulphur has greater tendency to form covalent bonds, especially S-S linkages, e.g. chalcopyrite, cuprite, pyrite, sphalerite, galena, etc.

- Oxide minerals include metal oxides, carbonates, silicates and fatty acids having saturated and unsaturated hydrocarbon chains that are used to float it, e.g. hematite, magnetite, goethite, quartz, malachite, etc.

Generally flotation is practised in two different ways around the globe:

1. Direct flotation-The flotation in which surfactants are added to selectively float the value minerals while the gangue minerals are collected in the tailing launder

2. Reverse flotation-The flotation in which surfactants are selectively added to float the gangue minerals while the value minerals remained depressed with specific reagents as pulp product

(a)

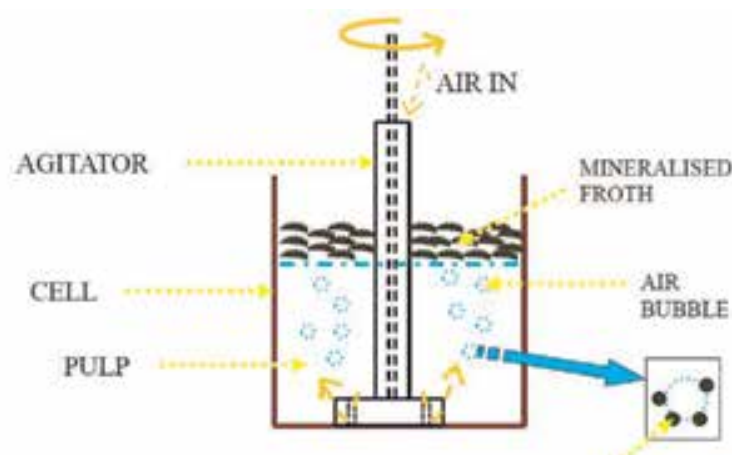

MINERALS' PARTICLES ATTACHED TO BUBBLE

(b)

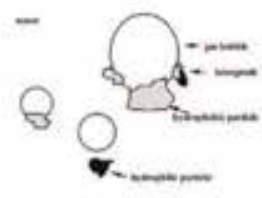

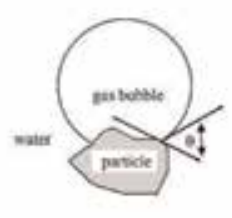

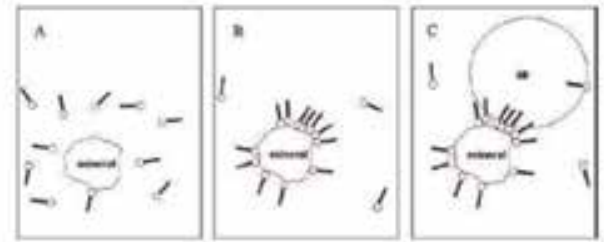

Figure 1.

(a) Schematic representation of flotation process and (b) flotation mechanism and role of contact angle [10]. 


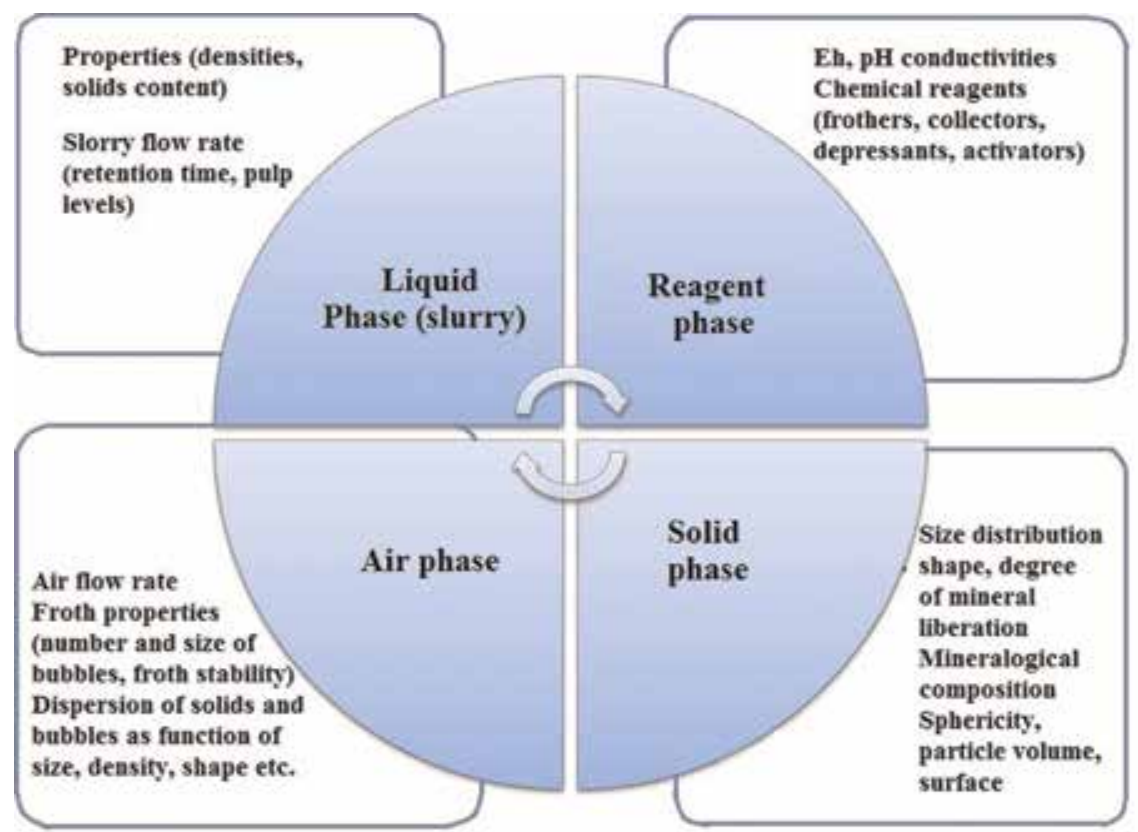

Figure 2.

Process and phases in flotation [11].

\subsection{Origin of surface charge and zeta potential}

When mineral is suspended in water, charged species/ions (potential determining ions) are transferred upon the surface which develops an electric charge or electric double layer. In the case of oxide minerals, $\mathrm{H}^{+}$and $\mathrm{OH}^{-}$ions are the principal potential determining ions, and they interact with water and produce surface hydroxyls [12]:

$$
\mathrm{MOH}_{2}^{+} \stackrel{+H^{+}}{\longleftarrow} \mathrm{MOH} \stackrel{-H^{+}}{\longrightarrow} \mathrm{MO}
$$

Due to the charge inequality, a double layer around the particle's surface is created. The potential difference between the stern layer and diffused layer is known as zeta potential.

At certain $\mathrm{pH}$, an equal number of positive and negative surface sites are created, where the surface is having no specific charge, termed as point of zero charge (PZC).

These two terms have great influence on the flotation performance of mineral at specific $\mathrm{pH}$.

Zeta potential denotes charge properties of particles and in turn implies adsorption, penetration and adherence of certain substances. Processes such as adsorption, particularly surfactants or macromolecules, can alter the interfacial behaviour of the solids markedly. Adsorption and desorption of potential determining ions $\left(\mathrm{H}^{+}\right.$and $\mathrm{OH}^{-}$ions) play an important role in accounting the surface charge:

$$
\begin{aligned}
& \frac{\mathrm{M}-\mathrm{OH}_{2}^{+}+\mathrm{H}_{2} \mathrm{O}}{\text { (Positively }} \stackrel{\mathrm{H}_{3} \mathrm{O}^{+}{ }_{(a q)}}{\longleftrightarrow} \frac{\mathrm{M}-\mathrm{OH}}{\text { (Uncharged }} \stackrel{\mathrm{OH}^{-}(a q)}{\longleftrightarrow} \frac{\mathrm{M}-\mathrm{O}^{-}+\mathrm{H}_{2} \mathrm{O}}{\text { (Negetively Charged }} \\
& \text { charged surface) surface surface) } \\
& P Z C)
\end{aligned}
$$




\begin{tabular}{lcc}
\hline Minerals & $\mathbf{p H}$ PZC & pH \\
\hline Quartz, $\mathrm{SiO}_{2}$ & $<5$ & 2.5 \\
\hline Cassiterite, $\mathrm{SnO}_{2}$ & $<5.5$ & $2.0-55$ \\
\hline Sulphides, $\mathrm{MeS}$ & - & $2.1-7.0$ \\
\hline Diamond, $\mathrm{C}$ & - & 3.5 \\
\hline Rutile, $\mathrm{TiO}_{2}$ & $4.8-5.3$ & 5.5 \\
\hline Ilmenite, $\mathrm{FeTiO}_{3}$ & 5,6 & - \\
\hline Hematite, $\mathrm{Fe}_{2} \mathrm{O}_{3}$ & $6.5-8.5$ & $5.98-7.01$ \\
\hline Barite, $\mathrm{BaSO}$ & - & $6.0-8.1$ \\
\hline Tenorite, $\mathrm{CuO}_{4}$ & $6.5-8.5$ & $6.0-7.6$ \\
\hline Dolomite, $(\mathrm{Ca}, \mathrm{Mg}) \mathrm{CO}_{3}$ & - & 7.5 \\
\hline Alumina, $\mathrm{Al} \mathrm{O}_{3}$ & $8-9.1$ & $5-9.6$ \\
\hline Magnesite, $\mathrm{MgCO}$ & - & 7.5 \\
\hline Periclase, $\mathrm{MgO}$ & - & 12.0 \\
\hline
\end{tabular}

Table 1.

Represents the $\mathrm{pH}_{P Z C}$ and $p H_{I E P}$ of some minerals, which has been modified from the data of Parks [13] and Kosmulski [14].

In Eqs. (1) and (2), $M$ denotes the metal.

In the case of iron ores, the isoelectric point of natural hematite varies in between 5.98 and 7.01, depending upon the association of gangues. If the hematite particles are not liberated completely, then isoelectric point will be closer to quartz. The zeta potential of quartz depends on the hydroxylation of quartz surface at different $\mathrm{pH}$ values and the interaction of amine species. The $\mathrm{pH}_{\mathrm{PZC}}$ and $\mathrm{pH}_{\text {iep }}$ values for various oxides and hydroxides of alumina vary widely (pH 5-9.6) depending upon the association of other minerals [11]. The $\mathrm{pH}_{\text {iep }}$ of quartz is at $\mathrm{pH}=2.5$, below which it acquires a positive charge, and above this $\mathrm{pH}$, the quartz surface acquires negative charge (Table 1 ).

\section{Flotation reagents}

The reagents are added to the system in order to create proper environment for the particles to adhere to the air bubbles and recovered. The minerals are characterized by the functional groups as non-polar minerals, polar minerals and heteropolar minerals. The non-polar minerals are those whose surface is predominantly of weak molecular bonds with very little polarity. The group of minerals, which consist of both polar and non-polar groups, are termed as heteropolar and constitute a large group of minerals, e.g. gibbsite (consisting of aluminium hydroxide $\mathrm{Al}(\mathrm{OH})_{3}$ ), bauxite (consisting of aluminium hydroxide), hematite $\left(\mathrm{Fe}_{2} \mathrm{O}_{3}\right)$, etc. The polarities of heteropolar minerals vary according to the proportion of polar minerals. Those groups of minerals, whose surface is predominantly of strong covalent bond or ionic bond, are termed as polar minerals and are hydrophilic.

\subsection{Collectors}

Collectors can be classified into ionizing and nonionizing based on their reaction with water. The nonionizing compounds do not dissociate into ions when contacted 


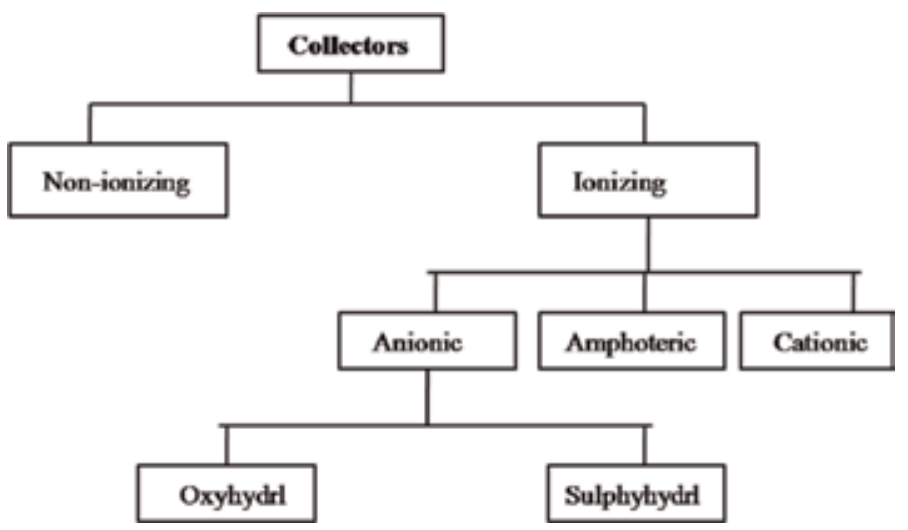

Figure 3.

Classification of collectors.

with water, while the ionizing compounds dissociate into ions in water. To float minerals, hydrophobicity/enhanced hydrophobicity has to be imparted to them, which is obtained by adding a special type of surfactants known as collectors to the pulp, which is further agitated or conditioned for adsorption to take place. Collectors are the chemical compounds which render hydrophobicity through adsorption and are further divided into ionizing compounds (dissociate into ions in water) and nonionizing compounds (which are practically insoluble and render the mineral water-repellent by covering its surface with a thin film) [15].

Ionizing collectors have been used widely in flotation era, e.g. sodium ethyl xanthate, potassium isopropyl xanthate, etc. They are composed of complex molecules asymmetric in structure and are heteropolar, i.e. the molecule contains a non-polar hydrocarbon group and a polar ionic group. The non-polar part of the molecule is a hydrocarbon radical which has pronounced water-repellent properties, and the polar part has the property of reacting with water.

Examples of nonionizing compounds are kerosene, creosote, grease, etc., which possess inherent hydrophobic property and do not dissociate in any polar liquids.

Based on classification of ionized groups, the collectors have been classified as shown in Figure 3.

Till now six main types of collectors are used in the mineral industry:

a. Anionic collector

b. Cationic collector

c. Mixed collector

d. Amphoteric collector

e. Bio-collector

f. Ionic liquids

(a) Anionic collector

- Anionic collectors are opted for minerals when the surface bears a net positive charge and these collectors ionize in the solution to give negative charge. Floatability assessments of oxide and carbonate ores are generally carried out by using highly soluble collectors consisting of organic 
molecules varying 10-18 carbon chain length [16]. Fatty acids (a distilled tall oil containing $\sim 91 \%$ oleic and linoleic acid, $6 \%$ resin acid and 3\% unsaponifiables) are used as collectors for mineral oxides with dosages in the range of $0.45-0.67 \mathrm{~kg} /$ ton [17]. Fatty acids, resin acids, soaps, alkyl sulphates and sulphonates are generally used to float iron oxide bearing minerals.

(b) Cationic collector

- Cationic collectors are opted for minerals when the surface bears a net negative charge and these collectors ionize in the solution to give positive charge. Organic bases containing a hydrocarbon group and salts of these bases are generally chlorides and acetates. This group includes the primary aliphatic amines, diamines, quaternary ammonium salts and ether amine products. Longer amphipathic linear chain molecules are more confirmatively adsorbed at the liquid/gas interface, as they are more hydrophobic through van der Waals interactive forces.

(c) Mixed collector

- The use of surfactant mixture was studied by several researchers and found that the surfactant mixtures can have an advantage over the use of single surfactant [18-20].

- Mixed collectors provide increased flotation selectivity and increased recovery with reduction in reagent consumption. The adsorption of single surfactants at the solid-liquid interface has been comprehensively studied, but the study of adsorption of mixed surfactant solutions has been limited.

(d) Amphoteric collector

- Amphoteric collectors are the surfactants having good acidic and basic group in their molecular structure and can function as a cation, anion and neutral molecules depending on the $\mathrm{pH}$ of the aqueous medium. The effect of cationic group is accentuated most in acidic media, while the anionic group is accentuated in alkaline media.

(e) Bio-collector

- Microbial flotation reagents are currently gaining attention as natural bacteria can be used in place of toxic chemicals from the environmental point of view, e.g. Bacillus polymyxa, Paenibacillus polymyxa and Rhodococcus opacus, for flotation of iron oxide minerals.

(f) Ionic liquids

- Ionic liquids are the salts having poorly coordinated ions and exist in liquid state below $100^{\circ} \mathrm{C}$, but these liquids are gaining the attention of researchers due to their easier handling properties, interesting electrochemical properties, low vapour pressure, low volatility and flammability, high viscosity, dual natural polarity, good thermal stability, low surface tension and wide range of miscibility with water and other organic solvents and most importantly their environment-friendly nature. 
- Ionic liquids are more suitable surfactants than conventional classical salts because of their versatility to switch their role as anionic and cationic part as per the requirement, which is due to the presence of large organic cations with a variety of associated anions.

Sahoo et al. [21, 22] experimented the flotation of pure quartz as well as low banded hematite quartzite (BHQ) having quartz as major impurity using tricaprylmethyl ammonium salicylate (TOMAS), an ammonium-based ionic liquid, Aliquat 336, tetrahexylammonium chloride (THEX) and dodecylammonium chloride as collectors and found that ionic liquids performed better than conventional surfactants. Due to the chaotropic character of anions of ionic liquids, they easily pair with ions of mineral surfaces, thus inducing increased hydrophobicity compared to conventional surfactants. It was observed that with lower concentration of ionic liquids, higher recovery and grade were achieved, and the reverse condition was observed in the case of conventional surfactants.

Adsorption between mineral surface and reagents occur by various means, which is represented in Figure 4.

\subsection{Frothers}

Frothers are organic compounds, which dissociate into ions and decrease the surface tension at the air-water interface, thus stabilizing the froth consisting of a multitude of mineral-laden air bubbles and inducing buoyancy effect on the mineralized surface.

When brought into contact with water, the water dipoles readily associate with the polar group while virtually having no affinity to the non-polar group. The non-polar group is projected into the air phase which leaves the polar group on the air surface orienting towards the water. A frother is required to provide conditions amicable to

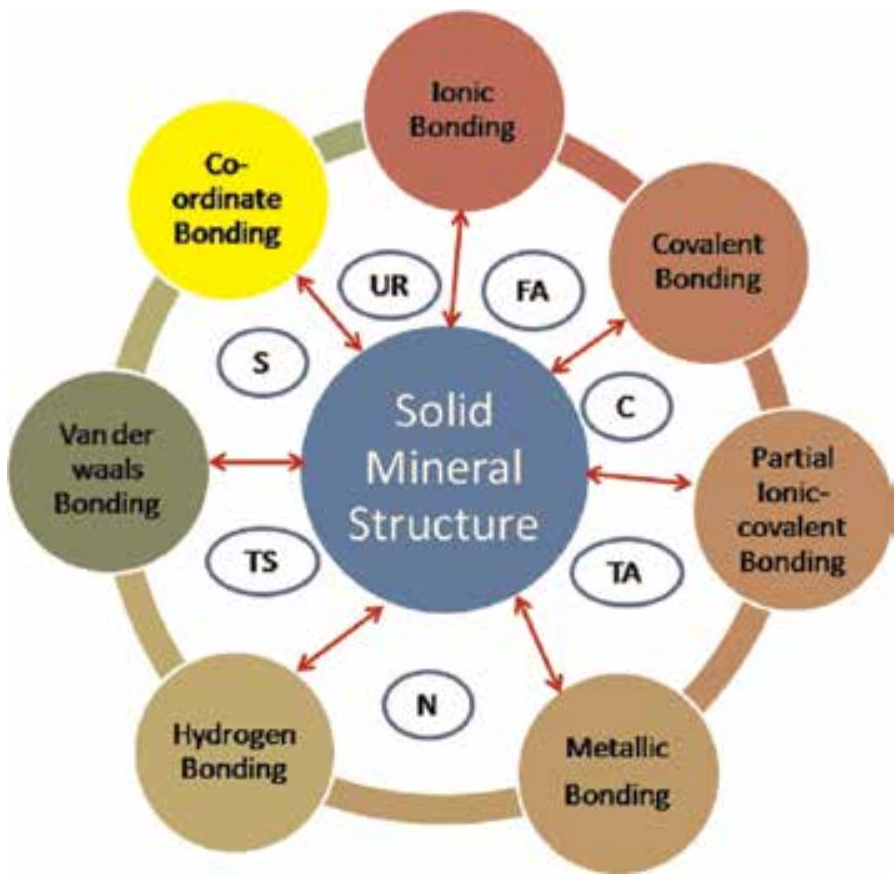

Figure 4 .

Types of bonding adsorption between mineral surface and reagents. 
the formation of froth that is stable enough to prevent undesirable froth breakage. The stability of bubble attachment to hydrophobic particles is further stabilized by the action of frother. A good frother should have negligible collecting power, should not affect the state of the particle surface and should act entirely in the liquid phase to produce froths which are just stable enough to retain the floated particles [15].

Frothers are consisted of aliphatic, aromatic, cyclic and polyglycol alcohol groups, e.g. methyl isobutyl carbinol (MIBC), cresylic acid or cresol, pine oil, etc. When surface-active groups of frother react with water, the water dipoles combine with the polar groups and hydrate them, but there is practically no reaction with the non-polar hydrocarbon group. Thus, the heteropolar structure of the frother molecule enhances its concentration at the air-water interface, with the non-polar groups oriented towards the air and the polar groups towards the water.

Hence, the frothing action is due to the ability of the frother to reduce the water surface tension, thus stabilizing the air bubbles. Frothers are generally soluble in water; otherwise they would be distributed very unevenly in the water, and their surface-active properties would not be fully effective.

Organic acids, amines and alcohols are the most common types of frothers. The alcohols are the most widely used because they have practically no collecting properties and in this respect are preferable to other frothers. The presence of collecting and frothing properties in the same reagent may make selective flotation difficult [16].

\subsection{Modifiers}

These are chemical compounds added to the flotation pulps to enhance collectormineral adsorption, that is, to improve the selectivity. This may be achieved by either (a) creating an environment or revitalizing the floatability of the desired mineral, (b) by suppressing the flotation activity of the undesired mineral (at a particular stage of flotation operation), (c) by removing the deleterious elements which hinder effective flotation of desired minerals or (d) by providing the proper pulp nature for the selective adsorption between the mineral and collector.

\subsubsection{Activators}

These chemicals are added, prior to collector addition, to react with the mineral surface and produce compounds on the surface which are highly responsive to collector adsorption, e.g. the use of 'sulphidisers' in activation of oxidized minerals of base metal sulphides. The deleterious effect of oxidation is overcome by the creation of a pseudo-sulphide surface to oxidized mineral, which would then respond favourably with the sulphydryl collector added, e.g. copper sulphate, cyanide, lime, etc.

\subsubsection{Depressants}

These are used to suppress the floatability of a mineral when it is not desired in case of multimineral system. Several natural polymers and their derivatives have been suggested as depressants for iron oxide in reverse flotation due to the presence of large number of hydroxyl groups and large molecular sizes. The depression mechanism is may be due to the blocking of surface sites for collector adsorption, resulting in hydrophilic surface and forming bridges of hydroxyl groups.

For example, in reverse flotation of iron ore, starch is used as depressant for iron ore and zinc sulphate as depressant for $\mathrm{ZnS}$ in $\mathrm{Pb}-\mathrm{Zn}$ flotation. 


\begin{tabular}{|c|c|c|c|c|}
\hline Reagents & Application & Classification & Composition & Functioning process \\
\hline $\begin{array}{l}\text { Collectors } \\
\text { Collectors }\end{array}$ & $\begin{array}{l}\text { 1. Hematitic } \\
\text { ore } \\
\text { 2. Hematitic } \\
\text { ore } \\
\text { 3. Ultrafine } \\
\text { hematite } \\
\text { particles } \\
\text { Goethite }\end{array}$ & $\begin{array}{l}\text { Anionic collectors } \\
\text { 1. Fatty acids } \\
\text { 2. Alkyl sulphates and } \\
\text { sulphonates (C12-C16) } \\
\text { 3. Oleic acid and lauric acid } \\
\text { 4. Hydroxamates } \\
\text { Amphoteric collectors } \\
\text { 5. Hexanoic acid, octanoic acid, } \\
\text { decanoic acid, dodecanoic acid, } \\
\text { tetradecanoic acid, stearic acid } \\
\text { Sarcosinates and } \\
\text { sulphosuccinates } \\
\text { 1. Dodecyltrimethylammonium } \\
\text { bromide } \\
\text { 2. Mycobacterium phlei, Bacillus } \\
\text { polymyxa, Paenibacillus } \\
\text { polymyxa, Rhodococcus opacus, } \\
\text { Bacillus subtilis, R. erythropolis } \\
\text { Sodium oleate } \\
\text { fatty acid }\end{array}$ & $\begin{array}{l}\text { Tall oil } \\
\text { containing 91\% } \\
\text { oleic acid, } 6 \% \\
\text { resin acid and } \\
3 \% \\
\text { unsaponifiables } \\
10^{-3} \text { molar, } \\
10^{-4} \text { molar } \\
\text { concentration } \\
70-100 \mathrm{mg} / \mathrm{L} \\
\text { Liquid } \\
\text { emulsion } \\
5-20 \% \text { solution }\end{array}$ & $\begin{array}{l}\text { Chemisorption on } \\
\text { hematite surface, } \\
\text { surface precipitation } \\
\text { Chemisorption } \\
\text { Classical chemisorption } \\
\text { Microbial strain } \\
\text { Form hydrophobic } \\
\text { floccules of hematite } \\
\text { particles } \\
\text { Chemisorption }\end{array}$ \\
\hline Collectors & $\begin{array}{l}\text { 1. Silica } \\
\text { (quartz) } \\
\text { 2. Both } \\
\text { alumina and } \\
\text { silica } \\
\text { 3. Alumina }\end{array}$ & $\begin{array}{l}\text { Cationic collector } \\
\text { 1. Etheramine and } \\
\text { etherdiamines } \\
\text { 2. Fatty amine (dodecylamine, } \\
\text { decyletheramine) } \\
\text { 3. Quaternary ammonium } \\
\text { compounds } \\
\text { 4. Gemini surfactant } \\
\text { Cetyltrimethylammonium } \\
\text { bromide, } \\
\text { hexadecyltrimethylammonium } \\
\text { bromide } \\
\text { SOKEM (503C, 504C, 520C, } \\
\text { 521C, 522C, 523C, 524C, 525C, } \\
\text { 701C, 720C) } \\
\text { Cationic, anionic and nonionic } \\
\text { polyacrylamide }\end{array}$ & $\begin{array}{l}\text { In kerosene } \\
5-10 \% \text { solution } \\
\text { Undiluted } \\
20-30 \% \\
\text { neutralization } \\
\text { degree with } \\
\text { acetic acid or } \\
\mathrm{NaOH}\end{array}$ & $\begin{array}{l}\text { Electrostatic } \\
\text { adsorption } \\
\text { Hydrogen bonding } \\
\text { with the surface } \\
\text { exhibiting low } \\
\text { interaction with } \\
\text { collectors }\end{array}$ \\
\hline Collectors & Silica & $\begin{array}{l}\text { Anionic collectors } \\
\text { Fatty acids }\end{array}$ & $\begin{array}{l}\text { Activation by } \\
\mathrm{Ca}^{2+} \text { ions }\end{array}$ & $\begin{array}{l}\text { Strong chemical } \\
\text { bonding between } \\
\text { mineral surface and } \\
\text { collector }\end{array}$ \\
\hline Collectors & Magnetite & $\begin{array}{l}\text { 1. Maleic acid } \\
\text { 2. Ethyl oleate } \\
\text { 3. Polyethylene glycol } \\
\text { monooleate } \\
\text { 4. Maleic acid ester } \\
\text { 5. Quaternary ammonium } \\
\text { surfactant }\end{array}$ & $10-50 \mathrm{mg} / \mathrm{L}$ & $\begin{array}{l}\text { Electrostatic } \\
\text { adsorption } \\
\text { High solubilization } \\
\text { capacity, stronger } \\
\text { biological activity }\end{array}$ \\
\hline Collectors & Phosphorous & $\begin{array}{l}\text { Anionic collectors } \\
\text { 1. Carboxylate surfactants } \\
\text { 2. Fatty acid } \\
\text { 3. Flotigam EDA manufactured } \\
\text { by Clariant }\end{array}$ & & Surface chemisorption \\
\hline $\begin{array}{l}\text { Mixed } \\
\text { collectors }\end{array}$ & $\begin{array}{l}\text { Silica } \\
\text { Iron oxides }\end{array}$ & $\begin{array}{l}\text { 1. Blending diamines and } \\
\text { monoamines } \\
\text { 2. Amalgamation of ammines } \\
\text { with kerosene } \\
\text { 3. Conjunction of diesel oil and }\end{array}$ & $\begin{array}{l}20-30 \% \\
\text { blending } \\
\text { Mass ratio of } \\
\text { 1:4 } \\
\text { Mass ratio of }\end{array}$ & $\begin{array}{l}\text { Co-adsorption of } \\
\text { collector on silicate } \\
\text { surface by } \\
\text { hydrocarbon tail-tail } \\
\text { interaction increasing }\end{array}$ \\
\hline
\end{tabular}




\begin{tabular}{|c|c|c|c|c|}
\hline Reagents & Application & Classification & Composition & Functioning process \\
\hline & & $\begin{array}{l}\text { ether amine } \\
\text { 4. Non-phenol ethoxylated } \\
\text { with ethylene oxide and } \\
\text { etheramine } \\
\text { 5. Mixture of amine and } \\
\text { hydrochloric acid } \\
6 . N \text {-dodecyl ethylene diamine } \\
\text { (mixture of 1-bromododecane, } \\
\text { ethanol and ethylenediamine } \\
\text { 7. Mixture of primary ether } \\
\text { monoamine, oxyethylated } \\
\text { nonylphenol and oxyethylated } \\
\text { fatty alcohol } \\
\text { 1. Non-polar oils emulsified } \\
\text { with fatty acids } \\
\text { 2. Fatty acids (anionic } \\
\text { collectors) and amphoteric } \\
\text { collectors }\end{array}$ & $\begin{array}{l}\text { 1:2 } \\
\text { Mass ratio of } \\
4: 1 \text { ether } \\
\text { monoamine to } \\
\text { nonylphenol }\end{array}$ & $\begin{array}{l}\text { hydrophobicity } \\
\text { Decreased surface } \\
\text { tension at liquid-gas } \\
\text { interface and reduce } \\
\text { froth depth }\end{array}$ \\
\hline Frothers & $\begin{array}{l}\text { All iron } \\
\text { oxides, } \\
\text { silica, } \\
\text { alumina, } \\
\text { phosphorus }\end{array}$ & $\begin{array}{l}\text { 1. Pine oil (alpha-terpineol) } \\
\text { 2. Cresylic 'acid' (cresols) } \\
\text { 3. Polypropylene glycols } \\
\text { 4. DF (Dow Froth) 200, DF } \\
\text { 250, DF } 450 \\
\text { 5. Fuel oil } \\
\text { 6. Aliphatic alcohols, } \\
\text { 7. MIBC }\end{array}$ & $\begin{array}{l}\text { The reagents } \\
\text { are used as } \\
\text { undiluted and } \\
\text { also prepared } \\
\text { as solution in } \\
\mathrm{H}_{2} \mathrm{O}\end{array}$ & $\begin{array}{l}\text { Provides most viscous, } \\
\text { stable froth, have } \\
\text { collecting action } \\
\text { Less viscous but stable } \\
\text { froth, have collecting } \\
\text { action } \\
\text { Fine, fragile froth; inert } \\
\text { to rubber } \\
\text { Slightly stable froth } \\
\text { Slightly stable froths } \\
\text { Fine-textured froth; } \\
\text { frequently used with } \\
\text { ores containing slimes }\end{array}$ \\
\hline $\begin{array}{l}\text { Modifying } \\
\text { agents }\end{array}$ & $\begin{array}{l}\text { Direct and } \\
\text { reverse iron } \\
\text { ore flotation }\end{array}$ & $\begin{array}{l}\text { 1. Lime }(\mathrm{CaO}) \text { or slaked lime } \\
\mathrm{Ca}(\mathrm{OH})_{2} \\
\text { 2. Soda ash, } \mathrm{NaOH} \\
\text { Caustic soda, } \mathrm{NaOH} \\
\text { Sulphuric acid, } \mathrm{H}_{2} \mathrm{SO}_{4} \\
\text { 3. } \mathrm{Ca}^{2+}\left(\mathrm{CaCl}_{2}\right), \mathrm{Mg}^{2+}\left(\mathrm{MgCl}_{2}\right) \\
\text { 4. } \mathrm{Na}_{2} \mathrm{SiO}_{3} \\
\text { 5. Starch, dextrin } \\
\text { Quebracho, tannic acid, gaur } \\
\text { gum, PAM }\end{array}$ & $\begin{array}{l}\text { Slurry } \\
\text { Dry } \\
5-10 \% \text { solution } \\
10 \% \text { solution } \\
\text { Solution } \\
\text { Solution of } \\
0.30-0.80 \\
\mathrm{~kg} / \text { ton } \\
\text { Solution of } \\
0.5-1.2 \mathrm{~kg} / \text { ton }\end{array}$ & $\begin{array}{l}\text { pH regulator; disperses } \\
\text { gangue slimes } \\
\text { Activates silica with } \\
\text { fatty acid collectors } \\
\text { Disperses siliceous } \\
\text { gangue slimes; } \\
\text { Fragile froth } \\
\text { Depress iron-bearing } \\
\text { minerals }\end{array}$ \\
\hline
\end{tabular}

Table 2.

Reagent types used in mineral oxide industries (specifically for iron ores).

\subsubsection{Dispersants}

These are used to minimize the deleterious effect of undesired slime coating (Tables 2 and 3), e.g. sodium silicate and sodium metasilicate.

\subsection{4 $\mathrm{pH}$ regulators}

The $\mathrm{pH}$ regulators help in maintaining adequate $\mathrm{pH}$ of the pulp, which determines the selective separation of minerals. These are achieved by variety of bases and acids. 


\begin{tabular}{|c|c|c|c|}
\hline $\begin{array}{l}\text { Classification } \\
\text { of collectors }\end{array}$ & Type & $\begin{array}{l}\text { Composition } \\
\text { and dosages }\end{array}$ & Method of adsorption \\
\hline $\begin{array}{l}\text { 1. Anionic } \\
\text { collectors }\end{array}$ & $\begin{array}{l}\text { - Xanthates } \\
\text { - Thiocarbonates } \\
\text { - Dithiophosphates } \\
\text { - Thiocarbamides } \\
\text { - Thiocarbanilides } \\
\text { - Mercaptans } \\
\text { - Thioles } \\
\text { - Mixture of } \\
\text { xanthate and } \\
\text { dixanthogen }\end{array}$ & $\begin{array}{l}\text { Consists of } \\
\text { sulphydryl } \\
\text { groups }\end{array}$ & $\begin{array}{l}\text { Forms dixanthogen on pyrite surface and } \\
\text { then hydrophobicity is generated } \\
\text { Hydrophobic chain interactions }\end{array}$ \\
\hline $\begin{array}{l}\text { 2. Mixed } \\
\text { collectors }\end{array}$ & & $\begin{array}{l}\text { Optimum } \\
\text { ratio 2:3 }\end{array}$ & $\begin{array}{l}\text { Co-adsorption of xanthate and } \\
\text { dixanthogen Hydrophobic chain } \\
\text { interaction of dixanthogen and reduction } \\
\text { of electrostatic repulsion between ionic } \\
\text { head groups of xanthate that are shield } \\
\text { from each other by dixanthogen molecules }\end{array}$ \\
\hline
\end{tabular}

Table 3.

Reagent types used in mineral sulphide industries.

\section{Flotation practice}

In industries froth flotation is a continuous process involving a regular flow of feed pulp and separation of minerals into the regular respective product streams. The major elements of flotation operations are:

i. Feed preparation

ii. Mode, quantity and point of reagent addition

iii. Flotation circuit configuration and flexibility

iv. Product removal and dewatering

\subsection{Importance of reagent conditioning}

As the choice of specific reagent for a given ore is difficult and challenging, so is the selection of quantity, mode and time of addition of the reagents. The selection of reagent quantity does not pose much problem as a more or less precise reagent type and quantity for a specific ore system are available through reagent manufacturers and practising personnel. Whether the total quantity is to be added at different stages is a matter of difficult choice and is to be based upon carefully laboratory investigation regarding the case of floatability of minerals.

Adsorption of surfactant is in direct correlation with the solid-water-air interfaces as the main role of surfactants is to modify the properties of interfaces for increased adsorption of reagents and enhanced flotation process. Modified starches and blended polymers can be better alternatives to normal starches due to their higher solubility and better flocculation action.

\subsection{Applications of flotation other than mineral industries}

Application of flotation has been envisaged in other areas besides mineral engineering. Some of the examples are: 
1. Deinking of paper in paper recycling

2. Flotation of wastewater treatment

3. Processing of oil sands

\section{Conclusions}

- There is a trade-off between the $\mathrm{pH}$ of the slurry, surfactants and the mineral surface for maximum flotation performance. It can thus be concluded that the length of alkyl chain, arrangement of atoms, nature and type of bonds present within the surfactants and regulation of $\mathrm{pH}$ in the flotation pulp are solely for an effective and successful flotation.

- Mineral surface and collector chemistry interaction is the first and critical step in flotation. The larger the electronegativity of the group, the stronger is the acting solid intensity, and the larger the radical section of collector, the stronger the selectivity of collector.

- Surfactants containing alcohol group and amine group have inherent frothing property along with their collecting capability.

- Though the cost of hydroxamate is higher than fatty acids, its superiority over fatty acids in flotation of the fine-grained oxide ore deserves further attention for industrial application. Research is geared at (a) developing alternate cheaper reagents with similar performances as hydroxamates, (b) modifying the structure of fatty acids for similar or better results than hydroxamates, (c) application of other chelating agents for enhanced flotation response, (d) successfully using flotation of silicated ores and other minerals, and (e) using green surfactants and solvents given their advantage of biodegradability and sustainability. However their high cost at present continues to be a barrier preventing their use although their benefits have been well realized.

- For cationic surfactants, another cationic group can be inserted, which can be further upgraded to dicationic and tricationic surfactants, which will work out well for reverse flotation process.

- For the use of depressants, more kosmotropic ions can be added to existing polymers to enhance their depressing action.

As discussed earlier, froth flotation has the ability to treat any mineral and thus reigns supreme as it is the most versatile concentration process for ore fines. A universal solution for all minerals is not possible but it depends on a case-by-case basis as each mineral ore has different compositions. The challenging aspect of the interaction of value and gangue minerals of any ore could be overcome by specifically improved reagents. A universal specific reagent recipe cannot be proposed for any ore flotation due to variation of mineralogical composition of different ores, tailings and slimes. The knowledge and research about surfactant chemistry have to be given due recognition and used judiciously through encouraging innovative, simple and customized reagent regimes for given ore deposits. 
Role of Surfactants in Mineral Processing: An Overview

DOI: http://dx.doi.org/10.5772/intechopen.85947

\section{Conflict of interest}

No potential conflict of interest was reported by the authors.

\section{Author details}

Abhyarthana Pattanaik* and Rayasam Venugopal

Department of Fuel and Mineral Engineering, Indian School of Mines, Dhanbad, India

*Address all correspondence to: abhyap10@gmail.com

\section{IntechOpen}

(C) 2019 The Author(s). Licensee IntechOpen. This chapter is distributed under the terms of the Creative Commons Attribution License (http://creativecommons.org/licenses/ by/3.0), which permits unrestricted use, distribution, and reproduction in any medium, provided the original work is properly cited. (cc)BY 


\section{References}

[1] Gaudin AM. Principles of Mineral Dressing. New York: McGraw Hill; 1939

[2] Down GC, Stocks J. Environmental problems of tailing disposal. In: Mining Magazine. London: Applied Science Publishers; 1977

[3] Svoboda J. Magnetic methods for the treatment of minerals. In: Fuerstenau DW, editor. Developments in Mineral Processing. Vol. 8. Amsterdam, Netherlands: Elsevier; 1987. p. 712

[4] Svoboda J. A realistic description of the process of high-gradient magnetic separation. Minerals Engineering. 2001; 14(11):1493-1503

[5] Xiong D, Liu S, Chen J. New technology of pulsating high gradient magnetic separation. International Journal of Mineral Processing. 1998;54: 111-127

[6] Pradip. Beneficiation of alumina-rich Indian iron-ore slimes. Metals Materials and Processes. 1994;6(3):179-194

[7] Roy S, Das A. Characterization and processing of low-grade iron ore slime from the Jilling area of India. Mineral Processing and Extractive Metallurgy Review. 2008;29:213-231

[8] Taggart AF. Handbook of Mineral Dressing. New York: Wiley \& Sons; 1956

[9] Jameson G, Fuerstenau MC. Froth flotation: A century of innovation. Society for Mining, Metallurgy, and Exploration; 2007. ISBN: 1920806318 , 9781920806316

[10] Drzymala J. Mineral processing: Foundation of theory and practice of minerallurgy. Wroclaw University of Technology; 2007. ISBN 978-83-7493362-9. www.ig.pwr.wroc.pl/minproc
[11] Pattanaik A, Venugopal R. Investigation of adsorption mechanism of reagents (surfactants) system and its applicability in iron ore flotation-An overview. Colloids and Interface Science Communications. 2018;25:41-65

[12] Yopps JY, Fuerstenau DW. Zero point of charge of alpha alumina. Colloids and Interface Science Communications. 1964;19:61-71

[13] Parks GA. Isoelectric points of solid oxides, solid hydroxides, and aqueous complex systems. Chemical Reviews. 1965;65(2):177-198

[14] Kosmulski M. Chemical properties of material surfaces. In: Surfactant Science Series. Vol. 102. New York: Dekker; 2001

[15] Wills BA. Mineral Processing Technology: An Introduction to the Practical Aspects of Ore Treatment and Mineral Recovery. ButterworthHeinemann, Elsevier; 2007

[16] Clemmer JB. Flotation of iron ore. In: 8th Annual Mining Symposium.

Duluth, Minnesota, U.S.A.; 1947

[17] Chen ZM, Sasaki H, Usui S. Cationic flotation of fine hematite using dodecyltrimethylammonium bromide (DTAB). Metallurgical Review of MMIJ. 1991;8(1):35-45

[18] Devaney FD. Iron ore. In: Weiss NL, editor. SME Mineral Processing Handbook, American Institute of Mining. New York: Metallurgical and Petroleum Engineers; 1985

[19] Yang DC. Reagents in iron ore processing. In: Somasundaran P, Moudgil BM, editors. Reagents in Mineral Technology. New York: Marcel Dekker Inc.; 1988. pp. 579-644 
Role of Surfactants in Mineral Processing: An Overview DOI: http://dx.doi.org/10.5772/intechopen.85947

[20] Scamehorn JF. Phenomena in Mixed Surfactant Systems: ACS Symposium Series. Vol. 311. Washington, DC: American Chemical Society; 1986

[21] Sahoo H, Rath SS, Das B. Use of the ionic liquid-tricaprylmethyl ammonium salicylate (TOMAS) as a flotation collector of quartz. Separation and Purification Technology. 2014;136:66-73

[22] Sahoo H, Rath SS, Jena SK, Mishra BK, Das B. Aliquat-336 as a novel collector for quartz flotation. Advanced Powder Technology. 2015;26(2):511-518 



\title{
Effect of Surfactants on Bubble- Particle Interactions
}

\author{
Pavlína Basařová and Mária Zedníková
}

\begin{abstract}
The interaction of air bubbles with solid particles is an important mechanism in many industrial processes, e.g., in flotation, fermentation, wetting, multiphase reactors, columns, etc. The surface-active agents are adsorbed both on air-liquid and solid-liquid interfaces and significantly influence the bubble-particle interaction. In this chapter, the mechanism, dynamics, and fundamental steps of bubble adhesion onto the solid surface are described. The first part is devoted to the description of influence of surfactants on the bubble behavior during the collision, as well as their influence on thinning and breaking of liquid film. The second part describes the effect of surfactants on the formation and expansion of the threephase contact line between the bubble and the hydrophobic solid particle. The important role of surfactant type, concentration, and purity is discussed.
\end{abstract}

Keywords: bubble-particle interaction, surfactant, three-phase contact line expansion, phase interface, bubble adhesion, bubble surface immobilization

\section{Introduction}

The interaction of air bubbles with solid particles is an important mechanism in many industrial processes. Significant applications are found in the chemical and process industry (separation of coal, mineral ores, or plastics by flotation) or wastewater treatment. The multiphase flows are in general more complex due to the presence of moving boundaries separating gas and liquid phases. The degree of complexity is further increased if some surface-active agents are present in the liquid. Molecules of these substances accumulate at the interface, and they decrease the surface tension [1]. Their presence has important consequences to the flow: for example, the size distribution of bubbles or drops changes, and the rise velocity of bubbles decreases $[2,3]$. The presence of surfactants in two-phase systems is very common. Sometimes, they are added intentionally to the system (e.g., in flotation as froth agents or detergents in cleaning applications). Also, many impurities in water are surface-active, and they affect flows even at trace concentrations.

In flotation, the capture of particles by rising bubbles is the central process [4]. For efficient capture between the bubble and the hydrophobic particle, they must first undergo a sufficiently close encounter. The collision process is then followed by the creation and movement of the three-phase contact line (the boundary between the solid particle surface, receding liquid phase, and advancing gas phase) until a stable wetting perimeter is established. This sequence of liquid film drainage, rupture, and contact line movement constitutes the second process of attachment. A stable particle-bubble aggregate is thus formed $[5,6]$. 
In this chapter, the influence of surfactants on the collision and attachment process is discussed. We focused especially on (i) the influence of surfactants on bubble behavior during the collision with the hydrophobic solid particle, (ii) the drainage and rupture of thin liquid film separating the bubble and the particle,

(iii) the influence of surfactants on the three-phase contact line enlargement, and

(iv) the influence of different types of surfactants and their purity on bubble stability.

\section{Effect of surfactants on the collision process}

Before the bubble and particle collide, the bubble rises in liquid. The bubble shape and velocity follow from balance of forces acting on the bubble [7-9]. In pure liquids, the bubble surface is free of any contaminants or surfactants, and the whole bubble surface is mobile (free-slip boundary condition is valid at the bubble interface). The drag coefficient depends on Reynolds number (related to the bubble size $\mathrm{D}_{\mathrm{b}}$, bubble steady rise velocity $U_{b}$, liquid density $\rho$, and viscosity $\eta$ ) and on bubble shape defined by aspect ratio $\chi[8]$. In the case of surfactant presence, the surfactant molecules adsorb to the bubble surface. The liquid flow around the rising bubble causes the transport of surfactant molecules resulting to the uneven surfactant distribution along the bubble surface. This leads to the formation of surface tension gradients and consequently the formation of Marangoni stresses, which reduce the mobility of a part of bubble interface [3]. Consequently, the drag coefficient increases, and the bubble velocity and distortion are reduced in comparison with clean bubbles. For high concentrated surfactant solutions, the reduction of bubble velocity is so significant that drag coefficient corresponds to the drag coefficient of solid particles with no-slip boundary condition at the interface [10].

Bubble approaching the particle surface starts to decelerate. An example of bubble-particle collision in pure liquid (deionized water) and in surfactant solution (n-octanol) is shown in Figure 1. In pure liquids, the bubble deforms from its initial shape before it collides with the solid surface $[11,12]$. The deformation is caused by an increase of pressure in the liquid film separating the bubble and particle. Then, the bubble impinges on the solid. In the case of surfactant presence, the bubble deformation before the impact is suppressed. It might be expected that the presence of surfactants would affect the impact velocity of bubble hitting the surface. However, the available experimental data show that impact velocities depend on
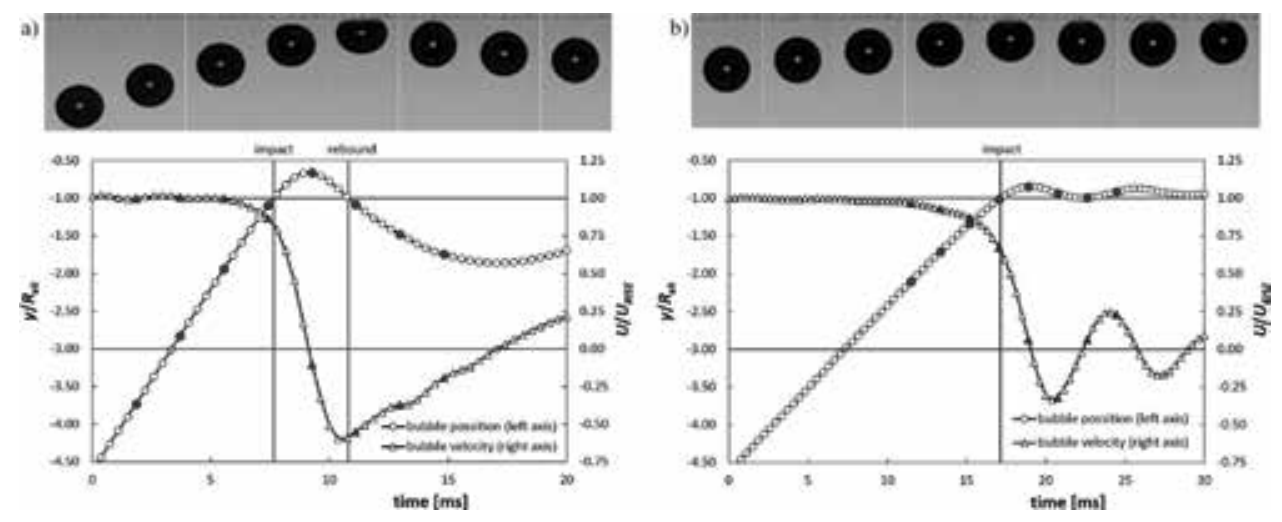

Figure 1.

An example of images illustrating the bubble-solid surface collision and corresponding normalized bubble position and velocity for (a) deionized water representing bubble with mobile interface and $(b)$ n-octanol solution (concentration $0.1 \times 10^{-3} \mathrm{~mol} / \mathrm{l}$ ) representing the bubble with partially immobile interface. Dark symbols correspond to individual images. 
the Reynolds number, but the effect of surfactant presence is minor [12] even for high concentrated solutions. It has to be noted that the steady rise velocity of bubble approaching the solid is reduced in contaminated liquid, but the normalized bubble impact velocity (ratio of impact and steady rise velocity) is similar to that in pure liquid. This observation is consistent with a concept of stagnant cup model $[3,13]$, which assumes the free-slip boundary condition at the front of a rising bubble and no-slip boundary condition at the bubble rear. This suggests that for bubbles rising in surfactant solution, the liquid flow causes the accumulation of surfactant molecules at the rear of bubble, and the bubble front remains free of surfactants and clean.

After the impact, the bubble in pure liquid visibly rebounds from the surface (Figure 1a). In surfactant solutions, the bubble rebound from the surface is suppressed (Figure 1b) $[12,14]$. While the normalized impact velocity is insensitive to surfactant presence, the rebound velocity significantly depends on the concentration of surface-active agents. Legendre et al. $[11,15,16]$ introduced the concept of restitution coefficient $\varepsilon$ :

$$
\varepsilon=\frac{U_{r}}{U_{b}}
$$

defined as the ratio of rebound velocity $U_{r}$ and steady rise bubble velocity $U_{b}$. The restitution coefficient gives overall information about the energy dissipation during the approach, first collision, and rebound of bubble from the surface. It is observed [12] that $\varepsilon$ decreases with increasing surfactant concentration and no rebound is observed for high concentrated surfactant solutions.

The bubble approaching the solid surface has kinetic energy which has to be dissipated before the bubble attaches to the surface. During the collision, the bubble kinetic energy is transferred to the surface energy (the bubble deforms), and/or it is dissipated by viscous stresses in thin liquid film. If bubble kinetic energy is too high to be completely dissipated in thin liquid film and during the surface deformation, the bubble rebounds from the surface. In the case of surfactant presence, the energy is dissipated also by other processes associated with adsorption/desorption of surfactant on the bubble interface, and the bubble rebound is suppressed. The possible additional energy dissipation can be caused by the increase of surface viscosity of the interface covered by surfactant and/or by Marangoni stresses around the bubble interface with uneven distribution of surfactant molecules $[17,18]$. The detailed characterization of the additional energy dissipation requires the knowledge of surfactant adsorption/desorption kinetics and actual surfactant distribution along the bubble interface during its deformation. Unfortunately, this information is quite difficult to obtain under steady conditions, and it is almost impossible to obtain them under dynamic conditions. When all the bubble kinetic energy is dissipated, the bubble stops to move and to deform. However, the bubble and particle is still separated by thin liquid film, and the stable bubble-particle connection is not formed yet.

\section{Wetting film drainage and rupture}

For formation of a stable bubble-particle connection, the following processes have to occur: (i) thinning of the liquid layer separating the bubble and particle to a critical rupture thickness, (ii) rupture of the liquid film and formation of a "hole" at the three-phase contact, and (iii) expansion and formation of the three-phase contact line. The stability of the liquid film is commonly considered in terms of the Derjaguin-Landau-Verwey-Overbeek (DLVO) theory, which describes the film stability as a result of balance between long-range electrostatic interactions of the electrical double layers of two interfaces (ranging from 1 to $100 \mathrm{~nm}$ ) and the van der Waals 
interactions (1-10 nm) [19]. Above that, the properties of the solid surface (hydrophobic or hydrophilic character, roughness, heterogeneity, surface electric charge, etc.) are of crucial importance for the stability and rupture kinetics of the liquid film. During the liquid film drainage between the bubble and particle surface, the film thickness decreases with time. Depending on the solid hydrophilic or hydrophobic properties, the thin liquid film ruptures, or a stable wetting film prevents the threephase contact formation. Generally, the more hydrophobic the surface, the less stable is the wetting film because in the case of hydrophobic particles the wetting films are generally of low stability and are expected to rupture easily and quickly [20]. The bubble attachment strongly depends also on the roughness of the hydrophobic solid surface. It was observed that the time of the TPC formation can be drastically reduced when the solid surface roughness increases [21].

\subsection{Effect of surfactants on wetting film drainage and rupture}

Surfactants significantly influence the dynamic properties of thin liquid films and the film lifetime. Thus, the wetting or dewetting of interface in the presence of surfactant is more complex and much less understood. It is more complex because the adsorption and orientation of a surfactant at or with respect to an interface depend on time. At the solid-liquid interface in pure liquids, we can assume a no-slip boundary condition. In contrast, the pure water-air interface is mobile and cannot withstand shear stress tangential to the air-water interface. In the presence of surfactants, the situation changes because the excess of surfactants can cause an effective no-slip boundary condition at both interfaces (liquid-solid and liquid-air). The tangential liquid velocity at the film surfaces may be reduced by an opposing gradient of surface tension, the so-called dynamic elasticity and/or Marangoni effect. The Marangoni effect would delay the outflow of liquid and cause the dynamic contact angle to decrease. On the receding side of the TPC line, a new airwater interface is continuously created during the film drainage. Consequently, the surface tension gradients are formed because the dissolved surfactant has no time to adsorb to the interface and to establish the equilibrium between the bulk and the interface [22]. Establishing the equilibrium between the surfactant concentration in the bulk and at the interface takes a considerable time, and it is limited by the diffusion of surfactant toward the interface. The situation is even more complex because the diffusion constant depends on the amount of surfactant bound in micelles and that dissolved as individual molecules. Surfactant micelles diffuse slowly, but single molecules diffuse quickly. Thus, the equilibrium between the bulk and interface may be established faster at low concentration, where most of the surfactant is not aggregated to micelles.

Stability of the thin liquid film depends also on the electrostatic interactions, which can by either attractive or repulsive. Electrostatic component of disjoining pressure (DLVO theory) depends on electric charge of the solid surface and on the charge of the liquid-gas interface. Adsorption of the ionic surfactants at the wetting film interfaces is the main reason of the surface charge changes. As the air-water interface in clean water is negatively charged, then the electrostatic forces are repulsive for negatively charged solid surface. These interactions, typical for weakly hydrophobic surfaces, stabilize the wetting film and prevent its rupture. Opposite situation, i.e., for positively charged solid surfaces, leads to the film destabilization and to its quick rupture. It was also shown that in the case of the negatively charged solid surface the preferential adsorption of the cationic surfactant can cause destabilization of the wetting film formed by the colliding bubble [23]. The significant time reduction of the TPC formation can also be caused by the presence of air molecules, which can be either trapped in the surface irregularities or formed 
spontaneously in the form of interfacial submicroscopic bubbles at rough solid surfaces. It was found that near rough hydrophobic solid surfaces, the boundary slip could be significantly increased [24-26].

\section{Three-phase contact line enlargement}

After the rupture of the liquid film, the liquid phase begins to retreat from the solid surface due to an uneven distribution of the liquid-gas interfacial tension. Generally, the movement of the three-phase contact line is involved in both the wetting and dewetting mechanisms. The contact line movement is driven by fluid dynamics and molecular interactions of the contacting phases. Surface tension and inertial and viscous forces influence the expansion of the TPC line. The resultant of the force action influences the curvature of the liquid-gas interface and therefore affects the shape of the attached bubble and contact angle. The dynamic process of either wetting or dewetting can be described by the velocity of the contact line movement $U_{T P C}$ which is defined as the time derivative of three-phase contact line radius $r_{T P C}$ :

$$
U_{T P C}=\frac{d r_{T P C}}{d t}
$$

If we focus on the wetting process (drop spreading on the surface of the solid particle), several theoretical models have been developed to describe the TPC line expansion, relating the velocity dependence on dynamic contact angle to measurable properties such as surface and interfacial tension, liquid viscosity, and static contact angle. The two main approaches prevail during the modeling of TPC line expansion: the hydrodynamic models are rather macroscopic and disregard the role of the solid surface, whereas the molecular-kinetic models involve also the properties of solid surface.

Cox [27] established the basics of the hydrodynamic model for the wetting mechanism in pure liquids. It suggests that the process is dominated by the fluid viscous dissipation. Thus, the bulk viscous friction is the main resistance force for the TPC line contact motion [28]. The model solves the equations governing the fluid dissipation, the continuity, and the Navier-Stokes equations and relates the expansion velocity $U_{T P C}$ to the dynamic contact angle $\theta$. The main disadvantage of this model is the inadequate description of the fluid motion very near to the contact line. The molecular-kinetic model eliminates the viscous dissipation but includes the solid surface characteristics. The theory is based on a statistical treatment of the transport mechanism of molecules and ions in pure liquids [29]. This model assumes the energy dissipation to occur only at the moving contact line, where adsorption and desorption processes occur. This idea is commonly applied to dynamic wetting. The movement of the three-phase contact line is ruled by the statistic kinetics of molecular events arising at the adsorption sites of the solid surface [26]. The dependence of expansion velocity on the dynamic contact angle is due to the disturbance of adsorption equilibrium, which is driven by the changes in the local interface tensions [30]. A combined molecularhydrodynamic approach is currently recommended $[28,31]$. The dewetting hydrodynamics is used to describe the effect of fluid flow on the interface deformation far from the three-phase contact line. Molecular kinetics is then used for the description of dewetting process close to the contact line. A comprehensive review of wetting and spreading problematics is reported by Bonn [32], Blake [33], or De Coninck [34]. 


\subsection{TPC line enlargement during the bubble adhesion onto the solid surface in pure liquids}

Experimental studies of three-phase contact line expansion during the bubble capture on solid surface are not very often published. In pure liquids, the contact line movement is again driven by fluid dynamics, where surface, inertial, and viscous forces influence the expansion of the TPC line. Phan [30] confirmed that the combined molecular-hydrodynamic model is suitable for describing the bubble dewetting process in deionized water. However, compared to drops, the surface of the bubbles in pure liquids is much more deformable. The spreading process is dominated by the fluid viscous dissipation, and the bulk viscous friction is usually the main resistance force for the TPC line contact motion [28]. The resultant of surface, inertial, and viscous forces influences the curvature of the liquid-gas interface and therefore affects the shape of the bubble. Thus, we have to consider also additional forces resulting from quite violent bubble shape pulsations occurring during the TPC line expansion. These pulsations were confirmed both experimentally [35] and numerically [36]. A typical example is illustrated in Figure 2, where the images of a bubble having the diameter $0.7 \mathrm{~mm}$ are given. The TPC line expansion continues together with significant bubble shape deformation, where the bubble vertical diameter is firstly extended and then compressed. The bubble shape deformation during expansion could be described as a form of bouncing while keeping the three-phase contact line (liquid-gas interface pulsates). The elongation of the bubble shape results from interplay between detachment and attachment forces [37]. Due to the TPC formation, the capillary force is too strong and prevents bubble to detach from the solid surface. Consequently, the bubble is pushed back, which is the source of additional pressing force (additional pressure) and facilitating (speeding up) the rate of expansion of the TPC line (local maximum at $U_{T P C}$ vs. time curves in Figure 3). Figure 3 shows the time dependence of the TPC line diameter and the expansion rate $U_{T P C}$ defined by Eq. 2 .

The rupture of a liquid film is not symmetrical with respect to the vertical axis of the bubble symmetry both for pure water and surfactant solutions. This finding is in accordance with the conclusion of Chan [38], who proved that the liquid film becomes the thinnest close to the apparent contact line. In pure water, the asymmetry of the TPC line formation leads to bubble surface oscillations and asymmetry in dynamic contact angles. Similar linear oscillations and irrotational flow during the bubble contact with the solid surface were described by Vejrazka [39].

\subsection{Influence of surfactants on the three-phase contact line enlargement}

In pure liquids, the stable perimeter of the TPC line is formed within a few milliseconds. The presence of surface-active agents significantly affects the kinetics

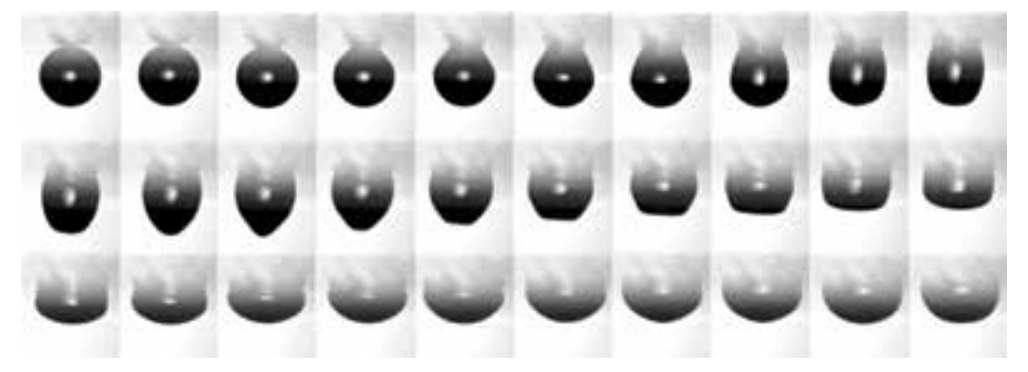

Figure 2.

A series of photos illustrating the adhesion of the bubble (bubble diameter $0.705 \mathrm{~mm}$ ) onto the solid surface (silanized glass, $\theta_{\text {equilibrium }}=102^{\circ}$ ) in pure water. The time interval between individual shots is $0.0625 \mathrm{~ms}$. The images illustrate the bubble adhesion process during the first $2 \mathrm{~ms}$. 


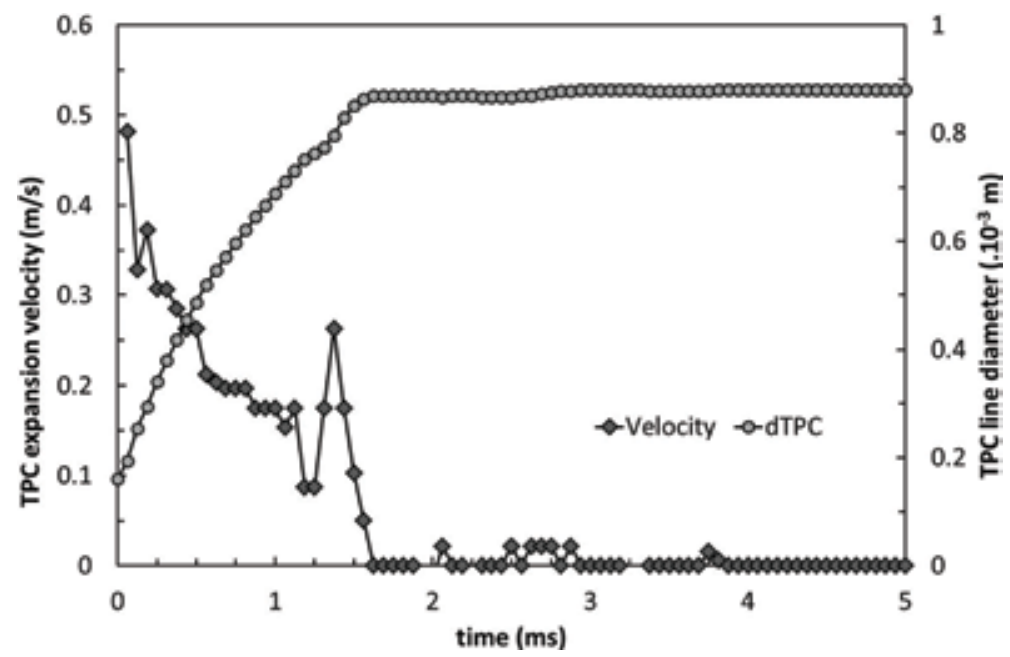

Figure 3.

The TPC expansion velocity and diameter of the TPC line expansion in pure water for a bubble of $0.705 \mathrm{~mm}$ in diameter.

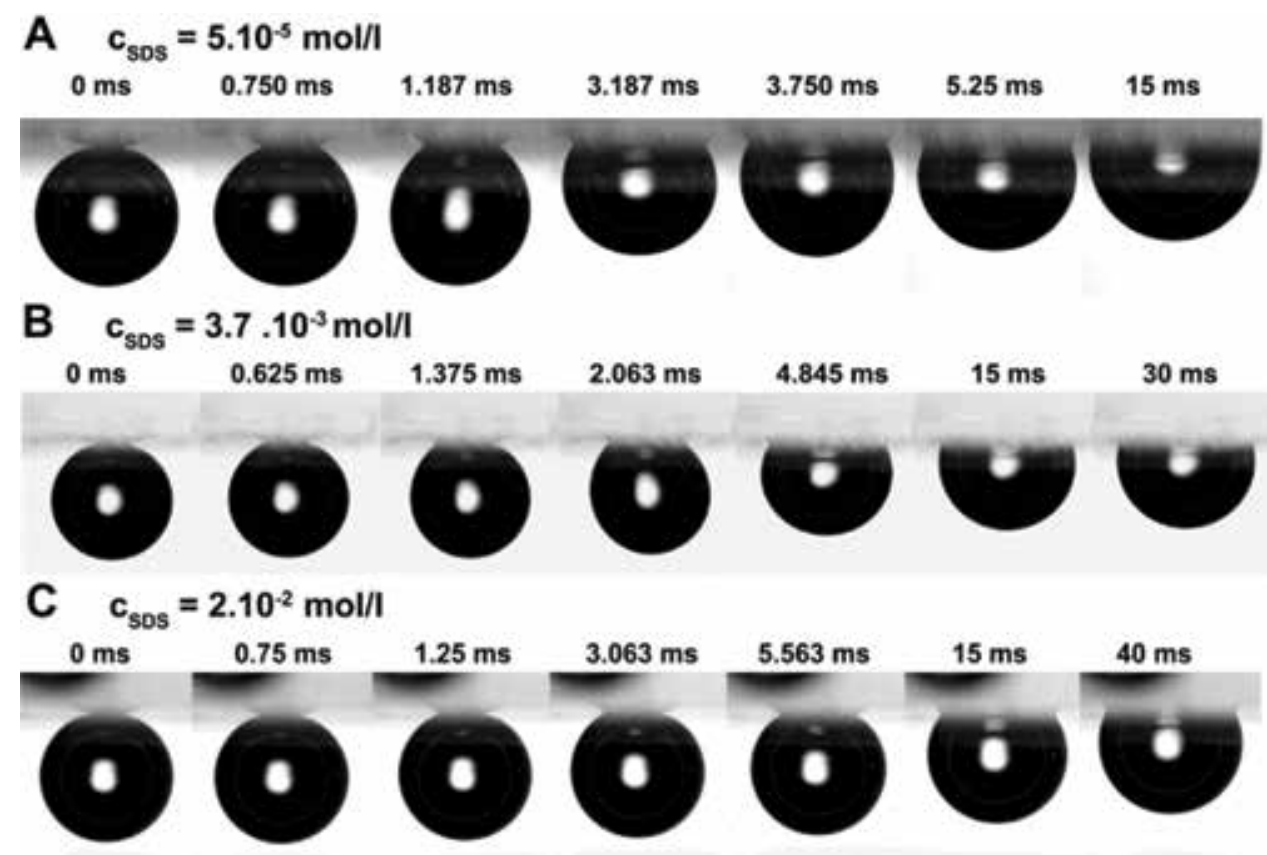

Figure 4 .

A series of photos illustrating the adhesion of the bubble (bubble diameter $0.86 \mathrm{~mm}$ ) onto the solid surface (silanized glass) in aqueous solutions of SDS with concentration $5 \times 10^{-5} \mathrm{~mol} / \mathrm{l}(\mathrm{A}), 3.7 \times 10^{-3} \mathrm{~mol} / \mathrm{l}(\mathrm{B})$ and $2 \times 10^{-2} \mathrm{~mol} / \mathrm{l}(\mathrm{C})$. The time in milliseconds indicates the time since the liquid film rupture and TPC line formation (time o ms).

of this process. The TPC line dynamics is influenced by the surfactant adhesion on solid-liquid, solid-gas, and liquid-gas interphases and also by the Marangoni flow along the bubble surface due to the changing surfactant concentration $[23,24,37,40$, 41]. The motion dynamics of surfactant molecules toward the bubble surface [42] should be considered as well. It can be summarized that the presence of surfactants usually slows down the entire expansion of the TPC line [43, 44]. A typical example is illustrated in Figure 4, where the images of a bubble having the diameter of $0.86 \mathrm{~mm}$ are given. Bubble adhesion is captured in three differently concentrated solutions of 


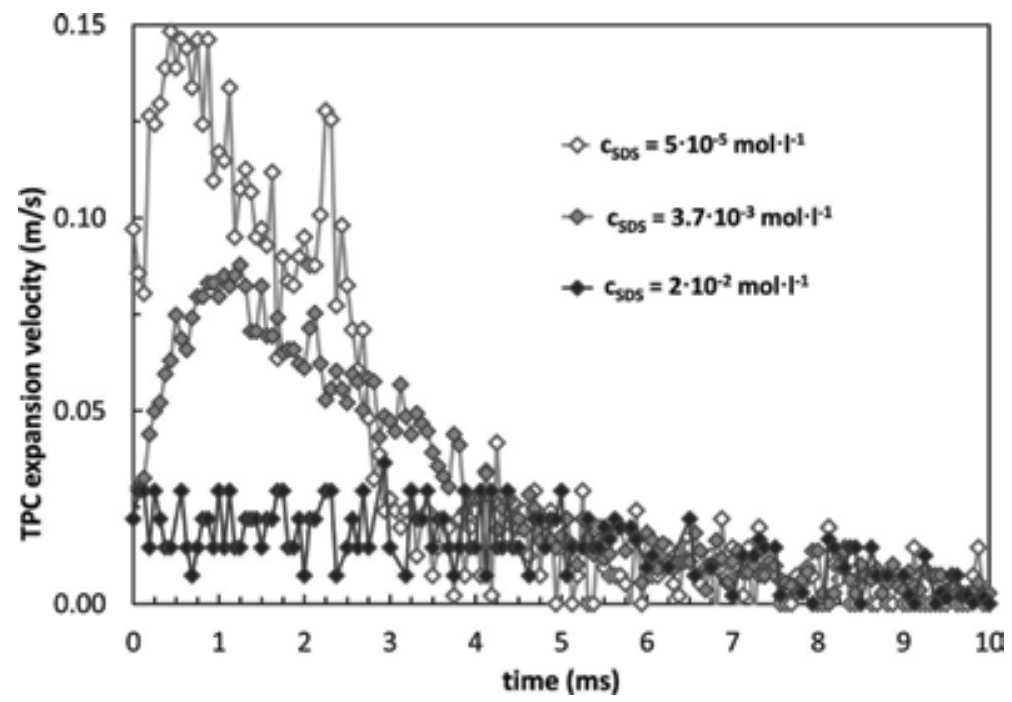

Figure 5.

The TPC line expansion velocity (bubble diameter $0.86 \mathrm{~mm}$ ) in aqueous solutions of SDS with concentration $5 \times 10^{-5}$, $3.7 \times 10^{-3}$, and $2 \times 10^{-2} \mathrm{~mol} / \mathrm{l}$. Details in [35].

sodium dodecyl sulfate (SDS). At low concentration (detail A, c $=5 \times 10^{-5} \mathrm{~mol} / \mathrm{l}$ ), the higher mobility and viscoelasticity of the bubble surface, which is manifested by shape oscillations, can be seen. The expansion of TPC line is quick; the equilibrium is reached in $15 \mathrm{~ms}$. At highest concentration (detail C, $\mathrm{c}=2 \times 10^{-2} \mathrm{~mol} / \mathrm{l}$ ), the mobility and viscoelasticity of the bubble surface are low, and all oscillations are damped. The bubble does not lose its spherical shape. The expansion of TPC line is slower; the equilibrium is reached in more than $40 \mathrm{~ms}$. As the surfactant concentration increases, the wetting angle decreases. Detailed sequences are published in [35].

Figure 5 shows the time dependence of TPC line expansion velocity for SDS solutions used in Figure 4. Compared to bubble adhesion in water $\left(U_{T P C \max }=0.48 \mathrm{~m} / \mathrm{s}\right)$, adhesion of bubbles in surfactant solutions is significantly slowed down, and $U_{T P C \max }$ ranges from $0.15 \mathrm{~m} / \mathrm{s}$ (low SDS concentration) to $0.03 \mathrm{~m} / \mathrm{s}$ (high SDS concentration). In the case of the highest SDS concentration, the critical micellar concentration is exceeded, and the TPC expansion velocity is very slow.

The nonlinearity of expansion velocity was also observed which cannot be explained by molecular-kinetic or by hydrodynamic model. Immediately after the TPC line formation, the solid-liquid and the air-liquid interfaces merge. Merging would be delayed if a long-range repulsive surface force acted between the interfaces. Here, the charged head groups of the surfactants adsorbed at both interfaces would lead to electrostatic double-layer repulsion. This long-range repulsion would keep the interfaces apart and delay the dewetting on the receding side [30]. Thus, the resulting gradient in surface tension would slow down the drainage of the liquid film and extend the bubble adhesion time. The dependence of the dynamic wetting angle on the dynamics of the three-phase interface motion has been confirmed experimentally in other cases as well [45].

\section{Influence of different types of surfactants and their purity on bubble stability}

The adhesion of the bubbles is significantly influenced by the type, charge, length, and purity of the surfactant, $\mathrm{pH}$, or other additives such as salts. The effect 
of nonionic, anionic, and cationic surfactants on kinetics of the TPC formation is completely dissimilar for hydrophobic and hydrophilic solid surfaces. The following surfactant types can be considered: (i) ionic surfactants on hydrophobic (nonpolar) surfaces, (ii) ionic surfactants on hydrophilic (polar) surfaces, (iii) nonionic surfactants on hydrophobic surfaces, and (iv) nonionic surfactants on hydrophilic (polar) surfaces [46]. In the case of the hydrophobic surfaces, the charge of surfactant plays a minor role [46], and the TPC line is formed and enlarged always, independently on the surfactant type [23]. On hydrophilic surfaces, the TPC line dynamics is electrostatically driven, and thus, the bubble attachment is determined by charge and/or polar interaction [46]. For example, the bubble attaches to negatively charged surface only when the natural negative electric charge at the bubble surface is reversed to positive, which can occur only in cationic surfactant solutions [23].

An important factor is also the molecular structure of the surfactant. The most common nonionic surfactants are those based on ethylene oxide. They are produced by ethoxylation of a fatty chain alcohol, and the most common ones have 12 carbons in the alkyl chain. In the case of large or other complex molecules, one should expect an adsorption barrier that consists of these branched molecules captured on phase interface and that prevents the adhesion of other molecules [47]. This barrier comes into existence in dilute solutions, then rises with increasing concentration, and again changes close to the CMC concentration. The existence of such a barrier is often connected with some steric restraints on the molecule in the proximity of the interface, because the molecules should be in the correct orientation. Unsuitable orientation could cause the molecule to diffuse back into the bulk rather than adsorbing. The transport of such molecules is low, and thus, surprisingly, their influence on the velocity of TPC line expansion could be very low [44].

The ionic surfactants used both in industrial applications and in scientific studies contain some admixtures of nonionic surfactants or other contaminants. The principal organic contaminants are homologous alkyl sulfates, n-alcohols, and carboxylic acids. Dodecanol is the most important contaminant and is one of the hardest to remove $[48,49]$. Even at impurity levels below $0.1 \%$, dodecanol reduces the surface tension and leads to the well-known minimum below the critical micelle concentration (CMC). Dodecanol also significantly influences the surfactant adsorption on the solid-liquid interface [50, 51], shear viscosity, and foam stability [50, 52]. Impurities (contaminants) usually act as cosurfactants or mixtures of two different types of surfactants. Mixed surfactants exhibit synergism which means that their interfacial properties are more pronounced than those of the individual components themselves. A significant reduction in surface tension is typical. Therefore, the contaminants decrease the ability of bubbles to attach to solid surfaces when compared with the mono-surfactant solution. The influence of

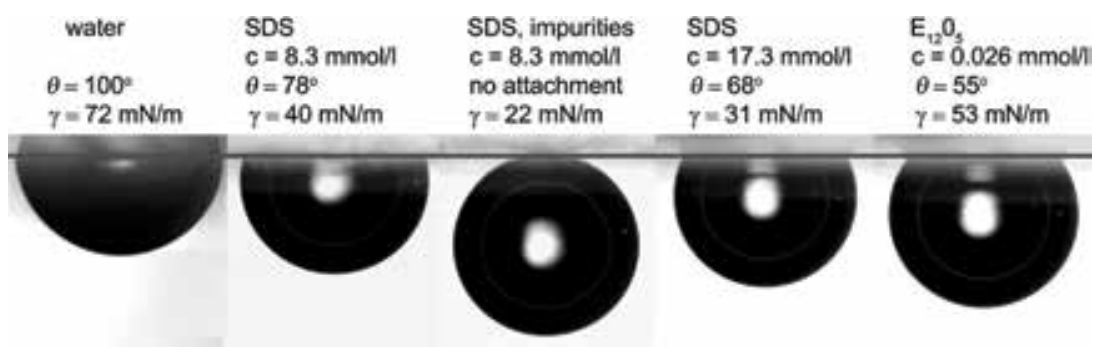

Figure 6.

Images of bubbles captured on the hydrophobic surface in water, in aqueous solutions of SDS (sodium dodecyl sulfate), and in $\mathrm{E}_{12} \mathrm{O}_{5}$ (pentaethylene glycol monododecyl ether). $\theta$ and $\gamma$ denote the contact angle in liquid phase and the surface tension, respectively. 
contaminants is crucial below the critical micelle concentration of the main surfactant, and it may even happen that the capture of bubbles is avoided [43]. Typical example, images of bubbles in five different solutions, is illustrated in Figure 6. The bubble is most stable attached in clean water. In solutions of common surfactants, e.g., in SDS, the wetting angle and thus the bubble stability decrease with the decreasing surface tension of the solution. For molecules with complex structure or, in the case of contaminants or additives, this simple rule may not apply.

\section{Conclusions}

In this chapter, we have reported on the state-of-the-art research on the influence of surface-active agents on bubble-particle interactions during the flotation process. The surfactants adsorb onto the phase interface and change its properties. Upon adhesion to the liquid-gas interface, surfactants reduce the mobility of the bubbles, which reduces their rising velocity and suppresses the shape oscillations. The surfactants also prevent the thinning of the liquid film, leading to an undesirable prolongation of the time required to break the film, and create a three-phase contact. The surfactants further extend the three-phase line extension and reduce the resulting bubble stability.

\section{Acknowledgements}

The authors would like to acknowledge the financial support from the specific university research fund of the Ministry of Education, Youth and Sport of the Czech Republic No. 21-SVV/2018.

\section{Author details}

Pavlína Basařová ${ }^{1 *}$ and Mária Zedníková

1 University of Chemistry and Technology, Prague, Czech Republic

2 Institute of Chemical Process Fundamentals of the CAS, Prague, Czech Republic

*Address all correspondence to: pavlina.basarova@vscht.cz

\section{IntechOpen}

(C) 2019 The Author(s). Licensee IntechOpen. This chapter is distributed under the terms of the Creative Commons Attribution License (http://creativecommons.org/licenses/ by/3.0), which permits unrestricted use, distribution, and reproduction in any medium, provided the original work is properly cited. (cc) BY 


\section{References}

[1] Chang CH, Franses EI. Adsorption dynamics of surfactants at the air/ water interface-A critical-review of mathematical-models, data, and mechanisms. Colloids and Surfaces A: Physicochemical and Engineering Aspects. 1995;100:1-45

[2] Clift R, Grace JR, Weber ME. Bubbles, Drops and Particles. 1st ed. New York: Academic Press, Inc.; 1978

[3] Cuenot B, Magnaudet J, Spennato $B$. The effects of slightly soluble surfactants on the flow around a spherical bubble. Journal of Fluid Mechanics. 1997;339:25-53

[4] Ralston J, Fornasiero D, Hayes R. Bubble-particle attachment and detachment in flotation. International Journal of Mineral Processing. 1999;56(1-4):133-164

[5] Nguyen AV, Schulze HJ. Colloidal Science of Flotation. 1st ed. New York: Marcel Dekker, Inc; 2004

[6] Nguyen AV, Schulze HJ, Ralston J. Elementary steps in particlebubble attachment. International Journal of Mineral Processing. 1997;51(1-4):183-195

[7] Moore DW. The rise of a gas bubble in a viscous liquid. Journal of Fluid Mechanics. 1959;6(1):113-130

[8] Moore DW. Velocity of rise of distorted gas bubbles in a liquid of small viscosity. Journal of Fluid Mechanics. 1965;23:749-766

[9] Magnaudet J, Eames I. The motion of high-Reynolds-mumber bubbles in inhomogeneous flows. Annual Review of Fluid Mechanics. 2000;32:659-708

[10] Clift R, Grace J, Weber ME. Bubbles, Drops, and Particles. Vol. xiii. Mineola, N.Y: Dover Publications; 2005. p. 381s
[11] Zenit R, Legendre D. The coefficient of restitution for air bubbles colliding against solid walls in viscous liquids. Physics of Fluids. 2009;21(8):083306

[12] Fujasova-Zednikova M, Vobecka L, Vejrazka J. Effect of solid material and surfactant presence on interactions of bubbles with horizontal solid surface. Canadian Journal of Chemical Engineering. 2010;88(4):473-481

[13] Sadhal SS, Johnson RE. Stokesflow past bubbles and drops partially coated with thin-films .1. Stagnant cap of surfactant film-Exact solution. Journal of Fluid Mechanics. 1983;126(Jan):237-250

[14] Malysa K, Krasowska M, Krzan M. Influence of surface active substances on bubble motion and collision with various interfaces. Advances in Colloid and Interface Science. 2005;114:205-225

[15] Legendre D, Daniel C, Guiraud P. Experimental study of a drop bouncing on a wall in a liquid. Physics of Fluids. 2005;17(9):097105

[16] Legendre D et al. A note on the modelling of the bouncing of spherical drops or solid spheres on a wall in viscous fluid. Chemical Engineering Science. 2006;61(11):3543-3549

[17] Lucassen J. Longitudinal capillary waves. 2. Experiments. Transactions of the Faraday Society. 1968;64:2230-2235

[18] Lucassen J. Longitudinal capillary waves. 1 . Theory. Transactions of the Faraday Society. 1968;64(548): 2221-2229

[19] Zawala J, Drzymala J, Malysa K. An investigation into the mechanism of the three-phase contact formation at fluorite surface by colliding bubble. International Journal of Mineral Processing. 2008;88(3-4):72-79 
[20] Ralston J, Dukhin SS, Mishchuk NA. Wetting film stability and flotation kinetics. Advances in Colloid and Interface Science. 2002;95(2-3):145-236

[21] Kosior D, Kowalczuk PB, Zawala J. Surface roughness in bubble attachment and flotation of highly hydrophobic solids in presence of frother-experiment and simulations. Physicochemical Problems of Mineral Processing. 2018;54(1):63-72

[22] Fell D et al. Influence of surfactant concentration and background salt on forced dynamic wetting and dewetting. Langmuir. 2011;27(6):2112-2117

[23] Kosior D et al. Influence of nonionic and ionic surfactants on kinetics of the bubble attachment to hydrophilic and hydrophobic solids. Colloids and Surfaces A: Physicochemical and Engineering Aspects. 2015;470: 333-341

[24] Krasowska M, Zawala J, Malysa K. Air at hydrophobic surfaces and kinetics of three phase contact formation. Advances in Colloid and Interface Science. 2009;147-148:155-169

[25] Krasowska M et al. Air-facilitated three-phase contact formation at hydrophobic solid surfaces under dynamic conditions. Langmuir. 2007;23(2):549-557

[26] Phan CA, Nguyen AV, Evans GA. Combining hydrodynamics and molecular kinetics to predict dewetting between a small bubble and a solid surface. Journal of Colloid and Interface Science. 2006;296(2):669-676

[27] Cox RG. The dynamics of the spreading of liquids on a solid-surface.

1. Viscous-flow. Journal of Fluid Mechanics. 1986;168:169-194

[28] Ranabothu SR, Karnezis C, Dai LL. Dynamic wetting: Hydrodynamic or molecular-kinetic? Journal of
Colloid and Interface Science. 2005;288(1):213-221

[29] Blake TD, Haynes JM. Kinetics of liquid/liquid displacement. Journal of Colloid and Interface Science. 1969;30(3):421

[30] Phan CM, Nguyen AV, Evans GM. Assessment of hydrodynamic and molecular-kinetic models applied to the motion of the dewetting contact line between a small bubble and a solid surface. Langmuir. 2003;19(17):6796-6801

[31] Petrov PG, Petrov JG. A combined molecular-hydrodynamic approach to wetting kinetics. Langmuir. 1992;8(7):1762-1767

[32] Bonn D et al. Wetting and spreading. Reviews of Modern Physics. 2009;81(2):739-805

[33] Blake TD. The physics of moving wetting lines. Journal of Colloid and Interface Science. 2006;299(1):1-13

[34] De Coninck J, de Ruijter MJ, Voue M. Dynamics of wetting. Current Opinion in Colloid \& Interface Science.

2001;6(1):49-53

[35] Basarova P, Souskova K. Detailed experimental study of bubble adhesion on hydrophobic surface. Physicochemical Problems of Mineral Processing. 2018;54(1):111-123

[36] Basarova P, Souskova K, Zawala J. Three-phase contact line expansion during air bubble attachment to hydrophobic solid surface-Experiment and modeling. Physicochemical Problems of Mineral Processing. 2018;54(4):1095-1106

[37] Kosior D et al. Influence of n-octanol and alpha-terpineol on thin film stability and bubble attachment to hydrophobic surface. Physical Chemistry Chemical Physics. 2013;15(7):2586-2595 
[38] Chan DYC, Klaseboer E, Manica R. Film drainage and coalescence between deformable drops and bubbles. Soft Matter. 2011;7(6):2235-2264

[39] Vejrazka J, Vobecka L, Tihon J. Linear oscillations of a supported bubble or drop. Physics of Fluids. 2013;25(6):062102

[40] Radulovic J et al. Review on kinetics of spreading and wetting by aqueous surfactant solutions. In: Ferrari ML, Miller LR, editors. Drops and Bubbles in Contact with Solid Surfaces. Boca Raton: CRC Press; 2013

[41] Zawala J, Kosior D, Malysa K. Formation and influence of the dynamic adsorption layer on kinetics of the rising bubble collisions with solution/gas and solution/solid interfaces. Advances in Colloid and Interface Science. 2015;222:765-778

[42] Stechemesser H, Nguyen AV. Dewetting kinetics between a gas bubble and a flat solid surface and the effect of three-phase solid-gas-liquid contact line tension. Colloids and Surfaces A: Physicochemical and Engineering Aspects. 1998;142(2-3):257-264

[43] Basarova P et al. Bubble adhesion on hydrophobic surfaces in solutions of pure and technical grade ionic surfactants. Colloids and Surfaces A: Physicochemical and Engineering Aspects. 2017;522:485-493

[44] Basarova P et al. Bubble adhesion onto the hydrophobic surface in solutions of non-ionic surface-active agents.

Colloids and Surfaces A: Physicochemical and Engineering Aspects. 2016;505:64-71

[45] Henrich F et al. Influence

of surfactants in forced

dynamic dewetting. Soft Matter.

2016;12(37):7782-7791

[46] Tadros TF. An Introduction to

Surfactants. 1st ed. Berlin: De Gruyter; 2014
[47] Eastoe J, Dalton JS. Dynamic surface tension and adsorption mechanisms of surfactants at the air-water interface. Advances in Colloid and Interface Science. 2000;85(2-3):103-144

[48] Danov KD et al. Effect of nonionic admixtures on the adsorption of ionic surfactants at fluid interfaces. 2. Sodium dodecylbenzene sulfonate and dodecylbenzene. Langmuir. 2003;19(12):5019-5030

[49] Kralchevsky PA et al. Effect of nonionic admixtures on the adsorption of ionic surfactants at fluid interfaces. 1 . Sodium dodecyl sulfate and dodecanol. Langmuir. 2003;19(12):5004-5018

[50] Ward RN, Davies PB, Bain CD. Coadsorption of sodium dodecyl sulfate and dodecanol at a hydrophobic surface. Journal of Physical Chemistry B. 1997;101(9):1594-1601

[51] Somasundaran P, Krishnakumar S. Adsorption of surfactants and polymers at the solid-liquid interface. Colloids and Surfaces A: Physicochemical and Engineering Aspects. 1997;123:491-513

[52] Harvey PA et al. Influence of sodium dodecyl sulphate and Dowfroth frothers on froth stability. Minerals Engineering. 2005;18(3):311-315 



\title{
Surfactant Mixtures: Performances vs. Aggregation States
}

\author{
Camillo La Mesa and Gianfranco Risuleo
}

\begin{abstract}
The focus of this chapter is on bio-intended procedures based on mixing surfactants with polymers and biopolymers, or surfactants among them (provided they are oppositely charged). In the first case, polymer-surfactant and protein-surfactant systems are dealt with. Both are characterized by the splitting of the solution phase into, at least, three regions having peculiar properties. At first, surfactant nucleation onto polymers takes place; this implies large modifications in properties with respect to the starting materials. The formation of gels is possible in some instances. As to mixtures of oppositely charged surfactants, it is indicated how they form cat-anionic vesicles if mixed in nonstoichiometric amounts. Vesicle sizes are modulated by the charge ratio. These systems are excellent vectors for biomedical purposes.
\end{abstract}

Keywords: ionic surfactant mixtures, size and shape, surface charge density of micelles and vesicles, polymer-surfactant systems, protein-surfactant systems

\section{Introduction}

The certified history of surfactants and detergents goes back to the Mesopotamian and Egyptian ages. In the Roman period, authors contemporary of Julius Caesar described the procedures in use from Gauls and Belges to produce soaps from the alkaline hydrolysis of beef fat [1]. They were horribly shocked for the excessive use of soaps that Gauls consumed in hair cleaning. Such procedures are still in use in the preparation of niche products as Marseille soap. In much more recent times, new procedures largely improved the preparation of surface-active products, synthetizing alkyl sulfates. These studies date back to the 1930s of the last century [2]. Later on, nonionic surfactants of the alkyl-polyoxyethylene family, as Triton TX-100, or zwitterionic ones were worked out and synthetized [3]. This induced chemists to prepare new classes of solid or liquid formulations, with better performances in terms of surface activity and solvent capacity. These efforts allowed preparing chemicals capable to operate in all working conditions, irrespective of $\mathrm{pH}$, the presence of calcium, and ionic strength of the dispersant [4-6].

Nowadays, focus is on surfactant mixtures, improving the intrinsic quality of formulations and allowing applications to much more cases than those originally intended for. Applications of surfactant-based systems are much more versatile with respect to canonical laundry and personal body care formulations that were exploited until now. Current research lines focus on unexpected fields, as applications in biomedicine and in the feminine personal hygiene formulations. We do not consider, in this review, the adjuvant action played by cosurfactants, as long-chain 
alkanols, glycerol, sterols, perfumes, softeners, bleaching adjuvants, and so forth. We mainly focus on the addition of species increasing the surface activity and solvency of existing surface-active/cleaning formulations and in applications thereof. In particular, the synergistic properties that are observed in surfactant mixtures [7, 8] are discussed.

Cases of interest span from mixtures of ionic species of the same charge, to ionic/nonionic ones, and to mixtures of species having oppositely charged polar head groups. Relevant are also the cases where polymers, enzymes, and proteins are added. We discuss separately all the above fields taking into account the reasons underlying such research lines. In turn, focus is on the following aspects:

i. addition of polymers/biopolymers, referred to as PSSs [9]; and

ii. use of mixtures made of oppositely charged surfactants, defined as Cat-An systems [10].

The above items are more strictly interconnected than one could think at a first glance. In both the organizing role played, surfactants are crucial both on small or medium size scale (for polymer/surfactant systems) and on a much larger size scale, in case of surfactant mixtures. Both classes of formulations are biomimetic, and the efficiency is related to biopolymer modifications induced by surfactants and to surfactant-driven vesicle formation, respectively.

As a starting point, we report the essential details on the physical meaning of surface activity and solvent capacity; both requisites are necessary to understand biomimicry, surfactancy, and detergency on solid grounds. For more details, the interested reader is referred to pivotal books and reviews that have dealt with that field [11-14]. In many aspects, we follow the "main street" that is suggested in a seminal book, which allowed scientists to unify in a whole field the formation of both micelles, vesicles, and biological membranes [15].

\section{Solvent capacity and surface activity}

The term surface active, or surfactant, refers to substances capable to lower significantly and permanently the surface tension of water, i.e., to decrease the work required increasing the surface area of a liquid. In terms of the classical Gibbs surface adsorption equation valid for aqueous binary mixtures, we define as surface active all species fulfilling the equation [16]:

$$
\mathrm{d} \sigma=-G_{2} \mathrm{dRTd} \ln a_{2}
$$

where $\sigma$ is the surface tension and $a_{2}$ is the solute activity. $G_{2}$, the surface excess concentration, indicates as to whether the surface tension will decrease, or increase, upon addition of a given solute. $G_{2}$ is defined with respect to the concentration of the given chemical in the bulk and depends on its modulus. That is the rationale underlying the meaning of the term "surface active." When $\mathrm{d} \sigma=0$, there is no more room for adsorption, and the surface is saturated. In addition, if $\operatorname{d\operatorname {ln}a_{2}}$ is zero, the solute activity is constant and a new phase is being formed. This is the basis for the so-called phase separation approach to micelle formation [17], discussed later on.

The solvent capacity arises from a more subtle behavior and is univocally related to micelles onset. The organization of surfactant molecules arises from the "schizophrenia" that such molecules suffer from. They associate in micellar entities whose interior, mostly composed of alkyl groups, is capable to dissolve 
nonpolar (i.e., hydrophobic) molecules. The polar groups facing outward the bulk guarantee thermodynamic stability to the aggregates so formed. In words, the solubilizing capacity toward oils and fats starts to occur only when micelles do form. For this reason, micelles are swelling units which grow in size upon addition of fats and oils.

From a thermodynamic viewpoint, micelle formation is mainly entropydriven. This is a rather counterintuitive behavior, if we consider that several molecules associate in a given entity. The reason underlying the entropy-based statement is that water molecules hydrophobically interacting with alkyl chains are released during micelle formation [15]. This substantially increases the number of degrees of freedom for $\mathrm{H}_{2} \mathrm{O}$ and those of the chains, as well. It is also worth noticing that an increase in temperature increases the number of rotational degrees of freedom of geometrically constrained surfactant alkyl chains, which are free to move into micelles. This is the main reason why micelle interior is assumed to be in a "liquid-like" form.

To unify the above features, that is, surface activity and solvent capacity, in a whole definition, we assume that the point at which surface activity ends and micelles begin to form is a "pseudo" phase separation threshold, indicated as critical micellar concentration or $\mathrm{cmc}[18,19]$. The definition "critical" indicates the steep discontinuity in many thermodynamic quantities (molar volumes, dilution enthalpies, activity coefficients, and so forth) observed in close proximity of the $\mathrm{cmc}$.

For a given class of surfactants, such as alkali metal alkylsulfates, alkyltrimethylammonium halides, polyoxyethylene glycol alkyl ethers, etc., the two features jointly depend on the length of alkyl chains. The longer the latter are, the lower is the $c m c$, the steeper is the decrease in surface tension, and the more efficient is solvent capacity. We do not enter in more details about micelle sizes, shape, and polydispersity and assume, in a first approximation, that such aggregates are spheroidal colloids. For these reasons, they scatter light, have much lower diffusion coefficients than molecules from which they are made of, and their solutions can be moderately or significantly viscous. At high concentrations, they form ordered phases known as lyotropic liquid crystals [20,21]. More aspects, such as the role of salts and cosolvents in micelle formation, shall be introduced when the need of "ad hoc" information will be necessary.

\section{Addition of polymers or biopolymers}

Studies on additives as salts and cosolvents have been widely investigated in the past and will not be reported, unless this is strictly necessary. Conversely, studies on systems containing synthetic polymers or biopolymers are still a matter of debate and investigation and will be discussed in this section. The first efforts along this line go back to the 1950s and were essentially dealing with protein separation from biological membrane lipids. These efforts were led to convergence in a classical textbook of the early 1990s [22]. This induced many scientists to focus on new and, sometimes, controversial fields [23-25].

The underlying phenomenology can be understood by looking at Figure 1. In the plot the behavior of a ternary system containing water, surfactant, and polymer is reported. If the relative $w t \%$ of the latter substances is much lower than water, the ternary phase diagram can be simplified in a pseudo-binary one. As can be seen in Figure 1, a pseudo-phase behavior occurs in absence of polymer; the $\mathrm{cmc}$ is the point separating the micellar from the molecular regime. Added polymer induces the splitting of the solution phase into three regions. For finite amounts of polymer, the following areas are observed, from the left: 


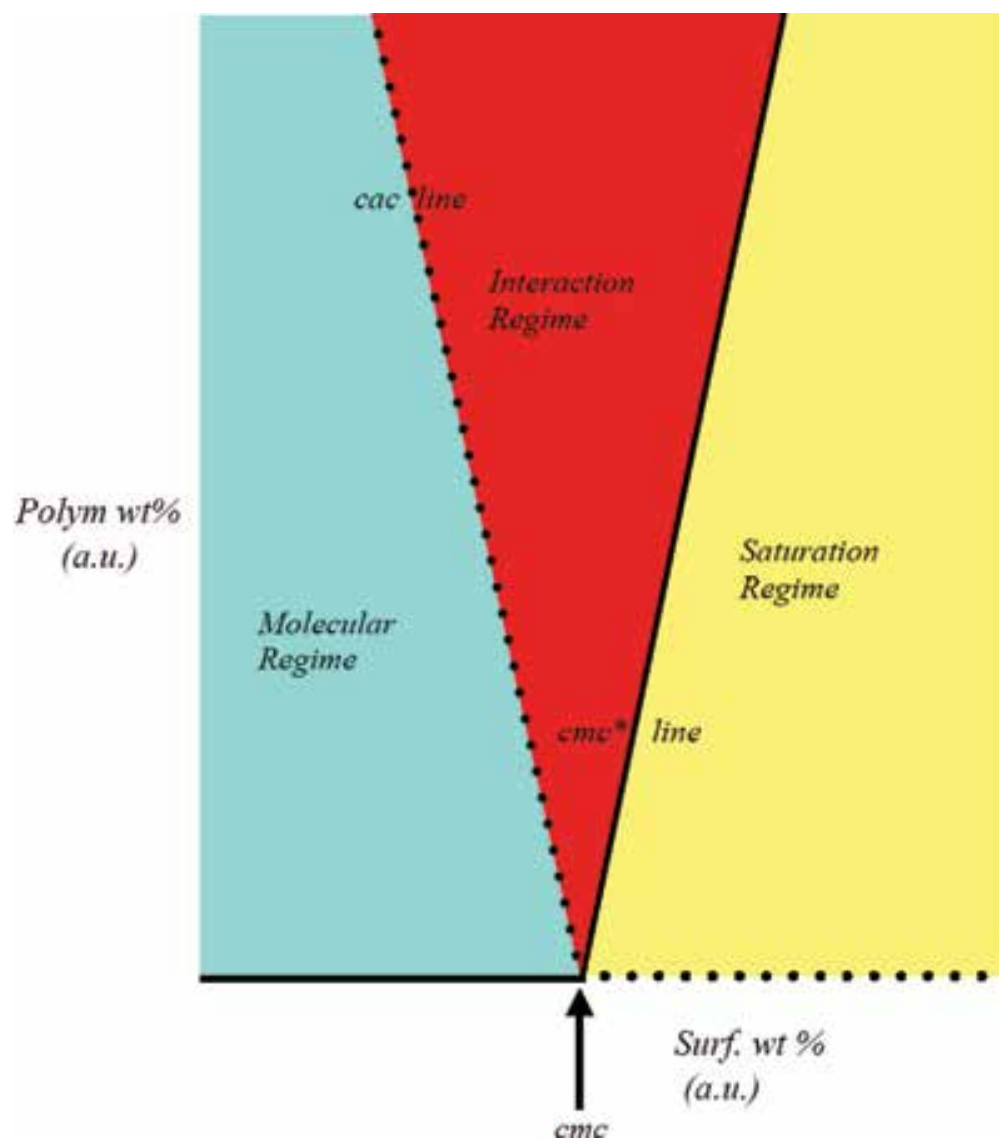

Figure 1.

The surfactant behavior in presence of a nonionic polymer. The black line in the left bottom of the figure indicates the molecular solution region and the dotted one the micellar regime. The turquoise area indicates the molecular regime and is limited by the cac, above which the surfactant starts to interact with the polymer. The red area indicates the interaction regime; the yellow one, the saturation regime, occurs when the polymer is saturated. The line separating the red and yellow regions is indicated as cmc* line.

\section{i. a molecular solution region, $\boldsymbol{I}$;}

ii. a polymer-surfactant one, II; and

iii. a region where free micelles coexist with polymer-surfactant adducts, III.

To build up the phase map, surface tension values are measured for a number of polymer $w t \%$ (Figure 2). There splitting of surface tension values in three regimes is evident. Cac and $c m c^{*}$ are easily determined form these and other experiments, as well [22].

On thermodynamic grounds, the line separating region $I$ from $I I$ indicates the points above which polymer/surfactant interactions start to occur; the line position depends on polymer content and nature. There is an ensemble of critical points, whose location in the phase map depends on the polymer amount. Once the process has occurred, the surfactants located on the polymer backbone act as nucleation sites for the binding of more surface-active species. Thus, entities similar to micelles (emi-micelles) aggregate thereon: a sort of "pearl necklace" is formed [26]. Thus, the polymer backbone is decorated by a series of small aggregates, whose number is dictated by its length; the interacting polymer sections, the so termed "polymer 


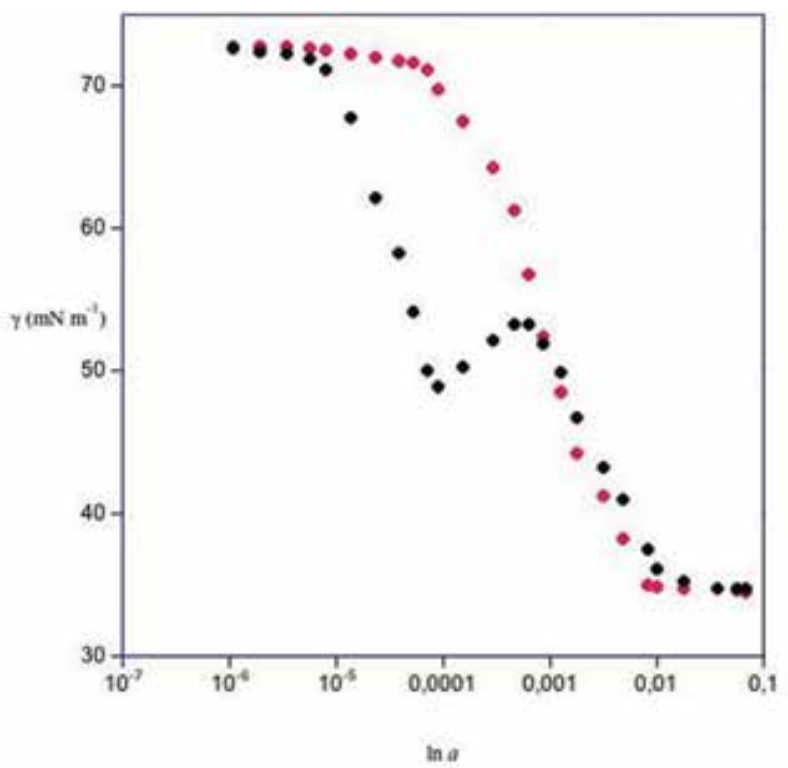

Figure 2.

Plot indicating how to get the cac, the first minimum, and the $\mathrm{cmc}^{*}$, at surface saturation, for a given amount of polymer vs. surfactant content. Black points refer to data in presence of polymer, the red ones to the surfactant alone.

binding sites”, are a few kdalton long. Surfactant nucleation thereon continues until all possible sites are saturated. In consequence of that, the polymer tends to assume a different conformation with respect to the native one, with subsequent changes in viscosity. This is the reason why polymer/surfactant systems act as "viscosity modulators" [27, 28]. Another important consequence is the fact that they are "kinetic buffers" as to matter exchange with the bulk is concerned [29].

Ancillary effects are concomitant to the mentioned behavior. First, micelles of smaller size compared with free ones are formed; they behave as a whole kinetic entity with the polymer (i.e., the binding energy is significant). This is a feature similar to those occurring in biological systems, as in the binding of molecules to the protruding parts of a receptor. The line separating the two regions is defined as "critical aggregation concentration" or cac line. The nucleation of fat droplets on a cotton string is a pertinent example for the formation of polymer-surfactant adducts; their location thereon is energetically more favored than in free form. The $c m c^{*}$ one, conversely, is a polymer saturation threshold, above which there is no room for binding. As a consequence, free micelles do form and coexist with polymer-adsorbed ones. Technological applications find place in formulation. The viscoelastic properties that such systems exhibit are used in shampoos, eye-drop fluids, etc. [30, 31]. Viscoelasticity is simply detected by abruptly rotating the fluid-containing vials, with transient formation of ellipsoidal bubbles or, in a more quantitative way, by rheology $[27,28]$. An alternative simple procedure requires pressing drops of these formulations between glass slides and looking by a polarizing microscope, to detect the preferred orientation that polymer-surfactant adducts assume during the flow.

There is no significant difference when polyelectrolytes replace nonionic polymers. In cases like such, precipitation may also occur; cases are known [32], mostly as to biopolymers are concerned [33-36]. In mixtures containing proteins, precipitates or, eventually, two-phase regions are usually met. As a rule, these are centered around the charge neutralization line, where precipitates or gels may coexist (Figure 3). In such systems relevant are the modifications observed in 


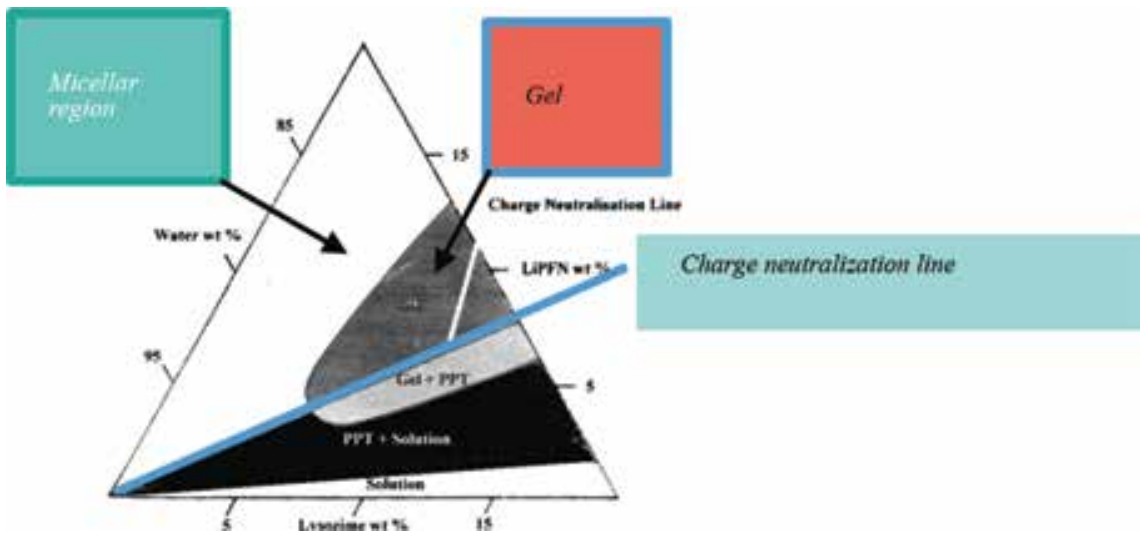

Figure 3.

Partial phase diagram for the system water-lysozyme-lithium perfluorononanoate (a stiff, fully fluorinated surfactant), at $25^{\circ} \mathrm{C}$. The coexistence of a solution and precipitate occurs in the black area, whereas a pure gel, in dark gray, and one empty of particles, in light gray, are met. The charge neutralization limit is indicated as a blue line. This is the point at which all nominal charges on the protein, at the given $p H$, are fully neutralized. Partly redrawn from Ref. [26].

protein conformation. Changes in the relative amounts of alpha-helix, beta-sheet, and random coil conformations are concomitant to protein-surfactant interactions in a wide part of the interaction regime. Such changes are responsible for significant variations in protein activity and three-dimensional structure of the "adducts" that are formed. All these systems are characterized by a not univocally defined stoichiometry, and the definition of "adduct" is more correct with respect to that of "complex." The rationale underlying that behavior finds origin in the fact that alkyl chains are essentially located in the protein hydrophobic tasks. Many possible locations are available in cases like such. The above statements are quite well acquainted from experiments on albumins and, more generally, on protein denaturation strategies [37]. Thus, biopolymer/surfactant systems offer the opportunity to prepare proteins in pure form from extensive dialysis of the corresponding mixtures. For these reasons they find extensive use in biochemically intended procedures.

\section{Mixtures made of oppositely charged surfactants}

Pioneering studies in the field are due to Wennerstroem [38], who focused on the synthetic analogues of lipids and suggested that stoichiometric mixtures of oppositely charged surfactants could be good substitutes of lipids. The original hypothesis dealt with systems of 1-1 stoichiometry, in terms of charge. There, the electrostatic interactions between polar groups mimic charge separation among entities bound on a glycerol backbone, which is also joining two alkyl chains. The above systems are models of swelling, lamellar domains. The first experimental results were discouraging; in fact, these mixtures often show thermotropic rather than lyotropic behavior [39], due to the high "Krafft point" [40] of alkyl chains in such mixtures. Later work demonstrated that nonstoichiometric Cat-An mixtures were more promising. It was noticed there the presence of vesicular entities [41, 42]. Debates occurred on the stability of largely polydispersed in size vesicles. It is actually accepted that they are kinetically stable entities although thermodynamic stability is demonstrated in some cases $[43,44]$.

The phenomenology of such systems, defined by the acronym "cat-anionic," is extremely appealing from a bio-intended viewpoint. In the phase diagram, in particular, the vesicular areas are located in proximity of micellar ones and are clearly 
distinguishable from them. The observation is in favor of a significant modification in the micellar structure induced by the second surfactant. Cat-anionic mixtures, hereafter termed Cat-An's, are characterized by a bluish color and may turn to yellowish or opalescent appearance when vesicle sizes exceed some $100 \mathrm{nms}$. They are both positively and negatively charged. This fact gives the opportunity to use Cat-An vesicles as vehiculating/binding agents of DNA (for positively charged ones) and proteins. In the latter eventuality, both positively and negatively charged vesicles may be used, depending on the demand dictated by protein charge.

Debates questioned on the possible protein denaturation that could be induced by the surfactants present in Cat-An formulations, until it was realized that the surfactant in molecular form is solely responsible for protein denaturation [45]. The amount of such species is orders of magnitude lower than in solutions of the single surfactants.

The above behavior is supported by the following thermodynamic considerations. The mutual interactions between polar head groups and alkyl chain packing play a key role in such systems. The observed behavior is different from that expected if ideality of mixing holds. In words, when fluid chains are presumably miscible in all proportions, the effect of surface charges modulates the area on which alkyl chains insist and determines their optimal packing. This results in a strong nonideality of mixing. It is not surprising, therefore, that the $c m c$ for an aggregate of given stoichiometry can be orders of magnitude lower than expected from primitive considerations. To quantify such effects, it was assumed the validity of regular solution theory, and it was imposed, accordingly, that "the free monomer has an activity coefficient of unity" [46]. This is an oversimplified viewpoint, since surfactant solutions are strongly nonideal even below the $\mathrm{cmc}$. To proceed along, we assume that the concentration above which added surfactant preferentially enters into aggregates (disregarding their size and shape) is the saturation threshold for the molecular species. In this way, the difference in composition between molecular and micellar form is immaterial. In two-component surfactant mixtures, thus, the $\mathrm{cmc}$ of the mixed system is defined according to the relation [47].

$$
\left.\left(1 / c m c_{\text {mixt }}\right)=\left[\left(X_{2} / \gamma_{3} c m c_{3}\right)+\left(1-X_{2}\right) / \gamma_{2} c m c_{2}\right)\right]
$$

where $\gamma_{2}$ and $\gamma_{3}$ are the activity coefficients of the surfactants, having $c m c_{3}$ and $\mathrm{Cmc}_{2}$ as the corresponding critical values. $\mathrm{cmcmix}_{\mathrm{t}}$ is the critical concentration of the mixed system. $X$ 's are the mole fraction of the given surface-active species. In the limits dictated by the regular solution theory [48], the solute-solute interaction parameter, $b$, results to be [47].

$$
b=\Delta G_{\text {exc,mixt }}\left[\left(X_{2}^{2}+X_{3}^{2}\right) /\left(X_{2}^{2} X_{3}^{2}\right)\right]
$$

The underlying rationale is as follows. Micelles are in fluid state with freely moving polar head groups. They may change position, adsorb/desorb counterions, and so forth. The constraints acting on alkyl chains are such that polar head groups close each other attract/repel. In consequence of that, mixed systems show strong deviations from the ideal behavior. This tendency is quantified by the mentioned $b$ parameter. The effect is substantial (Figure 4) and explains why the amount of both surfactants in molecular form is orders of magnitude lower than expected. In words, Cat- $A n$ 's are in equilibrium with their own counterions and with tiny amounts of free surfactants, as well. This is the basis for using cat-anionic vesicles as cargos for proteins and DNA [49-51].

Sizes of Cat-An vesicles strongly depend on the formulation stoichiometry. As mentioned above, 1-1 mixtures form indefinitely large smectic crystals; on both sides of this threshold, sizes depend regularly on composition and approach values 


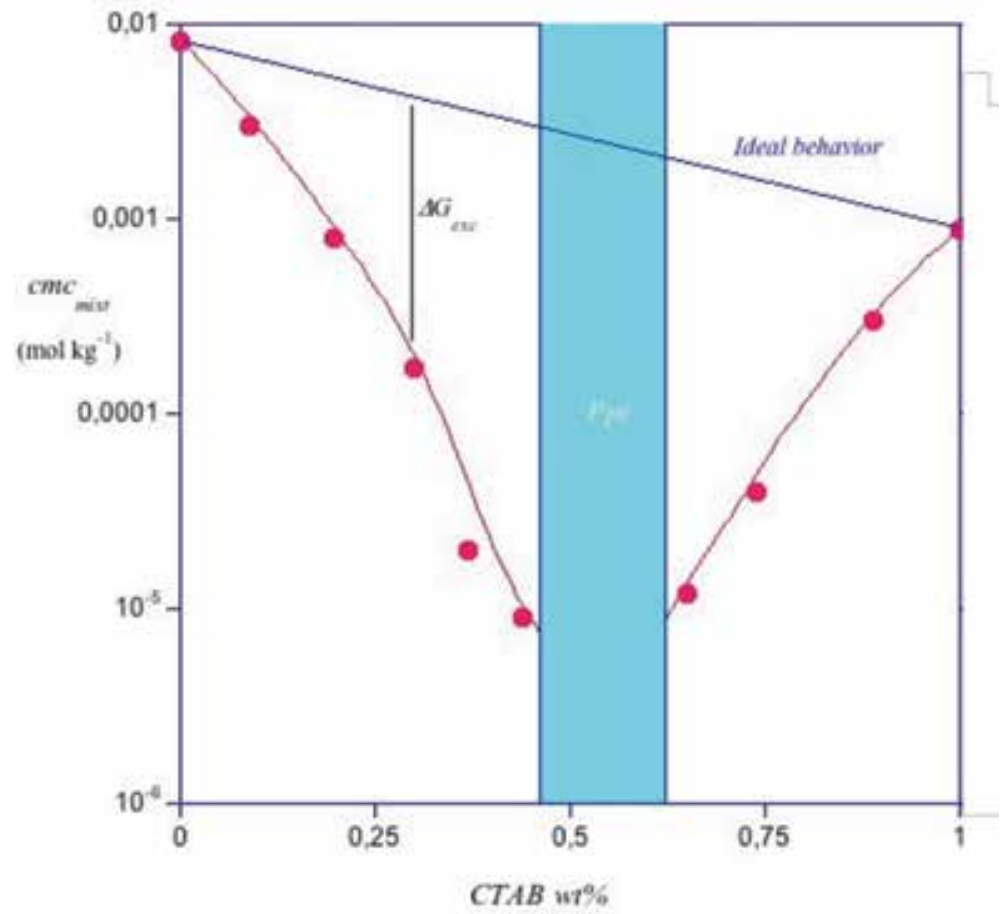

Figure 4.

Dependence of the cmc (in mol $\mathrm{kg}^{-1}$ ) on cetyltrimethylammonium bromide, CTAB, mole fraction for SDS$C T A B$ mixtures, at $25^{\circ} \mathrm{C}$. The red line is for visual purposes; the full on the top refers to ideal mixing and the vertical to the nonideality of mixing. The blue area indicates the precipitation regime.

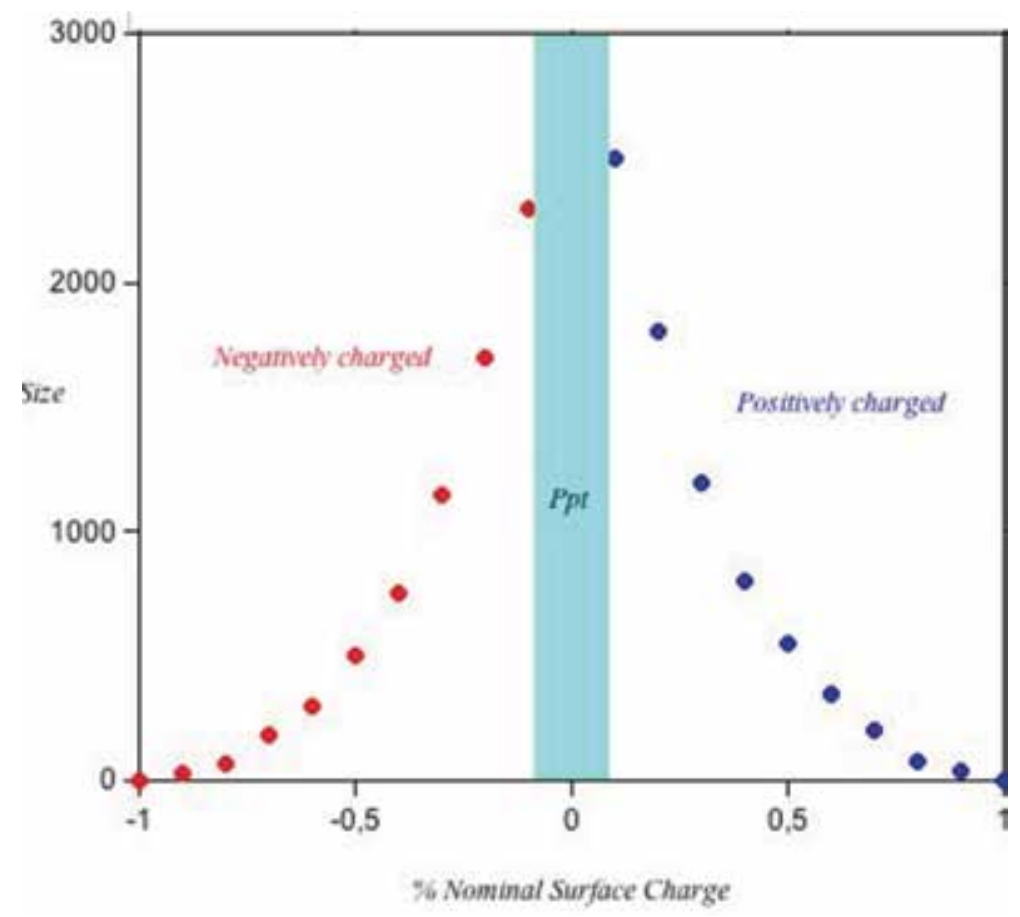

Figure 5 .

Vesicle size (in $\mathrm{nm}$ ) for SDS-CTAB mixtures, at $25^{\circ} \mathrm{C}$, vs. the nominal surface charge excess of the vesicular aggregate. The light blue area in the center of the figure refers to the precipitation regime. 
pertinent to the pure surfactant aggregates. In words, the excess surface charge determines vesicles sizes (Figure 5). It is worth to note that similar trends are also observed in mixtures of oppositely charged lipids [52]. The surface charge versatility is reminiscent of statements based on the relations between particles size and surface charge density. The higher the former, the lower the latter. This fact has important consequences on the links between (nominal) surface charge density and sizes. It is a sort of charge-based size tailoring and is quintessential in choosing the proper particles for transfection technologies. Another pertinent possibility along this line arises from thermal cycling procedures, which allow getting stable particles of proper size by raising the temperature above a certain value (which depends on the composition of the Cat-An mixture [53]. Thermally quenched vesicles obtained accordingly retain their size for indefinitely long times.

Sound procedures based on the combination of the above features allow getting vesicles of the desired size and surface charge density. This allows using them for DNA transfection technologies and protein immobilization onto vesicles [54]. An interesting feature is that vesicles of a given composition are destroyed by adding amounts of surfactant required for the complete neutralization of the Cat-An mixture. In consequence of that, the biopolymer which is eventually bound onto vesicles is released in its pristine form [55]. This is a terrific possibility for bio-intended technologies.

\section{Conclusions}

This contribution focuses on the possibilities offered by surfactants and their mixtures in selected bio-intended applications. The mentioned systems are niche fields, but are becoming of relevant impact in a lot of practical purposes. Think, for instance, that applications in shampoos and similar products almost always include silk proteins as adjuvants of hair state and health. Transfection, conversely, is quite appealing for biochemistry and molecular biology applications. In many aspects, thus, both fields of research are on the same line as those originally intended in the pre-Christian age. It is as if we were moving back to the roots of surfactancy. Luckily, we have much more knowledge in the field, and this allows us to exploit applications on more conscious grounds.

\section{Author details}

Camillo La Mesa ${ }^{1 *}$ and Gianfranco Risuleo ${ }^{2}$

1 Department Chemistry, Sapienza University, Rome, Italy

2 Formerly at Department Biology, Sapienza University, Rome, Italy

*Address all correspondence to: camillo.lamesa@uniroma1.it

IntechOpen

(C) 2019 The Author(s). Licensee IntechOpen. This chapter is distributed under the terms of the Creative Commons Attribution License (http://creativecommons.org/licenses/ by/3.0), which permits unrestricted use, distribution, and reproduction in any medium, provided the original work is properly cited. (cc) BY 


\section{References}

[1] Historia Naturalis. Old Plinius. 1582 Italian version. In: Gamba C, Vidali G, editors. 1992

[2] The phase behavior of dodecyl sulfonic acid and of its alkali salts with water, Vold MJ. Journal of the American Chemical Society. 1941;63:1427-1432

[3] Hielmeland LM. A nondenaturing zwitterionic detergent for membrane biochemistry: Design and synthesis. PNAS. 1980;77:6368-6370. N.B. The mentioned product is of current use in the formulation of mild detergents. See also Ref. 8

[4] Shinoda K, Takeda H. The effect of added salts in water on the hydrophilelipophile balance of nonionic surfactants. The effect of adde salts on the phase inversion temperature of emulsions. Journal of Colloid and Interface Science. 1970;32:642-646

[5] Mancuso JR, McClemens DJ, Decker EA. The effects of surfactant type, $\mathrm{pH}$, and chelators on the oxidation of salmon oil-in-water emulsions. Journal of Agricultural and Food Chemistry. 1999;47:4112-4116

[6] Baviere M, Bazin B, Aude R. Calcium effect on the solubility of sodium dodecyl sulfate in sodium chloride solutions. Journal of Colloid and Interface Science. 1983;92:580-583

[7] Hua XY, Rosen MJ. Synergism in binary mixtures of surfactants:

I. Theoretical analysis. Journal of Colloid and Interface Science. 1982;90:212-219

[8] Rosen MJ, Zhu BY. Synergism in binary mixtures of surfactants: III. Betainecontaining systems. Journal of Colloid and Interface Science. 1984;99:427-434

[9] Hoff E, Nystroem B, Lindman B. Polymer-surfactant interactions in dilute mixtures of a nonionic cellulose derivative and an anionic surfactant. Langmuir. 2001;17:28-34

[10] Jurassic DD, Segota S, Cadez V, Selmani A, Sikirc MD. Recent advances in catanionic mixtures. In: Najjar R, editor. Application and Characterization of Surfactants. Rijeka: IntechOpen; 2017

[11] Rosen MJ. Surfactants and Interfacial Phenomena. New York: Wiley and Sons; 2004

[12] Porter MR. Handbook of Surfactants. New York: Springer; 1991

[13] Schramm LL, editor. Surfactants. Fundamental and Applications in the Petroleum Industry. Cambridge: Cambridge University Press; 2009

[14] Laughling RJ. The Aqueous Phase Behavior of Surfactants. London: Acad. Press; 1994

[15] Tanford C, editor. The Hydrophobic Effect: Formation of Micelles, Vesicles and Biological Membranes. Vol. II. New York: Wiley; 1980

[16] Everett DH. Basic Principles of Colloid Science. Roy. Soc. Chem., Cambridge; 1994. Chapt. V, pp. 63-75

[17] Shinoda K, Hutchinson E. Pseudo-phase separation model for thermodynamic calculations on micellar solutions. The Journal of Physical Chemistry. 1962;66:577-582

[18] Ruckenstein E, Nagarajan R. Critical micelle concentration. Transition point for micellar size distribution. The Journal of Physical Chemistry. 1975;79:2622-2626

[19] Palladino P, Ragone R. Ionic strength effects on the critical micellar concentration of ionic and nonionic surfactants: The binding model. Langmuir. 2011;27:14065-14070 
[20] Hiltrop K. Lyotropic liquid crystals. In: Stegemeyer H, Mehret H, editors. Liquid Crystals. Topics Phys. Chem. Book Ser. 1993, Vol. 3, Chapt IV. pp. 143-171

[21] Ekwall P. Composition, properties and structures of liquid crystalline phases in systems of amphiphilic compounds. In: Adv. Liq. Cryst. Vol. I. Chapt. I. New York \& London: Acad. Press; 1975. pp. 1-142

[22] Goddard ED, Ananthapadmanabhan KP. Interactions of Surfactants with Polymers and Proteins. Boca Raton, FL: CRC Press; 1993. The whole book contains information on the most relevant points inherent to such systems

[23] Bell CG, Breward CJW, Howell PD, Penfold J, Thomas RK. Macroscopic modeling of the surface tension of polymer-surfactant systems. Langmuir. 2007;23:6042-6052

[24] Chatterjee S, Prajapati R, Bhattacharya A, Mukherjee TK. Microscopic evidence of "Necklace and Bead"-like morphology of polymerSurfactant complexes: A comparative study on poly(vinylpyrrolidone)sodium dodecyl sulfate and poly(diallyldimethylammonium chloride)-sodium dodecyl sulfate systems. Langmuir. 2014;30:9859-9865

[25] La Mesa C. Polymer-surfactant and protein-surfactant interactions. Journal of Colloid and Interface Science. 2005;286:148-157

[26] Sesta B, Gente G, Iovino A, Laureti F, Michiotti P, Paiusco O, et al. Supramolecular association in the system water-lysozymelithium perflorononanoate. The Journal of Physical Chemistry. B. 2004;108:3036-3043

[27] Tsianou M, Alexandridis P. Control of the rheological properties in solutions of a polyelectrolyte and an oppositely charged surfactant by the addition of cyclodextrins. Langmuir. 1999;15:8105-8112

[28] Roversi M, La Mesa C. Rheological properties of protein-surfactant based gels. Journal of Colloid and Interface Science. 2005;284:470-476

[29] D’Aprano A, La Mesa C, Persi L. Polymer-surfactant interactions: An ultrasonic relaxation study. Langmuir. 1997;13:5876-5888

[30] Kalantar TH, Tucker CJ, Zalusky AS, Boomgaard TA, Wilson BE, Ladika M, et al. High throughput workflow for coacervate formation and characterization in shampoo systems. Journal of Cosmetic Science. 2007;58:375-383

[31] Dubald M, Bourgeois S, Andrieu V, Fessi H. Ophtamic drug delivery systems for antibiotherapy: A review. Pharmaceutics. 2018;10:1-31

[32] Goddard DE. Polymer-surfactant interaction: Part II. Polymer and surfactant of opposite charge. In: Goddard ED, Ananthapadmanabhan KP, editors. Chapt. IVInteractions of Surfactants with Polymers and Proteins. Boca Raton: CRC Press; 1993. pp. 123-1170

[33] Reynolds JA, Tanford C. Binding of dodecyl sulfate to proteins at high binding ratios. Possible implications for the state of proteins in biological membranes. Proceedings of the National Academy of Sciences of the United States of America. 1970;66:1002-1003

[34] Turrro NJ, Lei X-G. Spectroscopic probe analysis of protein-surfactant interactions: The BSA/SDS system. Langmuir. 1995;11:2525-2533

[35] Kelley D, McClements DJ. Interactions of bovine serum albumin with ionic surfactants in aqueous solutions. Food Hydrocolloids. 2003;17:73-85 
[36] Otzen D. Protein-surfactant interactions: A tale of many states. Biochimica et Biophysica Acta. 2011;1984:562-591

[37] Ciurleo A, Cinelli S, Guidi M, Bonincontro A, Onori G, La Mesa C. Some properties of lysozyme-lithium perfluorononanoate complexes. Biomacromolecules. 2007;8:399-405

[38] Jokela P, Jonsson B, Wennerstroem H. Phase equilibria in systems containing both an anionic and a cationic amphiphile. A thermodynamic model calculation. Progress in Colloid and Polymer Science. 1985;70:17-22

[39] Jokela P, Jonsson B, Khan A. Phase equilibria of catanionic surfactantwater systems. The Journal of Physical Chemistry. 1987;91:3291-3298. To our knowledge this is the first article on which the term Catanionic is accounted for

[40] La Mesa C, Ranieri GG, Terenzi M. Studies on Kraft point solubility in surfactant solutions. Thermochimica Acta. 1988;137:143-150

[41] Shioi A, Hatton TA. Model for formation and growth of vesicles in mixed anionic/cationic (SOS/ CTAB) surfactant systems. Langmuir. 2002;18:7341-7348

[42] Marques EF, Regev O, Khan A, Miguel MDG, Lindman B. Vesicle formation and general phase behavior in the catanionic mixture SDS-DDABwater. The anionic-rich side. The Journal of Physical Chemistry. B. 1998;102:6746-6758

[43] Safran SA, Pincus P, Andelman D. Theory of spontaneous vesicle formation in surfactant mixtures. Science. 1990;248:354-356

[44] Segota S, Tezak D. Spontaneous formation of vesicles. Advances in Colloid and Interface Science. 2006;121:51-75
[45] Stenstam A, Khan A, Wennerströem $\mathrm{H}$. Lysozyme in catanionic surfactant mixtures. Langmuir. 2004;20:7760-7765

[46] Evans DF, Wennerstroem H. Chapt. IVThe Colloidal Domain: Where Physics, Chemistry, Biology and Technology Meet. New York: VCH; 1994. pp. 131-185

[47] Muzzalupo R, Gente G, La Mesa C, Caponetti E, ChilluraMartino D, Pedone L, et al. Micelles in mixtures of sodium dodecyl sulfate and a bolaform surfactant. Langmuir. 2006;22:6001-6009

[48] Takasugi K, Esumi K. Micellar surface charge modification for regular solution theory: Application to mixed systems of cationic fluorocarbonnonionic hydrocarbon surfactants. The Journal of Physical Chemistry. 1996;100:18802-18807

[49] Bonincontro A, Falivene M, La Mesa C, Risuleo G, Ruiz-Pena M. Dynamics of DNA Adsorption on and release from SDS-DDAB cat-anionic vesicles: A Multi-technique study.

Langmuir. 2008;24:1973-1978

[50] Letia C, Andreozzi P, Scipioni A, La Mesa C, Bonincontro A, Spigone E. Protein binding onto surfactant-based vesicles. The Journal of Physical Chemistry. B. 2007;111:898-908

[51] Russo L, Berardi V, Tardani F, La Mesa C, Risuleo G. Delivery of RNA and its intracellular translation into protein mediated by SDS-CTAB vesicles: Potential use in nanobiotechology. BioMed Research International. 2013;2013:1-6

[52] Lozano N, Pinazo A, La Mesa C, Perez L, Andreozzi P, Pons R. Catanionic vesicles formed with arginine-based surfactants and 1,2-dipalmitoyl-sn-glycero-3phosphate monosodium salt. The Journal of Physical Chemistry. B. 2009;113:6321-6327 
Surfactant Mixtures: Performances vs. Aggregation States DOI: http://dx.doi.org/10.5772/intechopen.85437

[53] Andreozzi P, Funari SS, La Mesa C, Mariani P, Ortore MG, Sinibaldi R, et al. Multi- to unilamellar transitions in catanionic vescicles. The Journal of Physical Chemistry. B. 2010;114:8056-8060

[54] Pucci C, Scipioni A, La Mesa C. Albumin binding onto synthetic vesicles. Soft Matter. 2012;8:9669-9675

[55] Bonincontro A, La Mesa C, Proietti C, Risuleo G. A biophysical investigation on the binding and controlled DNA release in a cetyltrimethylammonium bromidesodium octyl sulfate cat-anionic vesicle system. Biomacromolecules. 2007;8:1824-1829 



\title{
Biomimetic Nanomaterials from the Assembly of Polymers, Lipids, and Surfactants
}

\author{
Ana Maria Carmona-Ribeiro
}

\begin{abstract}
Nanostructured materials require evaluation at a molecular level to become controllable and useful in drug and vaccine delivery. Over the years self-assembled nanomaterials such as nanoparticles and thin films have been prepared, characterized and used for biomedical applications. In this review meaningful examples of biomimetic nanomaterials and their construction based on intermolecular interactions such as the electrostatic attraction or the hydrophobic effect will be discussed. Emphasis will be placed on the interactions between polymers, lipids, surfactants and surfaces leading to bioactive supramolecular assemblies such as nanoparticles and coatings. Among the important applications of the self-assembled nanostructures and films to be reviewed are their antimicrobial effect and their adjuvant activity for vaccine delivery.
\end{abstract}

Keywords: lipid polymer nanoparticles, antimicrobial nanostructures, adjuvants for vaccines, intermolecular interactions, assembly and disassembly

\section{Introduction}

Life is ephemeral as are the assemblies that make life possible. Among the nanomaterials, the biomimetic nanomaterials mimic the assemblies found in living creatures and may find a myriad of useful applications [1-9]. The bioactive biomimetic nanomaterials encompass a wide variety of hybrid metastable nanostructures keeping different or similar molecules transiently together thanks to weak but frequent intermolecular interactions as are the van der Waals, the hydrogen bridges, the electrostatic and electrodynamic interactions, and the hydrophobic effect $[10,11]$. Among these, one may say that the lipid polymer, the lipid inorganic materials and the coatings with NPs inclusion have been the subject of important developments in drug and vaccine delivery to fight pathogens and prevent, treat or diagnose major human diseases such as cancer. Stimuli responsive assemblies with the use of various triggers such as $\mathrm{pH}$, temperature, light, enzyme, and redox potential are emerging strategies for the effective localization of the bioactives at the tumor site for safe and effective cancer therapy or diagnosis despite all problems with multidrug resistance, long-lasting chemotherapy and low transfection and non-specific immuneresponse after systemic delivery of siRNa [12]. For example, a biomimetic phospholipid-like amphiphilic prodrug, 1-O-octodecyl-2-conjugated linoleoyl-sn-glycero-3-phosphatidyl gemcitabine (OLGPG) combined with cholesteryl hemisuccinate polyethylene glycol 1500 (CHS-PEG) upon injection in water 
formed the OLGPG and OLGPG/CHS-PEG nanometric spherical vesicles due to the hydrophobic interaction of lipid moieties. Since phospholipase A2 (PLA2) is highly expressed in tumor tissues and specifically degrades the 2-acyl of the phospholipids to lysophospholipids, a PLA2-sensitive OLGPG specific degradation in the tumor tissue was obtained [13]. In this same work, the in vivo experiments with a hepatocellular tumor-bearing mouse model showed that these long-circulating phospholipid-like prodrug nanoassemblies yielded the highest antitumor and tumor targeting effects compared to the other groups [13].

Today (30 November 2018) a search of the literature on lipid polymer coatings in the Scopus database produced 26,123 items whereas a search on lipid polymer nanoparticles resulted in 24,042 publications. I feel somewhat proud to have witnessed and contributed to some of the early and late developments on lipid polymer [14-23] and lipid silica NPs [24-29] that started about 3 decades ago. In particular, cationic lipids by themselves or in combination with other lipids or assemblies can yield interesting microenvironments to accommodate a variety of bioactive molecules such as drugs, antigens, peptides, nucleic acids, etc. [30-37]. The nanometric size and positive charge impart desirable properties for the cationic assemblies after injection via parenteral route in vivo. Good instances are the direct action at the lymph nodes for stimulation of dendritic cells for vaccines [9, 22, 31, 34-37], and the penetration of nasal mucosae to overcome the blood brain barrier releasing drugs into the brain [33]. Other important applications relate to the antimicrobial properties of a variety of cationic assemblies either by themselves such as cationic bilayers or in effective combinations with other antimicrobials such as antibiotics, polymers or peptides [7, 23, 38-45].

This review will discuss mostly seminal and recent contributions regarding applications of biomimetic nanoparticles and coatings in antimicrobial therapy and vaccine development. Emphasis will be placed on lipid polymer NPs and their coatings plus their biomedical applications in drug and vaccine delivery.

\section{Lipid polymer nanoparticles: overview on their applications}

Lipids and polymers have been yielding a myriad of combinations. From the 24,042 publications on lipid polymer nanoparticles found today, 6173 were review articles. Many of them referred to solid lipid nanoparticles or nanostructured lipid carriers and the associated problems regarding drug location and arrangements of the lipids and the stabilizing agents in the lipid particle nanostructure $[46,47]$. These NPs are based on lipid cores stabilized by layers of hydrophilic polymers [48, 49]. They may also assume the form of nanodiscs or open bilayer fragments (BF) [17]. The scaffold is then an organized and open lipid bilayer disk of charged and saturated synthetic lipids [50,51] or compositions containing polyethylene glycol covalently bound to lipids [52]. Dioctadecyldimethylammonium bromide bilayer fragments (DODAB BF) with two consecutively deposited layers of carboxymethylcellulose (CMC) and polydiallyldimethylammonium chloride (PDDA), respectively, were effective microbicidal assemblies $[39,40]$. This activity was associated with the outermost layer of the cationic antimicrobial polymer PDDA [39-41]. The visualization of the lipid or lipid polymer nanodiscs was achieved by advanced microscopy techniques such as shown from cryo-transmission electron micrographs (cryo-TEM) [52] in Figure 1(a), transmission electron micrographs with electronic staining of the nanodiscs in Figure 1(b) or scanning electron micrographs of the DODAB BF/ $\mathrm{CMC/PDDA}$ nanodiscs in Figure 1(c). It is interesting to notice that the disks could be observed both face-on and edge-on. 


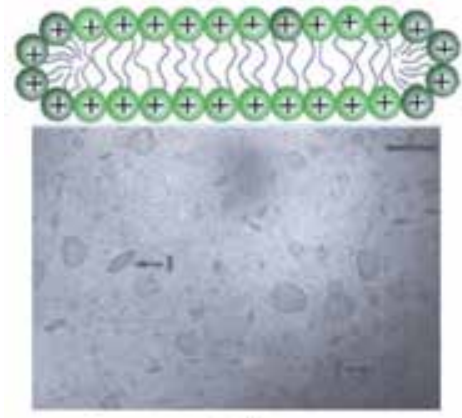

(a)

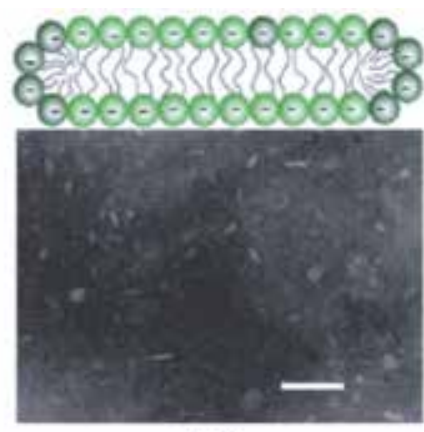

(b)

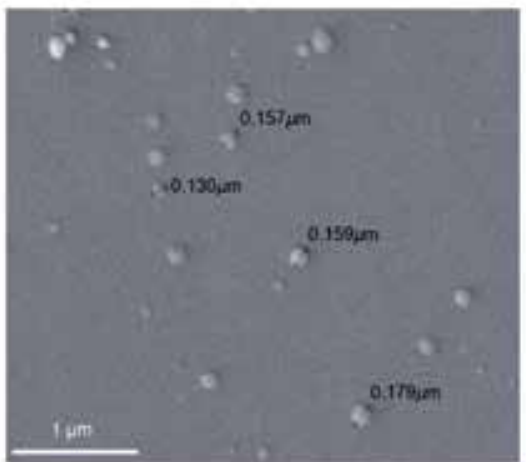

(c)

Figure 1.

Micrographs and some schemes of cross sections for discoidal NPs made of lipid bilayer disks or fragments without $(a, b)$ or with outer layers of polymers (c). On (a), the cryo-TEM of DODAB BF (bar is $100 \mathrm{~nm}$ ). Adapted from [50] with permission from 1995 American Chemical Society. On (b), negatively stained anionic sodium dihexadecylphosphate (DHP) BF seen from TEM (bar is $100 \mathrm{~nm}$ ). Adapted from [51] with permission from 1991 American Chemical Society. On (c), scanning electron micrograph of microbicidal discoidal NPs where DODAB BF supported consecutive polymer layers of carboxymethylcellulose (CMC) and polydiallyldimethylammonium chloride (PDDA) [41].

Dispersions of phospholipids such as 1,2-dimyristoyl-sn-glycero-3-phosphocholine (DMPC) and 1,2-dihexanoyl-sn-glycero-3-phophocholine (DHPC) can yield also discoidal and open lipid particles; the short-chain components preferentially occupy curved rim environments around bilayer disks of the long-chain components [53, 54]. Cationic peptides such as a lung surfactant protein and the antimicrobial peptide magainin 2 interacted with the DMPC/DHPC neutral bicelles but did not affect their structure as seen from magnetic resonance spectroscopy [53]; for disks containing the anionic 1,2-dimyristoyl-sn-glycero-3-phopho-(1'-rac-glycerol) (DMPG) the peptides lowered the temperature at which the particles coalesced into more extended lamellar structures or promoted partitioning of the zwitterionic and anionic long-chain lipid components into different environments [53].

Other lipid-polymer hybrid nanoparticles consist of a polymer core surrounded by a lipid shell combining properties of both polymeric nanoparticles and liposomes and often referred to as biomimetic nanoparticles [14-23, 55-58]. Sometimes, when the lipid has good affinity for the polymer, it can be embedded in the polymer matrix as was the case of the cationic lipid dioctadecyl dimethyl ammonium bromide (DODAB) and poly methyl methacrylate (PMMA) polymer for producing microbicidal PMMA/DODAB coatings from spin-coating [59]. In these coatings the cationic lipid DODAB accounted for the microbicidal activity [59]. Hadinoto and co-workers reviewed the literature on lipid-coated polymeric nanoparticles 
(LPNPs) prepared from natural polymers such as chitosan (CS) and the biocompatible and biodegradable poly-lactic-co-glycolic acid (PLGA), and their applications as a delivery platform for cancer therapy [60].

Leaf Huang and co-workers recently gave a comprehensive account on the important role of lipid polymer nanoparticles in combination therapy against cancer including chemotherapy, photodynamic therapy, thermal heating treatments with metals, siRNA delivery and others [61]. Some synergistic combinations of anti-cancer drugs can circumvent resistance to treatment and be effective in anticancer therapy. For example,

NPs formulated through self-assembly of the biodegradable PLGA and a cationic, hydrophobic molecule carried siRNA to knock down target oncogenes and to deliver cisplatin prodrug to tumors both in vitro and in vivo [62]. The NPs induced a significant and sustained suppression of genes in a human lymph node carcinoma of the prostate xenograft mouse model for up to 3 days after a single dose. Administering these NPs revealed a synergistic effect on tumor inhibition that was strikingly more effective than cisplatin monotherapy [62]. On reference [62] the cationic molecule was embedded in the PLGA-PEG shell and the cargo of siRNA was in the inner aqueous core.

Messerschmidt and coworkers [63] described another sophisticated system of lipid polymer NPs aiming at cancer combined therapy. Lipid coated -polystyrene NPs endowed with several functions such as targeting to the cancer cells with a single-chain Fv antibody fragment, steric stabilization of the outer lipid layer with polyethylene glycol (PEG) lipids and single chain tumor necrosis factor (scTNF) covalently bound to the polystyrene core [63]. Thereby, the system specifically delivered scTNF to the cancer cells inducing their death by apoptosis without affecting the healthy cells.

Many applications in drug and vaccine delivery for the hybrid polymer lipid NPs called biomimetic nanoparticles were systematically reviewed over the last three decades [7, 8, 17-19, 31, 38, 44, 55-58, 64-66]. In special when either the lipid or the polymer is cationic, lipid polymer NPs display remarkable interactive capability with bioactive molecules and can impart antimicrobial properties to a variety of nanomaterials adding functionality to dispersions, surfaces and coatings and allowing to obtain interesting combinations of bioactive molecules and assemblies. Novel approaches proliferate exponentially for the development of different advanced materials shaped as NPs, hydrogels and surface coatings with effective antimicrobial properties. Bassegoda and coworkers recently gave a comprehensive account on major strategies to prevent the occurrence of resistance against antibiotics by using advanced materials [67]. Advanced materials occur as anti-fouling molecules and surfaces that prevent microorganisms adhesion and formation of biofilms or they are bactericidal materials that cause cell membrane disruption, production of reactive oxygen species with damage to vital biomolecules in the cell or materials that damage vital proteins [67]. They recognized the importance of antimicrobial biomimetics from the need of a new generation of hybrid materials with strong antimicrobial/antifouling activities and improved biocompatibility imparted by "safety design" [67]. In the next section we discuss some of these cationic materials.

\section{Cationic lipid polymer nanoparticles, coatings and applications in antimicrobial biomimetics and vaccine delivery}

Cationic lipid polymer NPs and coatings are strategic for applications in antimicrobial biomimetics and vaccine design [7, 8, 38-45, 55-59]. Due to the cationic lipid, lipid polymer cationic NPs can combine effectively with antibiotics 
like amphotericin B or miconazole [39, 68-70], rifampicin [71], clarithromycin [72], anti-inflammatory hydrophobic drugs like indomethacin [32], nucleic acids [21], oligonucleotides $[35,73,74]$, proteins in general including serum proteins, transmembrane proteins, receptors and toxins [75-78], antigens [9, 20, 22, 34-37], peptides [23, 43-45] or polymers [79, 80].

Early work on the affinity between the biocompatible PMMA polymer and the antimicrobial DODAB lipid showed that thin films of PMMA/DODAB casted by spin-coating a chloroformic solution onto silicon wafers were homogeneous and retained the microbicidal activity of DODAB [59]. Figure 2 illustrates the polymer lipid coatings of polystyrene (PS)/DODAB and PMMA/DODAB; whereas DODAB did not mix homogeneously with PS (Figure 2(a), the film resulting from the PMMA/DODAB spin-coating procedure in Figure 2(c) was very smooth and homogeneous as reproduced from reference [59]. The live-dead testing for Escherichia coli showed green, and alive bacteria on the PMMA coating (Figure 2(e) and red, and dead ones on the PMMA/DODAB coating (Figure 2(f)).

Taking advantage of the good compatibility between DODAB lipid and PMMA, Melo and co-workers evaluated the interaction between different quaternary ammonium surfactants and PMMA from spin-coated PMMA/DODAB and PMMA/ CTAB films on silicon wafers or glass coverslips [81]. The mobility of CTAB in the coatings allowed this surfactant to leak to the outer medium in contrast with the permanence of DODAB in the coatings and its antimicrobial action by contact [81].

In another meaningful instance, Naves and co-workers synthesized PMMA NPs by emulsion polymerization in the presence of DODAB or CTAB and determined the antimicrobial activity of the dispersions [82]. Loading the biocompatible poly acrylic particles with the quaternary ammonium surfactants was a facile, fast, low-cost approach to obtaining highly efficient antimicrobial nanoparticles which either killed by contact in the case of embedded DODAB or by leakage to the outer medium in the case of CTAB [82].

The biocompatible PMMA polymer and the antimicrobial and cationic polymer PDDA reunited by synthesizing PMMA in the presence of PDDA yielded interesting
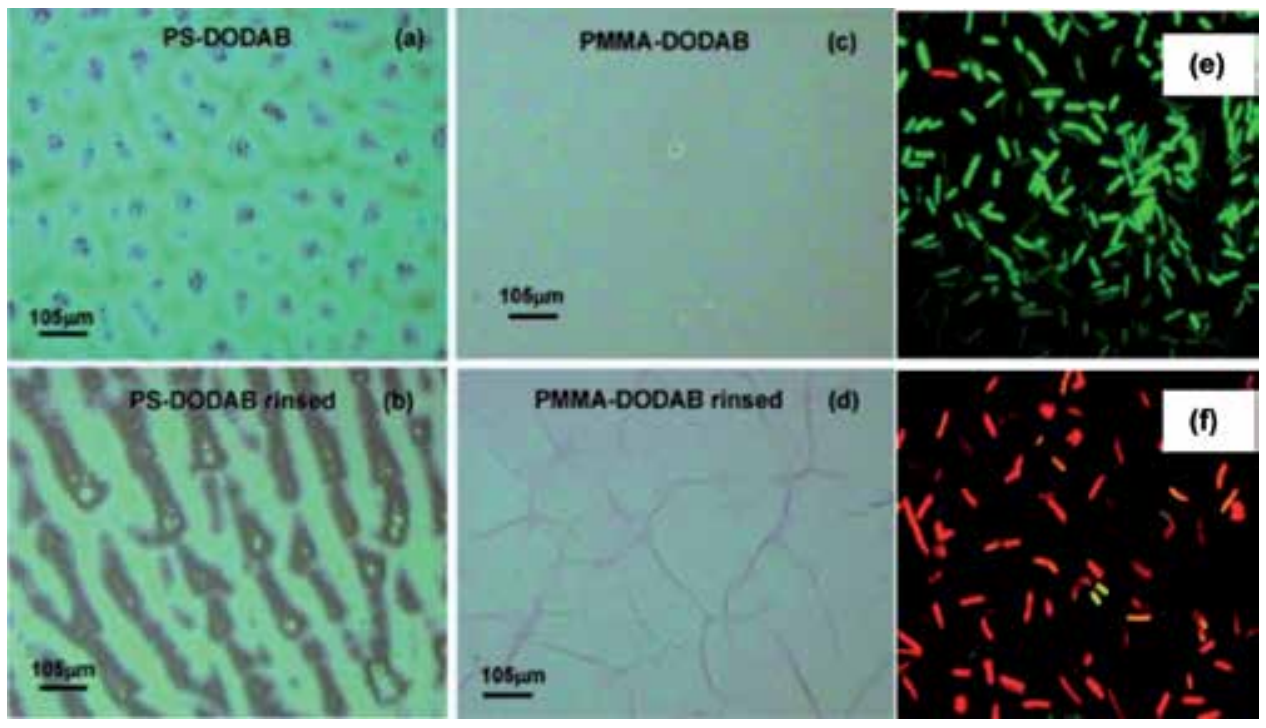

Figure 2.

Optical microscopy of hybrid polymer-DODAB films obtained by spin-coating: (a) PS-DODAB;

(b) PS-DODAB rinsed with ethanol; (c) PMMA-DODAB; (d) PMMA-DODAB rinsed with ethanol; (e) E. coli on PMMA film; $(f)$ E. coli on PMMA/DODAB film. Adapted from reference [59]. 
NPs [83]. This was a facile alternative approach in comparison to strategies based on the synthesis of block copolymers incorporating both functions. Figure 3 shows the macroscopic and microscopic appearance of the very stable dispersions of PMMA/ PDDA and PMMA/PDDA/cationic amphiphile and some of their films obtained
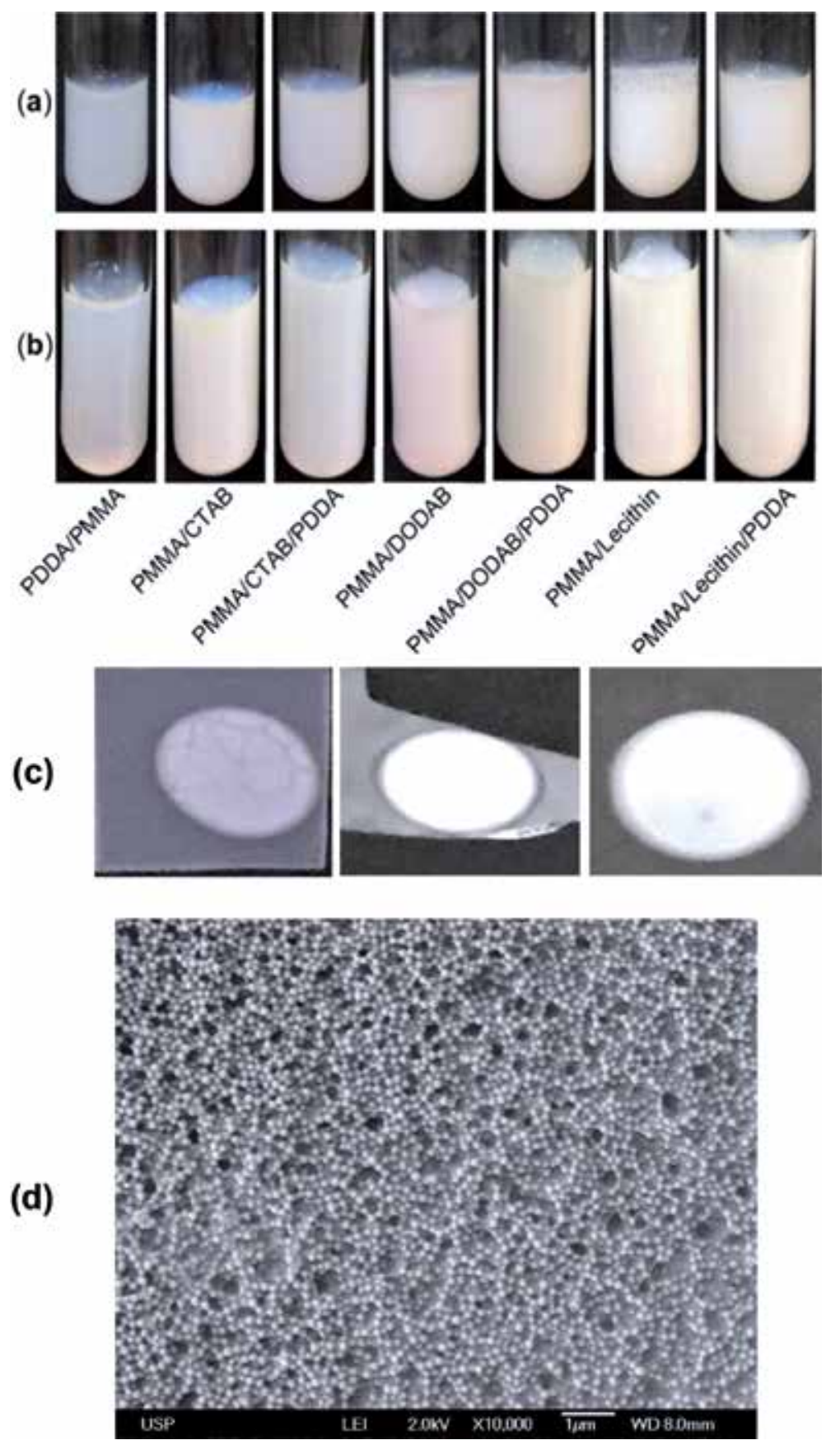

Figure 3.

Stable NPs dispersions of biocompatible polymer (PMMA), antimicrobial polymer (PDDA) and cationic lipid $(D O D A B)$ or surfactant (CTAB) in form of NPs dispersions in water just after synthesis (a) and 6 months after synthesis $(b)$. Coatings were obtained by casting and drying NPs water dispersions on polystyrene, silicon wafer or glass coverslip surfaces from left to right (c). The SEM micrograph for the PMMA/PDDA NPs coatings showed the NPs film obtained after drying $(d)$. Reproduced from reference [80]. 
by casting and drying the water dispersions of NPs onto different surfaces such as polystyrene, silicon wafers or glass coverslips [80].

Against fungus such as Candida albicans, the variable antimicrobial activity of the quaternary ammonium nitrogen in lipids, surfactants and polymers was previously established by our group [40, 84-86]. While substantial fungicidal activity was described for the micelle-forming CTAB surfactant, the bilayer-forming DODAB did not show the ability of moving from the bilayer assembly to the fungus cell membrane [85]. As a consequence a poor fungicidal activity of DODAB bilayers assembled as bilayer fragments or as large vesicles was obtained $[84,86]$. The microbicidal quaternary nitrogen only kills the fungus if its host molecule has mobility enough to cross the thick and dense layer of glycoproteins at the outer fungus cell wall. Adsorption isotherms of CTAB and DODAB on C. albicans were revealing; increasing DODAB concentration reduced its adsorption onto the cells due to the preferential vesicle-vesicle instead of the vesicle-cell interaction [87]. In contrast to other surfactants such as sodium dodecyl sulfate (SDS), CTAB did not disrupt the cell membrane and cell death occurred when the cell became positively charged [85]. Fungus death requires adsorption of the quaternary ammonium moiety to the cell, change in the cell charge and penetration through the cell wall reaching the fungus cell membrane. Since DODAB, in the DODAB bilayer, exists mostly in the rigid gel state there is no penetration of the quaternary ammonium moiety into the fungus cell wall and cytoplasmic membrane what explains the poor DODAB activity against fungus when compared to other micelle-forming surfactants $[84,85]$. These considerations directly lead to the prediction that mobile polymers bearing the quaternary ammonium moiety would be efficient antimicrobial agents against fungus. Polymer immobilization, however, would reduce their action and these were indeed the experimental results [40, 83]. Immobilization of PDDA in PMMA/PDDA NPs substantially reduced the PDDA fungicidal action against C. albicans [83]. PDDA by itself showed remarkable fungicidal activity (minimal fungicidal concentration of $0.5 \mu \mathrm{g} / \mathrm{mL}$ ) in complete absence of toxicity against red blood cells [86]. Very recently, Fait and co-workers comprehensively revised the structure-function activity of cationic surfactants as antifungal agents [88].

For vaccines, cationic nanostructures have been revealing their potential in several instances from combinations with cationic lipids or other hybrid assemblies shaped as microparticles or nanoparticles [7-9, 17-22, 28, 31, 34-37, 55, 58, 64, $66,76,78]$. The possibility of varying sizes from nanometric to micrometric and the positive charge are major assets for adjuvants since they allow combinations with the vast majority of antigens such as proteins, peptides, haptens, nucleic acids, oligonucleotides or other negatively charged biological combinations such as extracts of pathogens. The nanosize is valuable for localizing the antigen directly in the lymph nodes where capture by antigen presenting cells may elicit suitable humoral and cellular defenses. Manolova and co-workers showed that particles target distinct dendritic cell populations according to their size [89]. Virus-sized NPs with 20-200 nm diameter are captured by dendritic cells (DC) whereas bacteria with 500-5000 nm diameter are captured by phagocytes or macrophages. Whereas images of large particles (500-2000 nm) localized them in DC from the injection site, small (20-200 nm) NPs and virus-like particles (30 nm) were also found in lymph nodes-resident DC and macrophages, suggesting free drainage of NPs to the lymph nodes; particle size determined the mechanism of trafficking to the LN so that only small NPs could specifically target LN-resident cells [89]. Manolova and co-workers [89] considered the mechanism of NPs trafficking from the skin to the draining $\mathrm{LN}$ in vivo; the optimal size for lymphatic uptake would be between 10 and $100 \mathrm{~nm}$ [89]. The initial lymphatic vessels are lined with overlapping endothelial cells so that DC and fluids from the interstitial space enter lymphatic 
vessels through the endothelial cell junctions. Hence, these junctions might act as a molecular sieve and could prevent large particles from entering freely into the afferent lymphatics [89]. In the interstitial space, DC that captured large particles would carry them into the lymphatics. In addition, large particles would remain more tightly trapped in the interstitial space before entering the lymphatics. Their prolonged residence in the interstitium would increase the probability of phagocytosis. The role of NP charge was reviewed [90] and the boosting of cationic NPs for generating antigen-specific CD4(+) T cell proliferation was demonstrated [91].

\section{Conclusions}

The plethora of biomolecules that can be combined with polymers enables the design of new types of polymer-based NPs and interfaces, for example antimicrobial coatings from hybrid lipid polymer NPs $[80,83]$, possibly useful in medical devices, which will hopefully provide innovative preventive and therapeutic approaches in medicine.

Future generations of biomimetic systems will involve more complex compositions and combinations, leading to insights into fighting pathological conditions. Future developments in biomimetic assemblies including polymers will certainly improve and expand biomedical applications and significantly advance the treatment of cancer and many other diseases.

Nowadays lipid polymer, positively charged, biomimetic NPs are available over a range of sizes for vaccines design and drug delivery. Biomimetic lipid polymer NPs were first described by our group in the nineties [7-9, 14-16, 92]. The last decades witnessed significant extensions in our repertoire so that lipid-polymer and polymer-lipid dispersions or coatings, nanosized bilayer fragments, bilayer-covered polymeric particles, and layer-by-layer lipid polymer assemblies, most of them cationic, found novel applications as adjuvants for vaccines, as carriers for drug delivery and as antimicrobial assemblies.

\section{Acknowledgements}

This work was supported by Conselho Nacional de Desenvolvimento Científico e Tecnológico grant number 302352/2014-7.

\section{Conflict of interest}

The author declares no conflict of interest. 
Biomimetic Nanomaterials from the Assembly of Polymers, Lipids, and Surfactants DOI: http://dx.doi.org/10.5772/intechopen.84618

\section{Author details}

Ana Maria Carmona-Ribeiro

Departamento de Bioquímica, Biocolloids Laboratory, Instituto de Química, Universidade de São Paulo, São Paulo, Brazil

*Address all correspondence to: amcr@usp.br

\section{IntechOpen}

(C) 2019 The Author(s). Licensee IntechOpen. This chapter is distributed under the terms of the Creative Commons Attribution License (http://creativecommons.org/licenses/ by/3.0), which permits unrestricted use, distribution, and reproduction in any medium, provided the original work is properly cited. (cc) BY 


\section{References}

[1] Einfalt T, Witzigmann D, Edlinger C, Sieber S, Goers R, Najer A, et al. Biomimetic artificial organelles with in vitro and in vivo activity triggered by reduction in microenvironment. Nature Communications. 2018;9(1):1127. DOI: 10.1038/s41467-018-03560-x

[2] Garni M, Thamboo S,

Schoenenberger CA, Palivan CG. Biopores/membrane proteins in synthetic polymer membranes. Biochimica et Biophysica ActaBiomembranes. 2017;1859(4):619-638. DOI: 10.1016/j.bbamem.2016.10.015

[3] Schoonen L, van Hest JC.

Compartmentalization approaches in soft matter science: From nanoreactor development to organelle mimics. Advanced Materials. 2016;28(6):1109-1128. DOI: $10.1002 /$ adma.201502389

[4] De Martino MT, Abdelmohsen LKEA, Rutjes FPJT, van Hest JCM. Nanoreactors for green catalysis. Beilstein Journal of Organic Chemistry. 2018;14:716-733. DOI: $10.3762 /$ bjoc. 14.61

[5] Vonarbourg A, Passirani C, Desigaux L, Allard E, Saulnier P, Lambert O, et al. The encapsulation of DNA molecules within biomimetic lipid nanocapsules. Biomaterials. 2009;30(18):3197-3204. DOI: 10.1016/j.biomaterials.2009.03.009

[6] Groo AC, Matougui N, Umerska A, Saulnier P. Reverse micelle-lipid nanocapsules: A novel strategy for drug delivery of the plectasin derivate AP138 antimicrobial peptide. International Journal of Nanomedicine. 2018;13: 7565-7574. DOI: 10.2147/IJN.S180040

[7] Carmona-Ribeiro AM. Selfassembled antimicrobial nanomaterials. International Journal of Environmental Research and Public Health. 2018;15(7):1408. DOI: 10.3390/ ijerph15071408
[8] Carmona-Ribeiro AM. Biomimetic nanoparticles: Preparation, characterization and biomedical applications. International Journal of Nanomedicine. 2010;5:249-259

[9] Carmona-Ribeiro AM. Chapter Thirteen - Nanomaterials Based on Lipids for Vaccine Development. In: Skwarczynski M, Toth I, editors. Micro and Nanotechnology in Vaccine Development.William Andrew Publishing; 2017. pp. 241-257. DOI: 10.1016/B978-0-323-39981-4.00013-0 Available from: http://www. sciencedirect.com/science/article/pii/ B9780323399814000130

[10] Israelachvili JN. Intermolecular and surface forces. 3rd ed. San Diego: Academic Press; 2011. p. 674. DOI: 10.1016/B978-0-12-375182-9.10025-9

[11] Israelachvili JN, Mitchell DJ, Ninham BW. Theory of self-assembly of lipid bilayers and vesicles. Biochimica et Biophysica Acta. 1977;470(2):185-201

[12] Jain A, Jain SK. Stimuli-responsive smart liposomes in cancer targeting. Current Drug Targets. 2018;19(3): 259-270. DOI: $10.2174 / 138945011766616$ 0208144143

[13] Zuo J, Tong L, Du L, Yang M, Jin Y. Biomimetic nanoassemblies of 1-O-octodecyl-2-conjugated linoleoyl-sn-glycero-3-phosphatidyl gemcitabine with phospholipase A (2)-triggered degradation for the treatment of cancer. Colloids and Surfaces. B, Biointerfaces. 2017;152:467-474. DOI: 10.1016/j. colsurfb.2017.02.001

[14] Carmona-Ribeiro AM, Midmore BR. Synthetic bilayer adsorption onto polystyrene microspheres. Langmuir. 1992;8(3):801-806. DOI: 10.1021/ la00039a013 
[15] Carmona-Ribeiro AM, Herrington TM. Phospholipid adsorption onto polystyrene microspheres. Journal of Colloid and Interface Science. 1993;156(1):19-23. DOI: 10.1006/ jcis.1993.1074

[16] Carmona-Ribeiro AM, Lessa M. Interactions between bilayer membranes and látex. Colloids and Surfaces A: Physicochemical and Engineering Aspects. 1999;153(1-3):355-361. DOI: $10.1016 /$ S0927-7757(98)00532-9

[17] Carmona-Ribeiro AM. Bilayer vesicles and liposomes as interface agents. Chemical Society Reviews. 2001;30:241-247. DOI: 10.1039/ B101608N

[18] Carmona-Ribeiro AM. Bilayerforming synthetic lipids: Drugs or carriers? Current Medicinal Chemistry. 2003;10(22):2425-1446. DOI: $10.2174 / 0929867033456611$

[19] Carmona-Ribeiro AM. Lipid bilayer fragments and disks in drug delivery. Current Medicinal Chemistry. 2006;13(12):1359-1370. DOI: $10.2174 / 092986706776872925$

[20] Lincopan N, Espíndola NM, Vaz AJ, Carmona-Ribeiro AM. Cationic supported lipid bilayers for antigen presentation. International Journal of Pharmaceutics. 2007;340(1-2):

216-222. DOI: 10.1016/j.

ijpharm.2007.03.014

[21] Rosa H, Petri DF, Carmona-Ribeiro AM. Interactions between bacteriophage DNA and cationic biomimetic particles. The Journal of Physical Chemistry. B. 2008;112(51):16422-16430. DOI: 10.1021/jp806992f

[22] Lincopan N, Espíndola NM, Vaz AJ, da Costa MH, Faquim-Mauro E, Carmona-Ribeiro AM. Novel immunoadjuvants based on cationic lipid: Preparation, characterization and activity in vivo. Vaccine.
2009;27(42):5760-5771. DOI: 10.1016/j. vaccine.2009.07.066

[23] Xavier GRS, Carmona-Ribeiro AM. Cationic biomimetic particles of polystyrene/cationic bilayer/gramicidin for optimal bactericidal activity. Nanomaterials. 2017;7(12):422. DOI: 10.3390/nano7120422

[24] Rapuano R, Carmona-Ribeiro AM. Physical adsorption of bilayer membranes on silica. Journal of Colloid and Interface Science. 1997;193(1): 104-111. DOI: $10.1006 /$ jcis.1997.5060

[25] Rapuano R, Carmona-Ribeiro AM. Supported bilayers on silica. Journal of Colloid and Interface Science. 2000;226:299-307. DOI: 10.1006/ jcis.2000.6824

[26] Moura SP, Carmona-Ribeiro AM. Cationic bilayer fragments on silica at low ionic strength: Competitive adsorption and colloid stability. Langmuir. 2003;19(17):6664-6667. DOI: 10.1021/la034334o

[27] Moura SP, Carmona-Ribeiro AM. Biomimetic particles: Optimization of phospholipid bilayer coverage on silica and colloid stabilization. Langmuir. 2005;21(22):10160-10164. DOI: 10.1021/ la0504614

[28] Lincopan N, Santana MR, Faquim-Mauro E, da Costa MH, Carmona-Ribeiro AM. Silica-based cationic bilayers as immunoadjuvants. BMC Biotechnology. 2009;9:5. DOI: 10.1186/1472-6750-9-5

[29] Ribeiro RT, Braga VHA, Carmona-Ribeiro AM. Biomimetic cationic nanoparticles based on silica: Optimizing bilayer deposition from lipid films. Biomimetics. 2017;2(4):20. DOI: $10.3390 /$ biomimetics 2040020

[30] Sobral CN, Soto MA, CarmonaRibeiro AM. Characterization of DODAB/DPPC vesicles. Chemistry and 
Physics of Lipids. 2008;152(1):38-45.

DOI: 10.1016/j.chemphyslip.2007.12.004

[31] Carmona-Ribeiro AM.

Chapter Five-The versatile

dioctadecyldimethylammonium

bromide. In: Najjar R, editor. Application and Characterization of Surfactants.

Rijeka: InTech; 2017. pp. 157-181.

DOI: $10.5772 / 68020$. Available from:

https://www.intechopen.com/books/

application-and-characterization-

of-surfactants/the-versatile-

dioctadecyldimethylammonium-

bromide

[32] Lima EG, Gomes LR, Carmona-

Ribeiro AM. Stable indomethacin

dispersions in water from drug, ethanol, cationic lipid and carboxymethyl-

cellulose. Pharmaceutical

Nanotechnology. 2016;4(2):126-135.

DOI: $10.2174 / 2211738504666160304$

195436. Available from: http://www.

eurekaselect.com/node/140208/article

[33] Pashirova TN, Zueva IV, Petrov KA, Lukashenko SS, Nizameev IR, Kulik NV, et al. Mixed cationic liposomes for brain delivery of drugs by the intranasal route: The acetylcholinesterase reactivator 2-PAM as encapsulated drug model. Colloids and Surfaces. B, Biointerfaces. 2018;171:358-367. DOI: 10.1016/j. colsurfb.2018.07.049

[34] Carmona-Ribeiro AM. Chapter One-Cationic nanostructures for vaccines. In: Duc GHT, editor. Immune Response Activation. Rijeka: InTech; 2014. p. 3-43. DOI: 10.5772/57543. Available from: http://www.intechopen.com/books/ immune-response-activation/ cationic-nanostructures-for-vaccines

[35] Rozenfeld JH, Silva SR, Ranéia PA, Faquim-Mauro E, CarmonaRibeiro AM. Stable assemblies of cationic bilayer fragments and $\mathrm{CpG}$ oligonucleotide with enhanced immunoadjuvant activity in vivo.
Journal of Controlled Release. 2012;160(2):367-373. DOI: 10.1016/j. jconrel.2011.10.017

[36] de Oliveira Santos FA, Lincopan N, De Gaspari E. Evaluation of intranasal and subcutaneous route of immunization in neonatal mice using DODAB-BF as adjuvant with outer membrane vesicles of Neisseria meningitis B. Immunobiology. 2018;223(12):750-760. DOI: 10.1016/j. imbio.2018.07.021

[37] Gaspar EB, Rosetti AS, Lincopan N, De Gaspari E. Neisseria lactamica antigens complexed with a novel cationic adjuvant. Human Vaccines \& Immunotherapeutics. 2013;9(3):572-581

[38] Mamizuka EM, CarmonaRibeiro AM. Cationic liposomes as antimicrobial agents. In: Antonio Méndez Vilas. (Org.). Communicating Current Research and Educational Topics and Trends in Applied Microbiology. 1 ed. Badajoz: Formatex, 2007, v. 2, p. 636-647. ISBN-13: 97884-611-9423-0. Available from: http:// www.formatex.org/microbio/pdf/ pages636-647.pdf

[39] Vieira DB, Carmona-Ribeiro AM. Cationic nanoparticles for delivery of amphotericin B: Preparation, characterization and activity in vitro. Journal of Nanbiotechnology. 2008;6:6. DOI: 10.1186/1477-3155-6-6

[40] Melo LD, Mamizuka EM, CarmonaRibeiro AM. Antimicrobial particles from cationic lipid and polyelectrolytes. Langmuir. 2010;26(14):12300-12306. DOI: $10.1021 / \mathrm{la101500s}$

[41] De Melo Carrasco LD, Sampaio JL, Carmona-Ribeiro AM. Supramolecular cationic assemblies against multidrugresistant microorganisms: Activity and mechanism of action. International Journal of Molecular Sciences. 
2015;16(3):6337-6352. DOI: 10.3390/ ijms16036337

[42] Carrasco LD, Bertolucci R Jr, Ribeiro RT, Sampaio JL, Carmona-Ribeiro AM. Cationic nanostructures against foodborne pathogens. Frontiers in Microbiology. 2016;7:1804.

DOI: 10.3389/fmicb.2016.01804

[43] Ragioto DA, Carrasco LD, Carmona-Ribeiro AM. Novel gramicidin formulations in cationic lipid as broad-spectrum microbicidal agents. International Journal of Nanomedicine. 2014;9:3183-3192. DOI: 10.2147/IJN. S65289

[44] Carmona-Ribeiro AM, de Melo Carrasco LD. Novel formulations for antimicrobial peptides. International Journal of Molecular Sciences. 2014;15(10):18040-18083. DOI: 10.3390/ijms151018040

[45] Carvalho CA, Olivares-Ortega C, Soto-Arriaza MA, Carmona-Ribeiro AM. Interaction of gramicidin with DPPC/DODAB bilayer fragments. Biochimica et Biophysica Acta. 2012;1818(12):3064-3071. DOI: 10.1016/j.bbamem.2012.08.008

[46] Gordillo-Galeano A, Mora-Huertas CE. Solid lipid nanoparticles and nanostructured lipid carriers: A review emphasizing on particle structure and drug release. European Journal of Pharmaceutics and Biopharmaceutics. 2018;133:285-308. DOI: 10.1016/j. ejpb.2018.10.017

[47] Pereira I, Zielińska A, Ferreira NR, Silva AM, Souto EB. Optimization of linalool-loaded solid lipid nanoparticles using experimental factorial design and long-term stability studies with a new centrifugal sedimentation method. International Journal of Pharmaceutics. 2018;549 (1-2):261-270. DOI: $10.1016 / \mathrm{j}$. ijpharm.2018.07.068
[48] Mishra V, Bansal KK, Verma A, Yadav N, Thakur S, Sudhakar K, et al. Solid lipid nanoparticles: Emerging colloidal nano drug delivery systems. Pharmaceutics. 2018;10(4). DOI: 10.3390/pharmaceutics10040191

[49] Müller RH, Mäder K, Gohla S. Solid lipid nanoparticles (SLN) for controlled drug delivery-a review of the state of the art. European Journal of Pharmaceutics and Biopharmaceutics. 2000;50(1):161-177. DOI: 10.1016/ S0939-6411(00) 00087-4

[50] Andersson M, Hammarstroem L, Edwards K. Effect of bilayer phase transitions on vesicle structure, and its influence on the kinetics of viologen reduction. The Journal of Physical Chemistry. 1995;99(39):14531-14538. DOI: 10.1021/j100039a047

[51] Carmona-Ribeiro AM, Castuma CE, Sesso A, Schreier S. Bilayer structure and stability in dihexadecyl phosphate dispersions. The Journal of Physical Chemistry. 1991;95(13):5361-5366. DOI: 10.1021/j100166a080

[52] Zetterberg MM, Reijmar K, Pränting M, Engström Á, Andersson DI, Edwards K. PEG-stabilized lipid disks as carriers for amphiphilic antimicrobial peptides. Journal of Controlled Release. 2011;156(3):323-328. DOI: 10.1016/j. jconrel.2011.08.029

[53] Miranda C, Booth VK, Morrow MR. Effects of amphipathic polypeptides on membrane organization inferred from studies using bicellar lipid mixtures. Langmuir. 2018;34(39):11759-11771. DOI: 10.1021/ acs.langmuir.8b02257

[54] Sanders CR, Prosser RS. Bicelles: A model membrane system for all seasons? Structure. 1998;6(10):1227-1234

[55] Carmona-Ribeiro AM. Lipid-based biomimetics in drug and vaccine 
delivery. In: Mukherjee A, editor. Biomimetics Learning from Nature. Olajinica: InTech; 2010. pp. 507-534. DOI: $10.5772 / 8792$. Available from: http://www.intechopen.com/books/ biomimetics-learning-from-nature/ lipid-based-biomimetics-in-drug-andvaccine-delivery

[56] Carmona-Ribeiro AM, Barbassa B, Melo LD. Antimicrobial biomimetics. In: Cavrak M, editor. Biomimetic Based Applications. Olajinica: InTech; 2011. pp. 227-284. DOI: 10.5772/14400. Available from: http://www.intechopen.com/books/ biomimetic-based-applications/ antimicrobial-biomimetics

[57] Carmona-Ribeiro AM. Preparation and characterization of biomimetic nanoparticles for drug delivery. In: Soloviev M, editor. Nanoparticles in Biology and Medicine. Methods Mol Biol. (Methods and Protocols). Vol. 906. Totowa, NJ: Humana Press; 2012. pp. 283-294. DOI: 10.1007/978-1-61779-953-2_22

[58] Carmona-Ribeiro AM. Biomimetic particles in drug and vaccine delivery. Journal of Liposome Research. 2007;17(3-4):165-172

[59] Pereira EM, Kosaka PM, Rosa H, Vieira DB, Kawano Y, Petri DF, et al. Hybrid materials from intermolecular associations between cationic lipid and polymers. The Journal of Physical Chemistry. B. 2008;112(31):9301-9310. DOI: $10.1021 / j p 801297 t$

[60] Hadinoto K, Sundaresan A, Cheow WS. Lipid-polymer hybrid nanoparticles as a new generation therapeutic delivery platform: A review. European Journal of Pharmaceutics and Biopharmaceutics. 2013;85(3 Pt A):427-443.

DOI: 10.1016/j.ejpb.2013.07.002

[61] Miao L, Guo S, Lin CM, Liu Q, Huang L. Nanoformulations for combination or cascade anticancer therapy. Advanced Drug Delivery Reviews. 2017;115:3-22. DOI: 10.1016/j. addr.2017.06.003

[62] Xu X, Xie K, Zhang XQ, Pridgen EM, Park GY, Cui DS, et al. Enhancing tumor cell response to chemotherapy through nanoparticle-mediated codelivery of siRNA and cisplatin prodrug. Proceedings of the National Academy of Sciences of the United States of America. 2013;110(46):18638-18643. DOI: $10.1073 /$ pnas.1303958110

[63] Messerschmidt SK, Musyanovych A, Altvater M, Scheurich P, Pfizenmaier $\mathrm{K}$, Landfester K, et al. Targeted lipidcoated nanoparticles: Delivery of tumor necrosis factor-functionalized particles to tumor cells. Journal of Controlled Release. 2009;137(1):69-77. DOI: 10.1016/j.jconrel.2009.03.010

[64] Carmona-Ribeiro AM. Chapter Eight-Lipid-based biomimetics: General perpectives in drug and vaccines delivery. In: Souto EB, editor. Lipid Nanocarriers in Cancer Diagnosis and Therapy. Shawbury: Smithers; 2011. pp. $189-226$

[65] Petri DFS, Carmona-Ribeiro AM. Biomimetic particles. In: Nalwa HS, editor. Polymeric Nanostructures and Their Applications. Los Angeles: American Scientific Publishers; 2007. pp. $485-530$

[66] Carmona-Ribeiro AM. Biomimetic systems in nanomedicine. In: Torchilin V, editor. Handbook of Nanobiomedical Research. 1st ed. Vol. 4. Singapore: World Scientific; 2014. pp. 401-456. DOI: 10.1142/9789814520652_0063

[67] Bassegoda A, Ivanova K, Ramon E, Tzanov T. Strategies to prevent the occurrence of resistance against antibiotics by using advanced materials. Applied Microbiology and Biotechnology. 2018;102(5):2075-2089. DOI: $10.1007 /$ s00253-018-8776-0 
[68] Pacheco LF, Carmona-Ribeiro AM. Effects of synthetic lipids on solubilization and colloid stability of hydrophobic drugs. Journal of Colloid and Interface Science. 2003;258(1):146-154. DOI: $10.1016 /$ S0021-9797(02)00103-0

[69] Vieira DB, Pacheco LF, CarmonaRibeiro AM. Assembly of a model hydrophobic drug into cationic bilayer fragments. Journal of Colloid and Interface Science. 2006;293(1):240-247. DOI: $10.1016 /$ j.jcis.2005.06.046

[70] Lincopan N, Carmona-

Ribeiro AM. Lipid-covered drug particles: Combined action of dioctadecyldimethylammonium bromide and amphotericin B or miconazole. The Journal of Antimicrobial Chemotherapy. 2006;58(1):66-75. DOI: 10.1093/jac/dkl153

[71] Barbassa L, Mamizuka EM, Carmona-Ribeiro AM. Supramolecular assemblies of rifampicin and cationic bilayers: Preparation, characterization and micobactericidal activity. BMC Biotechnology. 2011;11:40. DOI: 10.1186/1472-6750-11-40

[72] Carrasco LDM, Santos HCAS, Sampaio JLM, Carmona-Ribeiro AM. Self-assembled antibiotic nanoparticles against intracellular bacteria. Drug Delivery Letters. 2017;7:39. DOI: 10.2174/ 2210303107666170203163102

[73] Nantes IL, Correia FM, FaljoniAlario A, Kawanami AE, Ishiki HM, Amaral AT, et al. Nucleotide conformational change induced by cationic bilayers. Archives of Biochemistry and Biophysics. 2003;416(1):25-30. DOI: 10.1016/ S0003-9861(03)00280-7

[74] Rozenfeld JH, Oliveira TR, Lamy MT, Carmona-Ribeiro AM. Interaction of cationic bilayer fragments with a model oligonucleotide. Biochimica et Biophysica Acta. 2011;1808(3):649-655. DOI: 10.1016/j.bbamem.2010.11.036
[75] Carvalho LA, Carmona-Ribeiro AM. Interactions between cationic vesicles and serum proteins. Langmuir. 1998;14(21):6077-6081. DOI: 10.1021/ la980345j

[76] Tsuruta LR, Quintilio W, Costa $\mathrm{MH}$, Carmona-Ribeiro AM. Interactions between cationic liposomes and an antigenic protein: The physical chemistry of the immunoadjuvant action. Journal of Lipid Research. 1997;38(10):2003-2011. Available from: http://www.jlr.org/ content/38/10/2003.long

[77] Sicchierolli SM, Carmona-Ribeiro AM. Biomolecular recognition at phospholipid-covered polystyrene microspheres. The Journal of Physical Chemistry. 1996;100(41):16771-16775. DOI: $10.1021 / j p 961785 r$

[78] Lincopan N, Carmona-Ribeiro AM. Protein assembly onto cationic supported bilayers. Journal of Nanoscience and Nanotechnology. 2009;9(6):3578-3586

[79] Carmona-Ribeiro AM, de Melo Carrasco LD. Cationic antimicrobial polymers and their assemblies. International Journal of Molecular Sciences. 2013;14(5):9906-9946. DOI: 10.3390/ijms14059906

[80] Galvão CN, Sanches LM, Mathiazzi BI, Ribeiro RT, Petri DFS, Carmona-Ribeiro AM. Antimicrobial coatings from hybrid nanoparticles of biocompatible and antimicrobial polymers. International Journal of Molecular Sciences. 2018;19(10):E2965. DOI: $10.3390 /$ ijms19102965

[81] Melo LD, Palombo RR, Petri DF, Bruns M, Pereira EM, Carmona-Ribeiro AM. Structure-activity relationship for quaternary ammonium compounds hybridized with poly (methyl methacrylate). ACS Applied Materials \& Interfaces. 2011;3(6):1933-1939. DOI: 10.1021/am200150t 
[82] Naves AF, Palombo RR, Carrasco LD, Carmona-Ribeiro AM. Antimicrobial particles from emulsion polymerization of methyl methacrylate in the presence of quaternary ammonium surfactants. Langmuir. 2013;29(31):9677-9684.

DOI: $10.1021 / \mathrm{la} 401527 \mathrm{j}$

[83] Sanches LM, Petri DF, de Melo Carrasco LD, Carmona-Ribeiro AM. The antimicrobial activity of free and immobilized poly (diallyl dimethyl ammonium) chloride in nanoparticles of poly (methyl methacrylate). Journal of Nanobiotechnology. 2015;13:58. DOI: 10.1186/s12951-015-0123-3

[84] Campanhã MTN, Mamizuka EM, Carmona-Ribeiro AM. Interactions between cationic vesicles and Candida albicans. The Journal of Physical Chemistry. B. 2001;105(34):8230-8236. DOI: 10.1021/jp003315+

[85] Vieira DB, Carmona-Ribeiro AM. Cationic lipids and surfactants as antifungal agents: Mode of action. The Journal of Antimicrobial Chemotherapy. 2006;58(4):760-767. DOI: $10.1093 /$ jac/ dkl312

[86] Carmona-Ribeiro AM, Carrasco LDM. Fungicidal assemblies and their mode of action. OA Biotechnology. 2013;2(3):25. DOI: 10.13172/-2-3-983

[87] Pacheco LF, Vieira DB, Correia FM, Carmona-Ribeiro AM. Interaction between cationic bilayers and Candida albicans cells. In: Surface and Colloid Science. Progress in Colloid and Polymer Science. Vol. 128. Berlin and Heildelberg: Springer; 2004. pp. 175-177. DOI: $10.1007 /$ b97059

[88] Fait ME, Bakas L, Garrote GL, Morcelle SR, Saparrat MCN. Cationic surfactants as antifungal agents.

Applied Microbiology and Biotechnology. 2019;103(1):97-112. DOI: 10.1007/s00253-018-9467-6
[89] Manolova V, Flace A, Bauer M, Schwarz K, Saudan P, Bachmann MF. Nanoparticles target distinct dendritic cell populations according to their size. European Journal of Immunology. 2008;38(5):1404-1413. DOI: $10.1002 /$ eji.200737984

[90] Blank F, Fytianos K, Seydoux E, Rodriguez-Lorenzo L, Petri-Fink A, von Garnier C, et al. Interaction of biomedical nanoparticles with the pulmonary immune system. Journal of Nanobiotechnology. 2017;15(1):6. DOI: 10.1186/s12951-016-0242-5

[91] Seydoux E, Rodriguez-Lorenzo L, Blom RA, Stumbles PA, PetriFink A, Rothen-Rutishauser BM, et al. Pulmonary delivery of cationic gold nanoparticles boost antigenspecific CD4(+) T cell proliferation. Nanomedicine. 2016;12(7):1815-1826. DOI: 10.1016/j.nano.2016.02.020

[92] Tsuruta LR, Lessa MM, CarmonaRibeiro AM. Effect of particle size on colloid stability of bilayer-covered polystyrene microspheres. Journal of Colloid and Interface Science. 1995;175(2):470-475. DOI: 10.1006/ jcis.1995.1477 


\title{
Cloud Microorganisms, an Interesting Source of Biosurfactants
}

\author{
Pascal Renard, Isabelle Canet, Martine Sancelme, \\ Maria Matulova, Iveta Uhliarikova, Boris Eyheraguibel, \\ Lionel Nauton, Julien Devemy, Mounir Traïkia,
} Patrice Malfreyt and Anne-Marie Delort

\begin{abstract}
A new scientific hypothesis states that biosurfactants from cloud microorganism origin could change the surface tension of aerosols and thus the mode of precipitations. In order to check this hypothesis, our team has screened a collection of 480 microbial strains isolated from cloud waters for the production of biosurfactants and showed that $42 \%$ of these strains were producing such molecules. In the present work, we isolated and identified by LC-MS-MS lipopeptides produced from three strains issued from this screening. Viscosin and massetolide E (cyclic lipopeptides) were produced by Pseudomonas sp. PDD-14b-2, and syringafactins (linear lipopeptides) were produced by Xanthomonas campestris PDD-32b-52 and Pseudomonas syringae $\mathrm{PDD}-32 \mathrm{~b}-74$. The critical micelle concentration (CMC) of these biosurfactants was determined using the pendant drop method. Finally, two approaches of molecular dynamics were used to model the conformation of viscosin and syringafactin $A$ at the water-air interface: one is based on all-atoms simulation (CHARMM force field), while the other one on coarse-grain (CG) simulation (MARTINI force field). To conclude, this work shows how the biodiversity of the cloud microbiota can be explored to search and produce biosurfactants of interest both for atmospheric sciences and also for biotechnological applications.
\end{abstract}

Keywords: cloud, mass spectrometry, biosurfactants, lipopeptides, Pseudomonas, Xanthomonas, modeling

\section{Introduction}

The structure and function of microbial communities in clouds have been studied only very recently. Although clouds are hostile environments (with acidic $\mathrm{pH}$, low temperature, UV exposure, and oxidative medium), it was shown that microorganisms are alive and metabolically active $[1,2]$. Our team was pioneer in isolating and describing microbial strains in cloud water isolated at the summit of the Puy de Dôme mountain, which is referenced as a European site for cloud studies [3-5]. Long-term survey at this site allowed to evaluate concentrations of $10^{5}$ bacteria $\mathrm{mL}^{-1}$ and $10^{4}$ fungi and yeasts $\mathrm{mL}^{-1}$ of cloud water. The most frequently encountered 
genera of cultivable bacteria are Pseudomonas, Sphingomonas, Streptomyces, Rhodococcus, and Bacillus, while Dioszegia, Udeniomyces, and Cryptococcus are dominant genera for cultivable yeasts [5]. Metagenomics and other DNA-based analyses confirmed the predominance of Proteobacteria, Actinobacteria, and Firmicutes [2, 6]. Recent metatranscriptomics data showed that Proteobacteria are the most active in clouds [6].

Microorganisms have long been considered as inert particles traveling in the atmosphere; however, the discovery of their metabolic activity suggested they could play a role in atmospheric chemistry and in the microphysics of clouds $[1,2,7]$.

Concerning atmospheric microphysics, one of the most difficult scientific problems today is to improve the fundamental understanding and prediction of cloud formation in the atmosphere. Recent papers have highlighted the role of surfactants in atmospheric particles, a role predicted by theory 80 years ago but denied by the scientific community for decades $[8,9]$. The group of Barbara Nozière extracted organic compounds from atmospheric aerosols that were able to lower the surface tension $(\sigma)$ under $30 \mathrm{mN} \cdot \mathrm{m}^{-1}$ for concentrations 5 or 6 orders of magnitude lower than those for organic acids [10-14].

These very low values suggested the presence of biosurfactants, and these surfaceactive agents are of microbial origin and are extremely efficient compared to classical surfactants [15-17]. They are amphiphilic with a lipid tail (hydrophobic) and a sugar or peptide moiety (hydrophilic). Although their chemical composition is extremely diverse, they can be classified in two main categories based on their molecular mass $[15,18,19]$ : (1) small biosurfactants $(\mathrm{PM}<1000 \mathrm{amu})$ including glycolipids (rhamnolipids, trehalolipids, sophorolipids etc.) and lipopeptides (viscosin, surfactin, polymyxin, syringomycin etc.) and (2) polymeric structures (PM $10^{6} \mathrm{amu}$ ) such as polysaccharides, proteins, liposaccharides, lipoproteins (alasan, emulsan etc.).

Biosurfactants could affect atmospheric microphysics by modifying cloud condensation nuclei (CCN) activation. Owing to their exceptional scope in reducing surface tension, these surface-active compounds are thus likely to enhance the propensity of the aerosols to form clouds, as the activation of particles into cloud droplets depends on surface tension according to Köhler's theory [20].

The discovery of the presence of biosurfactants on aerosols raised a new scientific hypothesis: could these biosurfactants be produced by airborne microorganisms? Traditionally, biosurfactant-producing microorganisms were mainly isolated in environments such as soils, seawaters, and sediments contaminated or not by petroleum products [21-24]. Biosurfactants producers can also be isolated from natural sources including fruits, leaves, honey, sugarcane, insects, marine sponges etc. [24]. More recently, extreme environments were described as sources of biosurfactants, microbial producers were isolated from desert and arid soils or from the cryosphere (polar soils and lakes) [24, 25]. The first report concerning the atmospheric environment was made by Ahern [26]. This team showed that 70 fluorescent Pseudomonas strains isolated from cloud and rain waters in Scotland were producing biosurfactants; among them, 43 isolates were high producers. More recently, our group screened 480 microbial strains isolated from cloud water collected at the Puy de Dôme station [27]. This microbial collection was composed mainly of Gammaproteobacteria (23.3\%), with a majority of Pseudomonas; Alphaproteobacteria (19.8\%), with a majority of Sphingomonas; Actinobacteria (24.2\%); and Basidiomycota (19.6\%). Using the pending drop method, we measured the decrease of the surface tension of water droplets (12 $\mu \mathrm{L}$ in volume) induced by the addition of crude culture medium of the different strains. Up to $41 \%$ of the tested strains were producing biosurfactants ( $\sigma \leq 55$ $\mathrm{mN} . \mathrm{m}^{-1}$ ), $7 \%$ of them (Pseudomonas and Xanthomonas strains) were very active producers $\left(\sigma \leq 30 \mathrm{mN} . \mathrm{m}^{-1}\right)$. 
These results show that the biodiversity present in clouds and rain can be a very interesting, still unexplored, source of biosurfactants. As atmospheric environments are cold habitats, these results confirm that cold-adapted organisms are good candidates to produce biosurfactants [25].

Biosurfactants may constitute very valuable compounds of industrial interest as they are promising substitutes for synthetic surfactants with higher biodegradability and lower toxicity. They reach such low surface tensions, even for trace concentrations. Typical desirable properties include solubility enhancement, surface tension reduction, and low critical micelle concentrations, higher foaming, higher selectivity, and specific gravity at extreme temperature, $\mathrm{pH}$, and salinity. In terms of economics, biosurfactants can be synthetized from a renewable stock; however, large-scale production remains challenging [28, 29]. The enormous diversity of biosurfactants also makes them an interesting group of materials for application in many areas such as agriculture, public health, food, health care, medicine, cleaning, textiles, nanotechnologies, waste utilization, and environmental pollution control such as in degradation of hydrocarbons present in soil or extraction of heavy metals [15, 16, 18, 19, 28, 30-35].

Considering the potential industrial interest of biosurfactants, we decided to go further in investigating our unique collection of microbial strains isolated from clouds as a source of biosurfactants. The objective of this work was thus to isolate biosurfactants produced by some of the best producers as determined from our previous screening in order to study their structure and their critical micelle concentration (CMC) properties. In addition, we were interested in modeling their conformation at the water-air interface to understand better their behavior in making cloud droplets. To reach these goals, we selected three strains isolated from clouds (Pseudomonas sp. PDD-14b-2, Xanthomonas campestris PDD-32b-52, and Pseudomonas syringae PDD-32b-74) that were high biosurfactant producers [27].

\section{Materials and methods}

\subsection{Production and purification of biosurfactants}

Pseudomonas sp. PDD-14b-2 (GenBank accession number of the 16S rRNA gene sequence: DQ512788), Xanthomonas campestris PDD-32b-52 (HQ256850), and Pseudomonas syringae PDD-32b-74 (HQ256872) were isolated from cloud water sampled at the Puy de Dôme summit (1465 m) [5]. The isolates obtained in pure cultures $\left(\mathrm{R} 2 \mathrm{~A}, 17^{\circ} \mathrm{C}\right)$ were stored in $10 \%(\mathrm{v} / \mathrm{v})$ glycerol at $-80^{\circ} \mathrm{C}$.

For each strain, preculture was performed from the glycerol stocks in $100 \mathrm{~mL}$ of a R2A growth medium [36] at $17^{\circ} \mathrm{C}$. After 3 days, the inoculum was grown in 10 Erlenmeyer flasks containing $200 \mathrm{~mL}$ of R2A medium ( $2 \% \mathrm{v} / \mathrm{v}$ plating). Cultures were incubated at $17^{\circ} \mathrm{C}$ at $200 \mathrm{rpm}$. The growth was monitored through measurement of optical density and $\mathrm{pH}$, the production of biosurfactants by measurement of the surface tension of the supernatant. After 3-5 days, cultures were centrifuged (8000 rpm) at $4^{\circ} \mathrm{C}$ for $15 \mathrm{~min}$. Supernatants were combined $(1.8 \mathrm{~L})$ and $\mathrm{pH}$ adjusted to 6.1.

Concentration of biosurfactants was achieved using a chromatographic method initially described by Reiling [37] for rhamnolipids, through adsorption chromatography on an Amberlite XAD2 (Sigma-Aldrich) column [38]. After equilibration to $\mathrm{pH} 6.1$ using $0.1 \mathrm{M}$ phosphate buffer, supernatant was passed through the resin $\left(300 \mathrm{~mL} . \mathrm{h}^{-1}\right.$ outflow) until saturation of the resin occurred (monitored by measuring the surface tension of the column outlet). The column was then washed by three volumes of distilled water before eluting the biosurfactants with three volumes of methanol. The process is repeated until complete treatment of the supernatant. Methanol fractions are collected and evaporated to dryness using a rotary evaporator. 
Purification was then undergone by flash chromatography (puriFlash ${ }^{\circledR}$ ) on a Chromabond ${ }^{\circledR}$ C18 column. Gradient elution was applied (water (A), acetonitrile (B), 5-95\% B in $30 \mathrm{~min}$.). Fractions ( $25 \mathrm{~mL}$ ) were collected at a flow rate of $12.5 \mathrm{~mL}$ per minute over a period of $40 \mathrm{~min}$. UV-detection of biosurfactants was made simultaneously at 219 and $237 \mathrm{~nm}$.

\subsection{Structure identification by LC-MS/MS}

Identification of biosurfactants was performed using an ultra-high-resolution mass spectrometer (LTQ-Orbitrap ${ }^{\mathrm{TM}}$, Thermo Scientific) coupled to an electrospray ionization (ESI) source.

Samples were directly infused into the ESI source. The mobile phases consisted in (A) $0.1 \%$ formic acid in water (Fluka, 98\%) and (B) acetonitrile (CAN; Optima LC-MS, Fischer). The gradient elution was performed at a flow rate of $5 \mu \mathrm{L} \mathrm{min}{ }^{-1}$ using $5-95 \%$ of B within $11 \mathrm{~min}$. The sample injection volume was $10 \mu \mathrm{L}$. Each sample was measured in the negative and positive ionization modes, with the following optimized settings: source voltage $4 \mathrm{kV}$ and capillary temperature $350^{\circ} \mathrm{C}$, in the positive mode. Transient acquisition time was set to $1 \mathrm{~s}$, which corresponds to a nominal resolution of $3 \mathrm{ppm}$, and to observe individual peaks resolution (FWHM) typically better than 70,000 (m/z 200). Identification was performed using MS/MS fragmentation to confirm the structure of the products. MS/MS experiments were carried out with a collision energy of $5 \mathrm{eV}$.

Data were collected from $\mathrm{m} / \mathrm{z} 50$ to 1200 in the positive and negative ionization modes. Elemental compositions from exact mass measurement were assigned using Xcalibur ${ }^{\circledR}$ software (Thermo Scientific). The data processing was done through the following steps: (1) the assignment of $\mathrm{m} / \mathrm{z}$ for each spectrum signal, (2) internal calibration of spectrum by homologs biosurfactant using the most intense class, (3) assignment of molecular formula for each signal by comparing experimental $\mathrm{m} / \mathrm{z}$ with a theoretical $\mathrm{m} / \mathrm{z}$ database for possible biosurfactant, and (5) solving of dubieties on molecular formula assignments by confirming the isotopic ratio.

\subsection{Surface tension measurements}

Samples were centrifuged $(10,480 \mathrm{~g} / 3 \mathrm{~min})$ just prior to surface tension measurements. All surface tension measurements were performed using the pendant drop method with an OCA 15 Pro tensiometer (Data Physics, Germany). The camera analyzes the pendant drop profile of the crude extract. A dosing needle with a 1.65-mm outside diameter was used, producing drops of $12 \mu \mathrm{L}$. The software fits this latter measurement to the Young-Laplace equation and averages out surface tension from all measurements [39]. The measurements were obtained at $295 \mathrm{~K}$ every second. The tensiometer was calibrated using Milli-Q water. The uncertainty of the instrument was $\pm 0.01 \mathrm{mN} \cdot \mathrm{m}^{-1}$. Each dynamic surface tension curve was measured three times for the most efficient biosurfactant-producing microorganisms, and the measurements displayed $\pm 10 \%$ variation. These dynamic surface tension measurements lasted until the equilibrium region was reached (maximum $30 \mathrm{~min}$ [27]). Along with the surface tension, each measurement also provided real-time monitoring of the droplet volume, facilitating an assessment of evaporation. No significant evaporation $(<5 \%)$ was observed during the experiments [27].

\subsection{Modeling}

Molecular dynamics based on all-atoms simulation was performed using NAMD programs with CUDA gpu acceleration designed especially for large 
biomolecular systems. The force field used is CHARMM with CHARMM22 parameter files. All air/water interface models were constructed using VMD as molecular visualization program. The water used in our solvent boxes is TIP3 water. Each model undergoes the same treatment: a first phase of minimization, followed by a canonical dynamics for reaching the set temperature of $298 \mathrm{~K}$, and a second phase of pressure equilibration at $1 \mathrm{~atm}$ in isothermal-isobaric ensemble followed by a third phase of production in the same isothermal-isobaric ensemble for a duration of 20 nanoseconds.

The coarse-grain (CG) molecular dynamics were performed by using the MARTINI force field $[1,2]$ at $300 \mathrm{~K}$ in the NVT statistical ensemble. The liquidvapor interfaces were modeled using a parallelepipedic box of dimensions $\mathrm{Lx}=60 \AA$, $\mathrm{Ly}=60 \AA$, and $\mathrm{Lz}=570 \AA$. The total number of CG water molecules was fixed to 6000 and the number of surfactants was varied from 4 to 32 for each interface. A CG water molecule corresponds to four water molecules. The equilibration time was set to $110 \mathrm{~ns}$ whereas the thermodynamics and structural properties were averaged during the acquisition phase over $200 \mathrm{~ns}$.

\section{Results and discussion}

\subsection{Production and purification of biosurfactants}

The 3 strains Pseudomonas sp. PDD-14b-2, Xanthomonas campestris PDD-32b-52, and Pseudomonas syringae PDD-32b-74 were selected from the screening of 480 strains isolated from cloud waters for their effectiveness in reducing surface tension [27]. They all belong to the class of Gammaproteobacteria and are representative of a genus very commonly encountered in cloud water samples [5].

For the production of biosurfactants, the bacterial cultures were carried out in R2A medium, a relatively poor but diversified medium in carbon and nitrogen sources, initially developed to isolate microorganisms from tap water. We choose this medium, without supplementing with compounds known to favor the production of biosurfactants, as it is representative of the cloud environment in its composition.

On each culture, the simultaneous kinetic monitoring of the bacterial growth and the decrease of the surface tension, using as reference value that of the medium R2A (62-64 mN.m ${ }^{-1}$ ), allowed us to stop the cultures for an optimal production of biosurfactants.

Extraction of the lipopeptides was carried out by adapting an adsorption column chromatography method (using Amberlite) initially described by Reiling [37] for the concentration of rhamnolipids. The surface tension of the crude supernatants was $25 \mathrm{mN} . \mathrm{m}^{-1}$. The adsorption of the biosurfactants was easily monitored by the measurement of the surface tension of the aqueous fractions at the column outlet, and the saturation of the column was detected when the surface tension reached a value greater than $40 \mathrm{mN} \cdot \mathrm{m}^{-1}$. The biosurfactants were then eluted with methanol. One advantage of the technique is that if the entire supernatant cannot be processed at one time, the operation is repeated until it is fully treated. We have thus shown that the use of adsorption column chromatography is particularly suitable for the extraction of lipopeptides. In addition, compared to conventional methods of extraction using organic solvents (preceded or not by acid precipitation) [40], this method effectively eliminates the culture medium nutrients present in the supernatant and leads to a preconcentration of biosurfactants which then allows easier purification by reversed phase chromatography. 


\subsection{Identification and surfactant properties of viscosin and massetolide $\mathrm{E}$ produced by Pseudomonas sp. PDD-14b-2}

Two biosurfactants issued from the culture of a cloud bacterium Pseudomonas sp. PDD-14b-2 were purified using an Amberlite column and a puriFlash ${ }^{\circledR}$ system. The structure of these biosurfactants was identified as that of cyclic lipopeptides (viscosin and massetolide E) using high-resolution LC-MS/MS. Figure 1A presents the ESI-MS-MS spectrum of viscosin, the details of the fragmentation of this molecule are shown in Figure $\mathbf{1 B}$ and $\mathbf{C}$.

Viscosin gave a $\left([\mathrm{M}+\mathrm{H}]^{+}\right)$protonated molecule at $\mathrm{m} / \mathrm{z} 1126.699$ (theoretical $\mathrm{m} / \mathrm{z}$ 1126.697) appropriate for a molecular formula of $\mathrm{C}_{54} \mathrm{H}_{95} \mathrm{~N}_{9} \mathrm{O}_{16}$ (monoisotopic mass is $1125.69 \mathrm{~g} \cdot \mathrm{mol}^{-1}$ ).

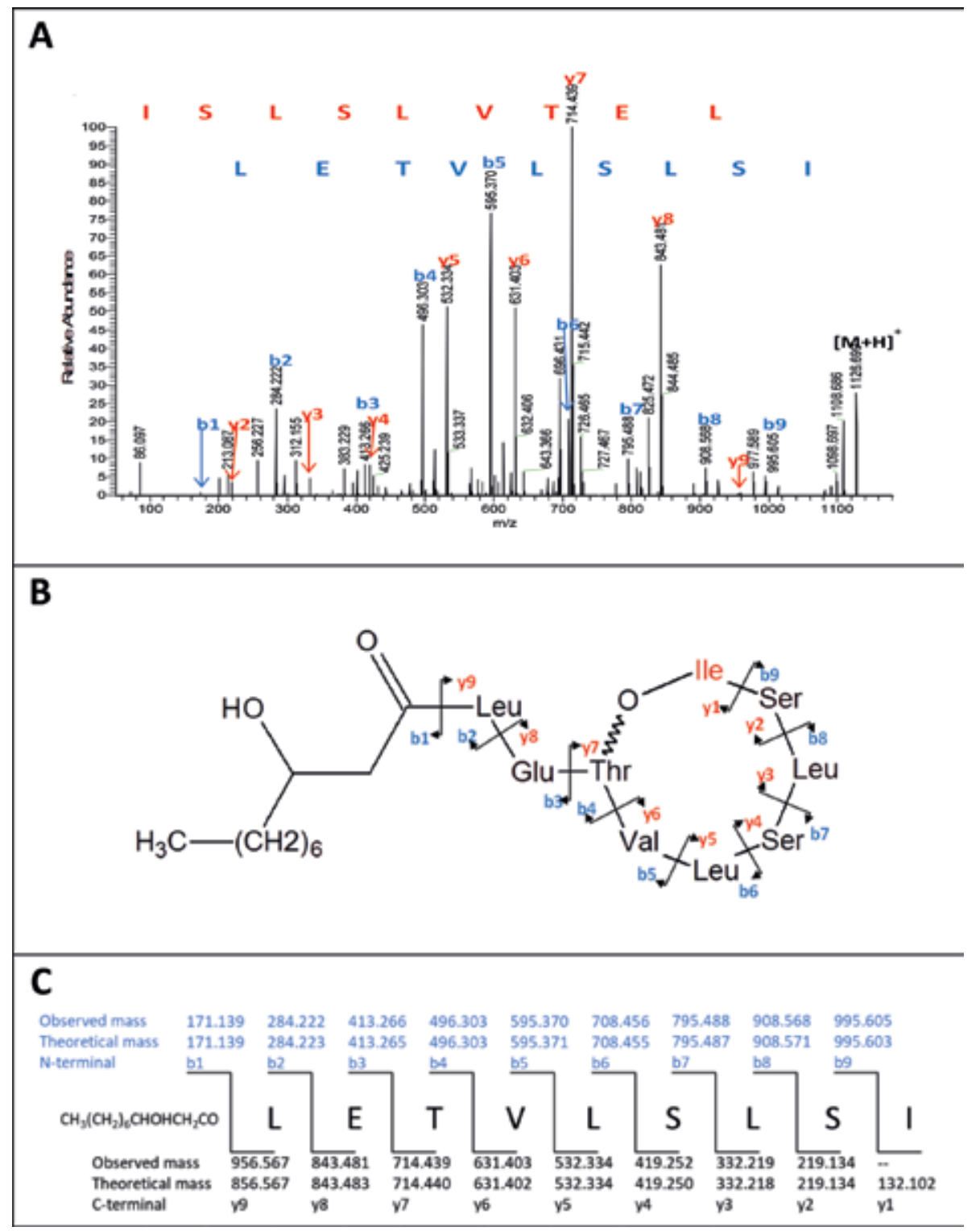

Figure 1.

(A) ESI-MS/MS (collision-induced dissociation) spectrum of parent ion of viscosin ( $m / z$ 1126.699),

(B) Chemical structure (fragments) for viscosin, (C) Identification of the fragments of viscosin. The Y1 fragment could be either isoleucine (I) or leucine $(L)$. 


\section{A}

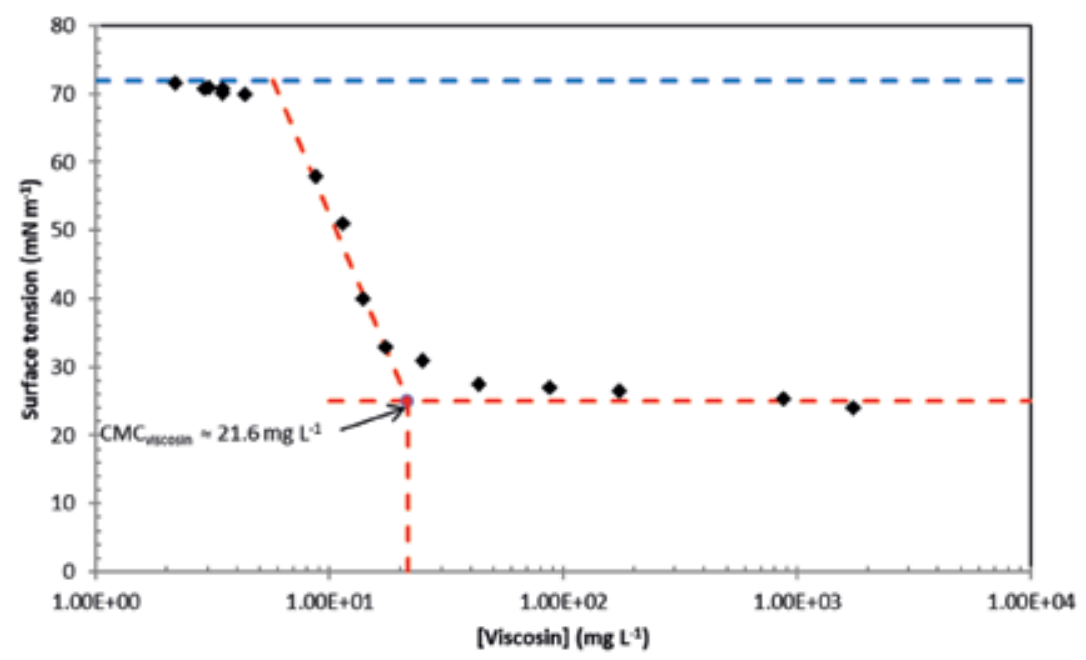

B

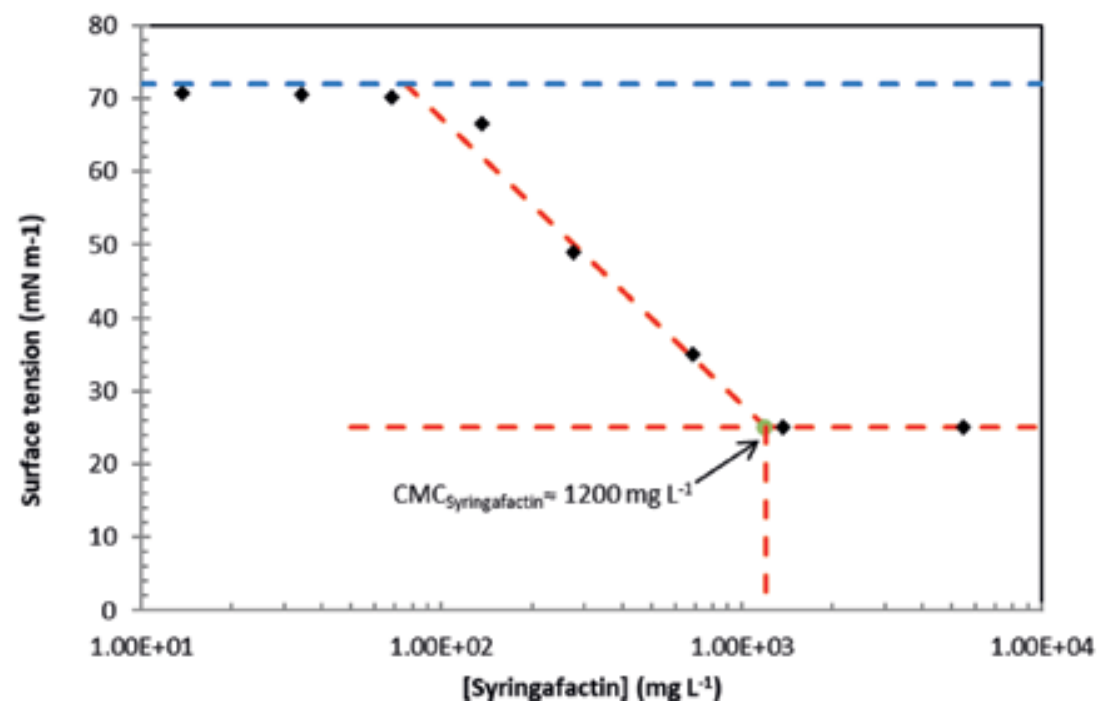

Figure 2.

Determination of the surface tension curve and CMC value of biosurfactants by the pendant drop technique. The red dot represents the initial crude extracts (consisting of the supernatants of the pure cultures). The black dots at lower concentrations are those obtained from successive dilutions. The blue dashed line represents the value for pure water, and red dashed lines illustrate the graphical determination of the CMC. (A) Viscosin $C M C=25 \mathrm{mN} \cdot \mathrm{m}^{-1}$ at $21.6 \mathrm{mg} \cdot \mathrm{L}^{-1} ;$ (B) Syringafactin B/C CMC $=25 \mathrm{mN} \cdot \mathrm{m}^{-1}$ at $1.2 \mathrm{gL} \mathrm{L}^{-1}$.

In the same way and with the same precision (observed mass: $\mathrm{m} / \mathrm{z} 1112.684$; theoretical mass: $\mathrm{m} / \mathrm{z} 1112.682)$, we identified the massetolide $\mathrm{E}\left(\mathrm{C}_{53} \mathrm{H}_{93} \mathrm{~N}_{9} \mathrm{O}_{16}\right)$ whose structure is rather similar to that of viscosin, the last amino acid fragment is a valine instead of a leucine.

These high-resolution MS data are consistent with those obtained by Gerard [41] who isolated and identified massetolides $\mathrm{A}-\mathrm{H}$ and viscosin from two Pseudomonas strains isolated from marine environment.

The synthesis of viscosin has been reported by other Pseudomonas strains including $P$. syringae, $P$. tolaasii, $P$. fuscovaginae, $P$. corrugate, $P$. fluorescens, $P$. libanensis, and $P$. putida $[16,42-45]$. Massetolides whose structures are very closely 
related to those of viscosin are less frequently described; massetolide A was produced by P. fluorescens SS101 [46].

We measured the surface tension of the isolated viscosin and determined its CMC using the pendant drop method (Figure 2A). This CMC is extremely low (21.6 mg. $\mathrm{L}^{-1}$ for a minimum surface tension of $25 \mathrm{mN} . \mathrm{m}^{-1}$ ) showing that this molecule has very strong biosurfactant properties. Very few authors measured the CMC of viscosin; Saini [42] found a value of $54 \mathrm{mg} . \mathrm{L}^{-1}$ for a minimum surface tension of $27.5 \mathrm{mN} . \mathrm{m}^{-1}$ for viscosin isolated from $P$. libanensis $\mathrm{M} 9$ while de Bruijn [46] measured a CMC of $10-15 \mathrm{mg} . \mathrm{L}^{-1}$ for a surface tension around $30 \mathrm{mN} . \mathrm{m}^{-1}$ for viscosin isolated from $P$. fluorescens SBW25. These CMC values are within the same range of order of our results for the case of Pseudomonas $s p$. PDD-14b-2.

Viscosin is one of the most effective biosurfactants among the cyclic lipopeptides of pseudomonads together with arthrofactin (minimum surface tension of $24 \mathrm{mN} . \mathrm{m}^{-1}$, CMC of $13.5 \mathrm{mg} . \mathrm{L}^{-1}$ ) [45]. In spite of its very low CMC, viscosin has not yet been produced and exploited at an industrial scale. Some studies report viscosin as a surface-active, bioemulsifier with anticancer properties and massetolide as a biocontrol agent [16]. Raaijmakers [22] pointed out natural functions of viscosin and massetolide A including their role in mobility and biofilm formation.

\subsection{Identification and surfactant properties of syringafactins produced by Xanthomonas campestris PDD-32b-52 and by Pseudomonas syringae PDD-32b-74}

Using the same technique as described before, we produced and purified syringafactins (linear lipopeptides) by cultivation of two strains isolated from clouds (Xanthomonas campestris PDD-32b-52 and Pseudomonas syringae PDD-32b-74). Their amino acid sequence was identified by LC-MS-MS (Figure 3) using the same methodology for fragment assignments as described for viscosin (Figure 3B and $\mathbf{C}$ ). Six types of syringafactins (A, B, C, D, E, and F) could be identified; syringafactins $\mathrm{B} / \mathrm{C}$ and $\mathrm{E} / \mathrm{F}$ were isolated as mixtures.

The ESI-MS-MS data obtained in this work and used to assign the syringafactin structures are fully consistent with those initially published by Berti [47]. Syringafactins are the only linear lipopeptides described up to now and are poorly documented. They were first isolated from P. syringae pv. tomato DC3000 [47] and more recently from $P$. syringae pv. syringae B728a $5 \mathrm{~b}$ [48]. We show here that they can be produced by another strain of Pseudomonas syringae (P. syringae PDD-32b-74) and also by a strain of Xanthomonas (X. campestris PDD-32b-52).

The measured CMC of syringafactin $\mathrm{B} / \mathrm{C}$ was $1.2 \mathrm{~g} . \mathrm{L}^{-1}$ for a minimum surface tension of $25 \mathrm{nM} \cdot \mathrm{m}^{-1}$ (Figure $2 \mathrm{~B}$ ) proving the surfactant properties of this molecule. To our knowledge, this is the first report of a CMC value for this compound. This CMC is much higher than that of viscosin and closer to that of syringomycin, a cyclic lipopeptide, produced by Pseudomonas syringae B301D (CMC of 1.25. mg.L $\mathrm{L}^{-1}$ and minimum surface tension of $33 \mathrm{mN} \cdot \mathrm{m}^{-1}$ ) [45].

Biotechnological applications of syringafactins are not described yet, only natural functions related to their secretions by Pseudomonas syringae isolates present on the phyllosphere are described (enhancement of bacterial fitness on leaf surfaces during fluctuating humidity, swarming motility) [47, 48].

\subsection{Modeling the conformation of biosurfactants at the water-air interface}

Both descriptions can be used to simulate interfacial systems: an atomistic description that performs very well for relatively small and simple systems and a 
A
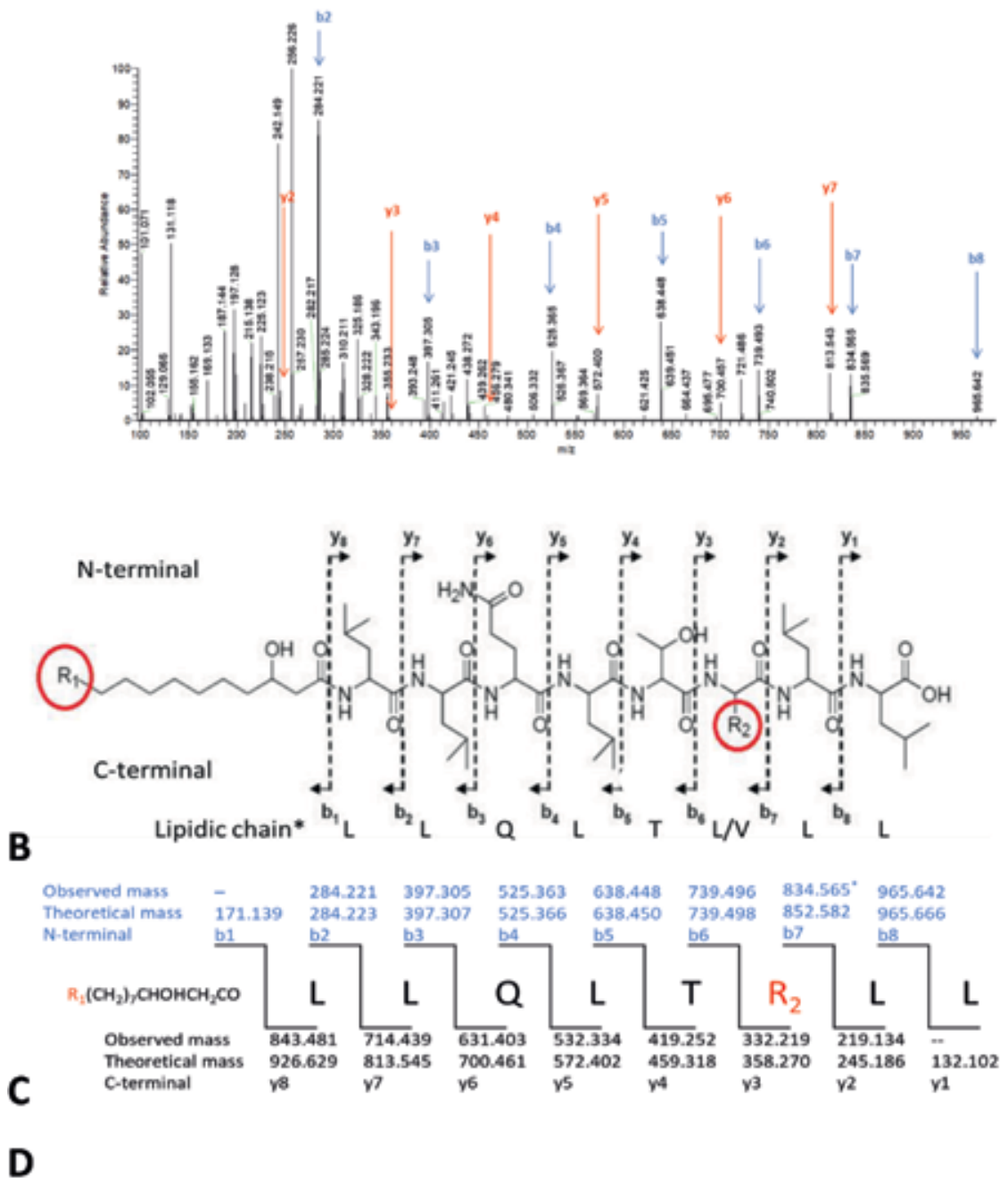

$\begin{array}{llll}\text { Syringafactin A } & \text { (R1: H / R2: Val) } & \mathrm{C}_{54} \mathrm{H}_{99} \mathrm{O}_{13} \mathrm{~N} 9 & 1081.736 \mathrm{amu} \\ \text { Syringafactin B/C } & \text { (R1: H / R2: Leu) } & \mathrm{C}_{55} \mathrm{H}_{101} \mathrm{O}_{13} \mathrm{~N} 9 & 1095.752 \mathrm{amu} \\ \text { Syringafactin D } & \left(\mathrm{R} 1: \mathrm{CH}_{3} \mathrm{CH}_{2} / \mathrm{R2}: \text { Val) }\right. & \mathrm{C}_{56} \mathrm{H}_{103} \mathrm{O}_{13} \mathrm{~N}_{9} & 1109.768 \mathrm{amu} \\ \text { Syringafactin E/F } & \left(\mathrm{R} 1: \mathrm{CH}_{3} \mathrm{CH}_{2} / \mathrm{R2} \text { : Val) }\right. & \mathrm{C}_{57} \mathrm{H}_{105} \mathrm{O}_{13} \mathrm{~N}_{9} & 1123.783 \mathrm{amu}\end{array}$

Figure 3.

(A) ESI-MS/MS (collision-induced dissociation) spectrum of parent ion of syringafactin $B / C(\mathrm{~m} / z$ 1095.752),

(B) Chemical structure (Fragments) for syringafactin, $(C)$ MS/MS fragmentation for the syringafactin $B / C$ with $R_{1}: H$ and $R_{2}:$ Leu (b7 fragment is dehydrated), (D) Formula and exact masses of the different syringafactins.

CG model that is designed for complex interfacial systems involving surfactants for example. Nevertheless, these two descriptions may even be complementary. Indeed, the CG model can be built from the configurations obtained at the atomistic level through a bottom-up approach.

Figure 4A shows the structure of viscosin at the water-air interface with the distribution of the hydrophobic and hydrophilic zones. Figure 4B presents the density 
A

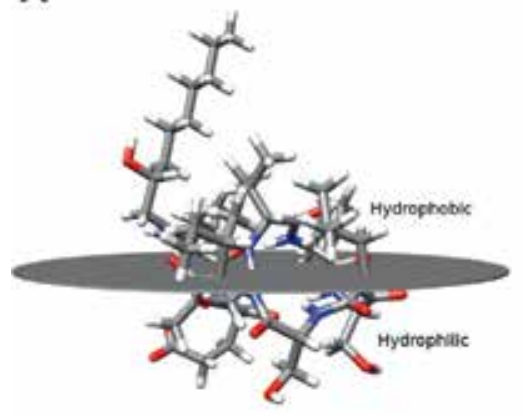

B

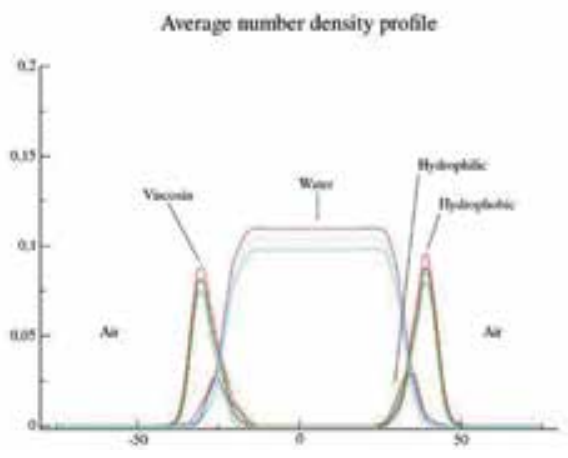

Figure 4.

(A) Structure of viscosin. (B) Viscosin at the water-air interface in a water box using all-atoms simulation (CHARMM force field).
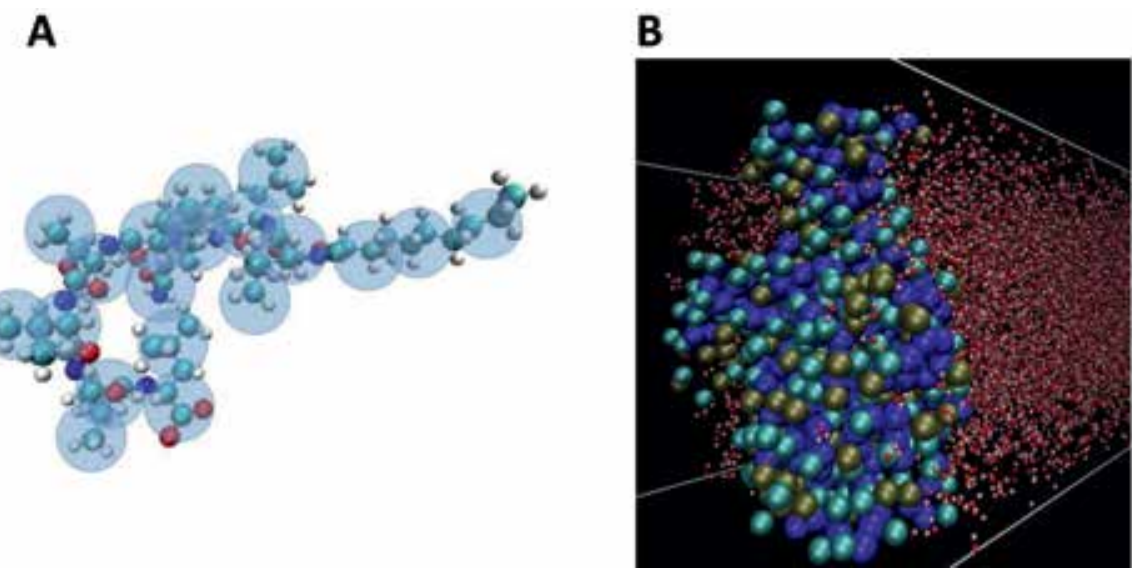

Figure 5.

(A) CG structure of syringafactin A represented. (B) Typical configuration of a liquid-vapor water interface with 32 surfactants at each interface.

profiles of the water box containing viscosin. These profiles were obtained by running a trajectory over $20 \mathrm{~ns}$ and establish a bidimensional structure of the biosurfactant at the water-air interface. The hydrophobic parts defined by the leucine $(\mathrm{L})$; valine $(\mathrm{V})$; isoleucine (I); and alanine, cysteine and glycine (ACG) amino acids of the surfactant populate the side of the interfacial region toward the vapor phase. The hydrophilic parts defined by the group of glutamic acid (E) and serine (S) amino acids are rather located at the interface at the position of the Gibbs dividing plane. The density profiles have been calculated by using atomistic models with 30 surfactant molecules at each interface. We also show that the liquid-water region is quite well developed over a region of $40 \AA$. This is a necessary condition to simulate the behavior of surfactants at least at the atomistic level.

These atomistic simulations take a very long time to equilibrate the interfacial region.

It is well known that the use atomistic force field models is problematic for simulating complex liquid-vapor interfacial systems with surfactants that relax over time and length scales inaccessible for these atomistic descriptions. An alternative is to simplify the model by using a CG description $[49,50]$ for which the key element called a bead represents several atoms or molecules. By using these CG models [51-53], we can improve the description of the systems by using larger system sizes. The modeling of the interfacial systems with surfactants can then be conducted by CG models [51-53]. Figure 5A shows the CG representation of syringafactin A and 


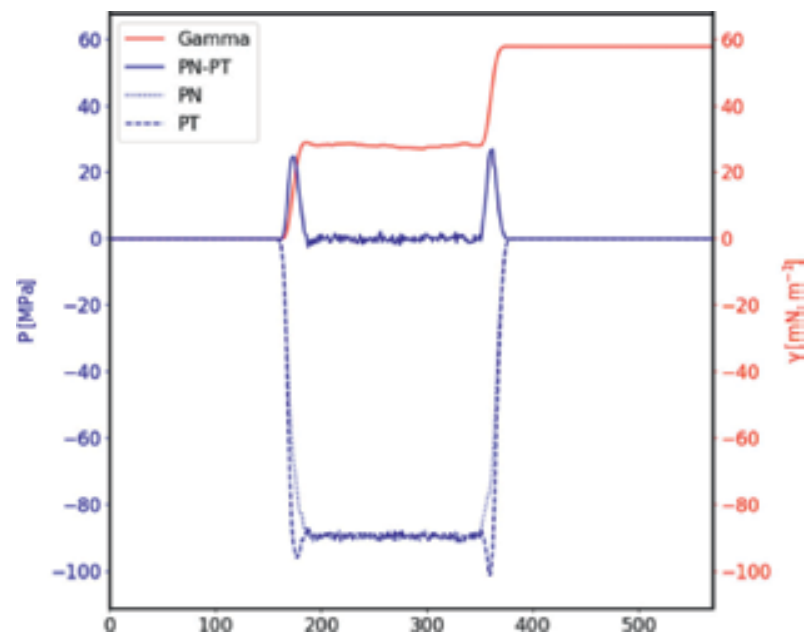

Figure 6.

Profiles of the normal $P_{N}(z)(M P a)$ and tangential $P_{T}(z)(M P a)$ components of the pressure tensor, the difference $\left(P_{N}(z)-P_{T}(z)\right)$ (left axis) and the integral $\gamma(z)$ (right axis) as a function of the $z$-axis (direction normal to the interface). These profiles are calculated in the liquid-vapor interface of water with four surfactants at each interface.

Figure 5B represents an equilibrated liquid-vapor water interface with 32 biosurfactants in the interfacial region.

One of the key properties in the modeling of the liquid-vapor systems is the interfacial tension. It is now well known that the calculation of this property is under control at the atomistic level [54-57]. It is far from being the same for the CG simulations. Indeed, an accurate calculation of the interfacial tension requires to check that the mechanical equilibrium of the CG liquid-vapor equilibrium is respected. Figure 6 shows the profiles of the normal $\left(\mathrm{P}_{\mathrm{N}}\right)$ and tangential $\left(\mathrm{P}_{\mathrm{T}}\right)$ components of the pressure tensor along the direction normal to the interface calculated in the liquid-vapor interface of water with four surfactants at each interface. The profile of the difference $\left(\mathrm{P}_{\mathrm{N}}-\mathrm{P}_{\mathrm{T}}\right)$ exhibits two peaks at both interfaces and no contribution in the water bulk liquid and vapor phases. $\gamma(z)=\frac{1}{2} \int_{0}^{L z}\left(P_{N}(z)-P_{T}(z)\right) d z$ is the local interfacial tension along the direction normal to the interface. As expected from mechanical equilibrium and observed in Figure 6 (blue curve), this profile is flat in the bulk phases with two symmetric contributions at both interfaces. The resulting interfacial tension is about $60 \mathrm{mN} . \mathrm{m}^{-1}$ and does not deviate very much from experiments. Whereas the prediction of the surface tension, calculated from atomistic simulations, is quantitative, it is still subject to some adjustments due to the CG nature of the interactions. It means that the CG model must be calibrated on this property to predict in the future both the interfacial tension and its dependence on the concentration of surfactants [51]. Indeed, recent studies [52,53] show that the degree of coarse-graining impacts on the description of the interface. A good reproduction of the interfacial tension requires a new parametrization of the CG model by considering the interfacial tension in the experimental database.

Nevertheless, the use of CG models has the advantage of providing very wellequilibrated interfacial regions. Figure 7 shows the density profiles along the z-axis for the liquid-vapor interface of water with both 4 and 32 syringafactin molecules at each interface. We observe that the surfactant molecules populate the interfaces with sharp peaks at weak concentrations (Figure 7a). At strong concentrations, we observe that the thickness of the interface increases. In any case, the interfacial region is well recovered by surfactants with no preferential coverage between the lipid and protein parts of the syringafactin molecule. We only observe a slight increase of coverage of the lipid part on the vapor side. 

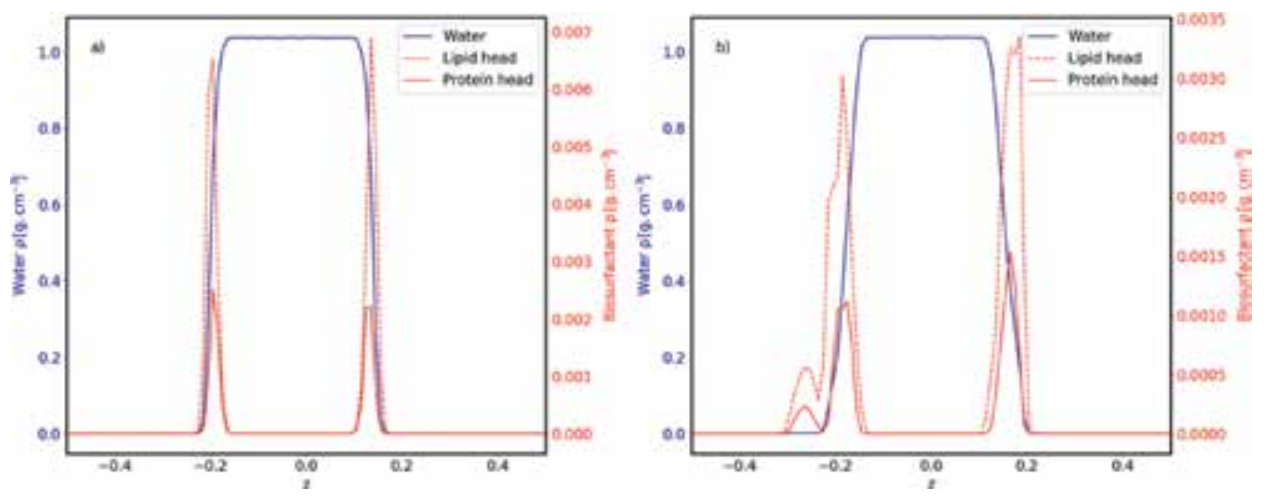

Figure 7.

Density distributions of the water and different parts of the syringafactin molecules at two surfactant concentrations: (a) 4 surfactant molecules and (b) 32 surfactant molecules at each interface. The lipid head is represented by the first three beads of the lipid chain whereas the protein part is represented by a typical bead of this part.

On this aspect of modeling complex interfacial systems, we can conclude that the development of CG models will open the way to new force fields capable of quantitatively predicting the surface tension and main properties such as the CMC. The prediction of the CMC, already operational for some CG models [51], will require additional adjustments for new molecules with various intramolecular interactions. The development of CG force fields using mesoscale simulation methods [58-60] is an active area of research. Different methodologies coexist to develop these CG interactions: a bottom-up approach consisting in deriving the force field from atomistic simulations and a top-down approach aiming to build the parameters of the model from mapping onto macroscopic properties such as the interfacial tension.

\section{Conclusions}

This work is the first report of a detailed study of biosurfactants produced by Pseudomonas and Xanthomonas strains isolated from cloud samples. We have used a convenient method to purify these compounds based on adsorption on Amberlite coupled with a puriFlash ${ }^{\circledR}$ chromatographic technique; the different steps were monitored using the pendant drop method. High-resolution LC-MS-MS allowed assigning unambiguously the structure of viscosin, massetolide $\mathrm{E}$, and different syringafactins. The measurements of CMC of viscosin and syringafactin showed that viscosin is a particularly powerful biosurfactant. Finally, two approaches of molecular dynamics were used to model the conformation of these biosurfactants at the water-air interface: an atomistic description for viscosin (CHARMM force field) and a CG model for syringafactin A (MARTINI force field). This last approach is particularly original and promising. To our knowledge, these studies constitute the first modeling of interfacial properties of such complex biosurfactants.

In addition to fundamental knowledge of biosurfactant properties, this work shows that cloud microorganisms can provide an unexplored source of biosurfactants. Rather few strains, mainly Pseudomonas, were shown to produce visco$\sin$, massetolides, and syringafactins, and two new isolates from this genus are described here. We report here the first production of syringafactins by a strain of Xanthomonas. Considering that more than 30 strains of our microbial collection isolated from clouds were very active biosurfactant producers $\left(\sigma \leq 30 \mathrm{mN} . \mathrm{m}^{-1}\right)$ [27], further investigation is very promising to isolate and study other unusual or even new biosurfactants. 


\section{Acknowledgements}

This work was funded by the French-USA program ANR-NSF SONATA and the French-Slovak Program Stefanik $N^{\circ} 35588 Z$ Z.

\section{Conflict of interest}

The authors declare no conflict of interest.

\section{Author details}

Pascal Renard ${ }^{1}$, Isabelle Canet ${ }^{1}$, Martine Sancelme ${ }^{1}$, Maria Matulova ${ }^{2}$, Iveta Uhliarikova ${ }^{2}$, Boris Eyheraguibel ${ }^{1}$, Lionel Nauton ${ }^{1}$, Julien Devemy ${ }^{1}$, Mounir Traïkia ${ }^{1}$, Patrice Malfreyt ${ }^{1}$ and Anne-Marie Delort ${ }^{1 *}$

1 Université Clermont Auvergne, CNRS, Sigma-Clermont, Institut de Chimie de Clermont-Ferrand, Clermont-Ferrand, France

2 Slovak Academy of Sciences, Bratislava, Slovakia

*Address all correspondence to: a-marie.delort@uca.fr

\section{IntechOpen}

(C) 2019 The Author(s). Licensee IntechOpen. This chapter is distributed under the terms of the Creative Commons Attribution License (http://creativecommons.org/licenses/ by/3.0), which permits unrestricted use, distribution, and reproduction in any medium, provided the original work is properly cited. (cc) BY 


\section{References}

[1] Delort A-M, Vaïtilingom M, Amato P, Sancelme M, Parazols M, Mailhot G, et al. A short overview of the microbial population in clouds: Potential roles in atmospheric chemistry and nucleation processes. Atmospheric Research. 2010;98(2):249-260

[2] Hu W, Niu H, Murata K, Wu Z, Hu M, Kojima T, et al. Bacteria in atmospheric waters: Detection, characteristics and implications. Atmospheric Environment. 2018;179:201-221

[3] Amato P, Ménager M, Sancelme M, Laj P, Mailhot G, Delort A-M. Microbial population in cloud water at the Puy de Dôme: Implications for the chemistry of clouds. Atmospheric Environment. 2005;39(22):4143-4153

[4] Amato P, Parazols M, Sancelme M, Laj P, Mailhot G, Delort A-M.

Microorganisms isolated from the water phase of tropospheric clouds at the Puy de Dôme: Major groups and growth abilities at low temperatures. FEMS Microbiology Ecology. 2007;59(2):242-254

[5] Vaïtilingom M, Attard E, Gaiani N, Sancelme M, Deguillaume L, Flossmann AI, et al. Long-term features of cloud microbiology at the puy de Dôme (France). Atmospheric Environment. 2012;56:88-100

[6] Amato P, Joly M, Besaury L, Oudart A, Taib N, Moné AI, et al. Active microorganisms thrive among extremely diverse communities in cloud water. PLoS One. 2017;12(8):e0182869

[7] Ariya PA, Amyot M. New directions: The role of bioaerosols in atmospheric chemistry and physics. Atmospheric Environment. 2004;38:1231-1232

[8] Ruehl CR, Davies JF, Wilson KR. An interfacial mechanism for cloud droplet formation on organic aerosols. Science. 2016;351(6280):1447
[9] Noziere B. Don't forget the surface. Science. 2016;351(6280):1396

[10] Ekström S, Nozière B, Hultberg M, Alsberg T, Magnér J, Nilsson ED, et al. A possible role of ground-based microorganisms on cloud formation in the atmosphere. Biogeosciences. 2010;7(1):387-394

[11] Baduel C, Nozière B, Jaffrezo J-L. Summer/winter variability of the surfactants in aerosols from Grenoble, France. Atmospheric Environment. 2012;47:413-420

[12] Noziere B, Baduel C, Jaffrezo J. Dynamic surface tension of atmospheric aerosol surfactants: A new look at cloud activation. AGU Fall Meeting Abstract. 2013;31:A31D-0110

[13] Nozière B, Gérard V, Baduel C, Ferronato C. Extraction and characterization of surfactants from atmospheric aerosols. Journal of Visualized Experiments. 2017;(122). https://www.ncbi.nlm.nih.gov/pmc/ articles/PMC5565068/

[14] Gérard V, Nozière B, Baduel C, Fine L, Frossard AA, Cohen RC. Anionic, cationic, and nonionic surfactants in atmospheric aerosols from the Baltic Coast at Askö, Sweden: Implications for cloud droplet activation. Environmental Science \& Technology. 2016;50(6):2974-2982

[15] Gautam KK, Tyagi VK. Microbial surfactants: A review. Journal of Oleo Science. 2006;55(4):155-166

[16] Mnif I, Ghribi D. Review lipopeptides biosurfactants: Mean classes and new insights for industrial, biomedical, and environmental applications: Lipopeptides Biosurfactants and their Applications. Biopolymers. 2015;104(3):129-147 
[17] Banat IM, Franzetti A, Gandolfi I, Bestetti G, Martinotti MG, Fracchia L, et al. Microbial biosurfactants production, applications and future potential. Applied Microbiology and Biotechnology. 2010;87(2):427-444

[18] Rosenberg E, Ron EZ. High- and low-molecular-mass microbial surfactants. Applied Microbiology and Biotechnology. 1999;52(2):154-162

[19] Santos DKF, Rufino RD, Luna JM, Santos VA, Sarubbo LA. Biosurfactants: Multifunctional biomolecules of the 21st century. International Journal of Molecular Sciences. 2016;17(3):401

[20] Köhler H. The nucleus in and the growth of hygroscopic droplets. Transactions of the Faraday Society. 1936;32:1152

[21] Bodour AA, Drees KP, Maier RM. Distribution of biosurfactantproducing bacteria in undisturbed and contaminated arid Southwestern soils. Applied and Environmental Microbiology. 2003;69(6):3280-3287

[22] Raaijmakers JM, De Bruijn I, Nybroe O, Ongena M. Natural functions of lipopeptides from Bacillus and Pseudomonas: More than surfactants and antibiotics. FEMS Microbiology Reviews. 2010;34(6):1037-1062

[23] Jackson SA, Borchert E, O’Gara F, Dobson AD. Metagenomics for the discovery of novel biosurfactants of environmental interest from marine ecosystems. Current Opinion in Biotechnology. 2015;33:176-182

[24] Pessôa MG, Vespermann KAC, Paulino BN, Barcelos MCS, Pastore GM, Molina G. Newly isolated microorganisms with potential application in biotechnology. Biotechnology Advances. 2019;37(2):319-339

[25] Perfumo A, Banat IM, Marchant R. Going green and cold: Biosurfactants from low-temperature environments to biotechnology applications. Trends in Biotechnology. 2018;36(3):277-289

[26] Ahern HE, Walsh KA, Hill TCJ, Moffett BF. Fluorescent pseudomonads isolated from Hebridean cloud and rain water produce biosurfactants but do not cause ice nucleation. Biogeosciences. 2007;4(1):115-124

[27] Renard P, Canet I, Sancelme M, Wirgot N, Deguillaume L, Delort A-M. Screening of cloud microorganisms isolated at the Puy de Dôme (France) station for the production of biosurfactants. Atmospheric Chemistry and Physics. 2016;16(18):12347-12358

[28] Desai JD, Banat IM. Microbial production of surfactants and their commercial potential. Microbiology and Molecular Biology Reviews. 1997;61(1):47-64

[29] Banat IM, Satpute SK, Cameotra SS, Patil R, Nyayanit NV. Cost effective technologies and renewable substrates for biosurfactants' production. Frontiers in Microbiology. 2014;5. Disponible sur: https://www.frontiersin.org/ articles/10.3389/fmicb.2014.00697/full

[30] Lang S. Biological amphiphiles (microbial biosurfactants). Current Opinion in Colloid \& Interface Science. 2002;7(1-2):12-20

[31] D’aes J, De Maeyer K, Pauwelyn E, Höfte M. Biosurfactants in plantPseudomonas interactions and their importance to biocontrol: Biosurfactants in plant-Pseudomonas interactions. Environmental Microbiology Reports. 2009;2(3):359-372

[32] Singh P, Cameotra SS. Potential applications of microbial surfactants in biomedical sciences. Trends in Biotechnology. 2004;22(3):142-146

[33] Mulligan CN. Recent advances in the environmental applications 
of biosurfactants. Current Opinion in Colloid \& Interface Science.

2009;14(5):372-378

[34] Sachdev DP, Cameotra SS.

Biosurfactants in agriculture. Applied Microbiology and Biotechnology. 2013;97(3):1005-1016

[35] Singh A, Van Hamme JD, Ward OP. Surfactants in microbiology and biotechnology: Part 2. Application aspects. Biotechnology Advances. 2007;25(1):99-121

[36] Reasoner DJ, Geldreich EE. A new medium for the enumeration and subculture of bacteria from potable water. Applied Environmental Microbiology. 1985;49:7

[37] Reiling HE, Thanei-Wyss U, Guerra-Santos LH, Hirt R, Käppeli O, Fiechter A. Pilot plant production of rhamnolipid biosurfactant by Pseudomonas aeruginosa. Applied and Environmental Microbiology. 1986;51(5):985

[38] Haba E, Pinazo A, Jauregui O, Espuny MJ, Infante MR, Manresa A. Physicochemical characterization and antimicrobial properties of rhamnolipids produced by Pseudomonas aeruginosa 47T2 NCBIM 40044. Biotechnology and Bioengineering. 2003;81(3): 316-322

[39] Hansen FK, Rødsrud G. Surface tension by pendant drop. Journal of Colloid and Interface Science. 1991;141(1):1-9

[40] Smyth TJP, Perfumo A, McClean S, Marchant R, Banat IM. Isolation and analysis of lipopeptides and high molecular weight biosurfactants. In: Timmis KN, éditeur. Handbook of Hydrocarbon and Lipid Microbiology. Berlin, Heidelberg: Springer Berlin Heidelberg; 2010. pp. 3687-3704.
Disponible sur: http://link.springer. com/10.1007/978-3-540-77587-4_290

[41] Gerard J, Lloyd R, Barsby T, Haden P, Kelly MT, Andersen RJ, et al. Antimycobacterial cyclic depsipeptides produced by two pseudomonads isolated from marine habitats. Journal of Natural Products. 1997;60(3):223-229

[42] Saini HS, Barragán-Huerta BE, Lebrón-Paler A, Pemberton JE, Vázquez RR, Burns AM, et al. Efficient purification of the biosurfactant viscosin from Pseudomonas libanensis strain M9-3 and its physicochemical and biological properties. Journal of Natural Products. 2008;71(6):1011-1015

[43] Braun PG, Hildebrand PD, Ells TC, Kobayashi DY. Evidence and characterization of a gene cluster required for the production of viscosin, a lipopeptide biosurfactant, by a strain of Pseudomonas fluorescens. Canadian Journal of Microbiology. 2001;47(4):294-301

[44] de Bruijn I, de Kock MJD, Yang M, de Waard P, van BeekTA, Raaijmakers JM. Genome-based discovery, structure prediction and functional analysis of cyclic lipopeptide antibiotics in Pseudomonas species. Molecular Microbiology. 2007;63(2):417-428

[45] Roongsawang N, Washio K, Morikawa M. Diversity of nonribosomal peptide synthetases involved in the biosynthesis of lipopeptide biosurfactants. International Journal of Molecular Sciences. 2011;12(1):141-172

[46] de Bruijn I, de Kock MJD, de Waard $\mathrm{P}$, van Beek TA, Raaijmakers JM. Massetolide A biosynthesis in Pseudomonas fluorescens. Journal of Bacteriology. 2008;190(8):2777

[47] Berti AD, Greve NJ, Christensen QH, Thomas MG. Identification of a biosynthetic gene cluster and the six associated lipopeptides involved in 
swarming motility of Pseudomonas syringae pv. tomato DC3000. Journal of Bacteriology. 2007;189(17):6312

[48] Burch AY, Zeisler V, Yokota K, Schreiber L, Lindow SE. The hygroscopic biosurfactant syringafactin produced by Pseudomonas syringae enhances fitness on leaf surfaces during fluctuating humidity. Environmental Microbiology. 2014;16(7):

2086-2098

[49] Marrink SJ, Risselada HJ, Yefimov S, Tieleman DP, de Vries AH. The MARTINI force field: Coarse grained model for biomolecular simulations. The Journal of Physical Chemistry. B. 2007;111(27):7812-7824

[50] Marrink SJ, de Vries AH, Mark AE. Coarse grained model for semiquantitative lipid simulations. The Journal of Physical Chemistry. B. 2004;108(2):750-760

[51] Ndao M, Goujon F, Ghoufi A, Malfreyt P. Coarse-grained modeling of the oil-water-surfactant interface through the local definition of the pressure tensor and interfacial tension. Theoretical Chemistry Accounts. 2017;136(1):21

[52] Ndao M, Devémy J, Ghoufi A, Malfreyt P. Coarse-graining the liquidliquid interfaces with the MARTINI force field: How is the interfacial tension reproduced? Journal of Chemical Theory and Computation. 2015;11(8):3818-3828

[53] Goujon F, Dequidt A, Ghoufi A, Malfreyt $P$. How does the surface tension depend on the surface area with coarse-grained models? Journal of Chemical Theory and Computation. 2018;14(5):2644-2651

[54] Ghoufi A, Goujon F, Lachet V, Malfreyt P. Multiple histogram reweighting method for the surface tension calculation. The Journal of Chemical Physics. 2008;128(15):154718
[55] Ghoufi A, Malfreyt P, Tildesley DJ. Computer modelling of the surface tension of the gas-liquid and liquidliquid interface. Chemical Society Reviews. 2016;45(5):1387-1409

[56] Paredes X, Fernández J, Pádua AAH, Malfreyt P, Malberg F, Kirchner B, et al. Bulk and liquid-vapor interface of pyrrolidinium-based ionic liquids: A molecular simulation study. The Journal of Physical Chemistry. B. 2014;118(3):731-742

[57] Ghoufi A, Malfreyt P. Entropy and enthalpy calculations from perturbation and integration thermodynamics methods using molecular dynamics simulations: Applications to the calculation of hydration and association thermodynamic properties. Molecular Physics. 2006;104(18):2929-2943

[58] Ghoufi A, Emile J, Malfreyt P. Recent advances in many body dissipative particles dynamics simulations of liquid-vapor interfaces. European Physical Journal E: Soft Matter and Biological Physics. 2013;36(1):10

[59] Maurel G, Schnell B, Goujon F, Couty M, Malfreyt P. Multiscale modeling approach toward the prediction of viscoelastic properties of polymers. Journal of Chemical Theory and Computation. 2012;8(11):4570-4579

[60] Goujon F, Malfreyt P, Tildesley DJ. Interactions between polymer brushes and a polymer solution: Mesoscale modelling of the structural and frictional properties. Soft Matter. 2010;6(15):3472-3481 
